\title{
Practitioner Insights Regarding Modern Slavery in Gloucestershire, UK
}

\author{
JORDAN BREALY
}

A thesis submitted to the University of Gloucestershire in accordance with the requirements of the degree of MSc by

Research in the School of Natural and Social Sciences

$27 / 01 / 2020$

Word count: 29,428 


\section{Author's Declaration}

I declare that the work in this thesis was carried out in accordance with the regulations of the University of Gloucestershire and is original except where indicated by specific reference in the text. No part of the thesis has been submitted as part of any other academic award. The thesis has not been presented to any other education institution in the United Kingdom or overseas.

Any views expressed in the thesis are those of the author and in no way represent those of the University.

Signed:

Print: Jordan Brealy

Date: $27^{\text {th }}$ January 2020

doi: $10.46289 /$ NSCS4598 


\section{Acknowledgements}

I sincerely thank all those who aided me with their incredible support throughout this process.

Firstly, I would like to thank Rachel Bennett, Louise Livesey and Kenny Lynch for their invaluable supervision. I truly appreciate all the time, guidance and encouragement during this project.

I must also gratefully acknowledge my family and closest friends for the support and patience during this lengthy process.

Finally, thank you to all the participants that took the time to take part in this research project. 


\section{Abstract}

Slavery remains present in society and has been found to occur under various manifestations throughout the United Kingdom. Knowledge derived from academic enquiry regarding modern slavery has increased over recent years although sparse attention has been given to localised communities. It is important to develop the evidence-base locally to effectively increase the understanding of this diverse issue and aid local responses.

This study aimed to produce evidence on local practitioners' perspectives on modern slavery, focusing on the case study of Gloucestershire. Fourteen semistructured interviews were conducted with a range of local practitioners in modern slavery related fields in Gloucestershire, including the police, healthcare and non-governmental organisations (NGOs). Thematic analysis was used to identify key themes from the data. These themes related to differing perceptions of the problem locally and numerous types of exploitation e.g. sexual exploitation, labour exploitation, criminal exploitation. One example of this is the alleged increase in sexual exploitation during a localised sporting event. The data also highlighted several barriers hindering local responses, progress and awareness e.g. victims not perceiving themselves as victims, victim cooperation with services and public service funding issues.

This study contributes to the evidence indicating that localities such as Gloucestershire are not exempt from a variety of slavery practices. The enquiry highlights evidence of various types of slavery offences manifesting in Gloucestershire. However, a key finding of this study is the fragmented perceptions of localised modern slavery, which highlights the need to support a collaborative approach to this diverse problem. Barriers and complexities with the local response are acknowledged such as; concerns regarding local awareness, pressures associated with resourcing and the struggles associated with identifying victims of hidden criminality and exploitation. Although these findings relate to Gloucestershire they carry wider implications relevant to other localities across the UK. Due to the wider implications of this enquiry, a number of research, policy and practice recommendations are made based on the data from this study. 


\section{Contents}

Chapter 1: Introduction; researching local perspectives on modern slavery in the UK... 1

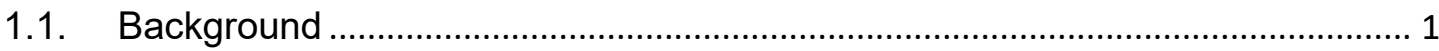

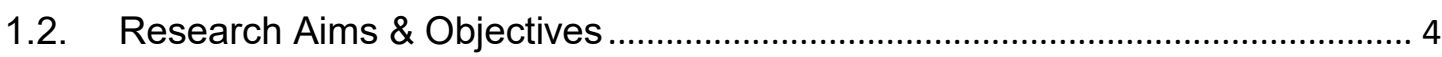

Chapter 2: Reviewing the research on modern slavery .................................................... 6

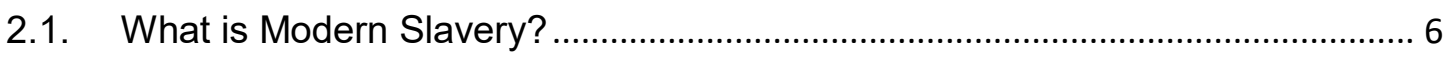

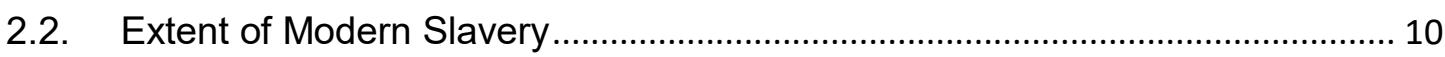

2.3. Types of Modern Slavery Offences ................................................................ 12

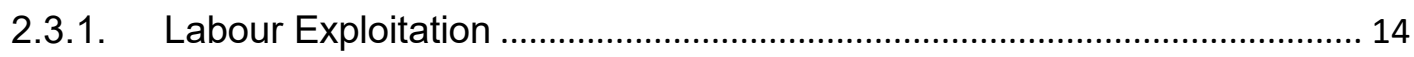

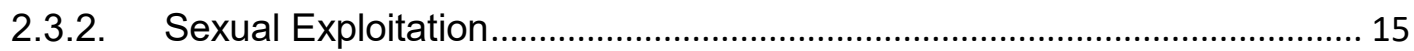

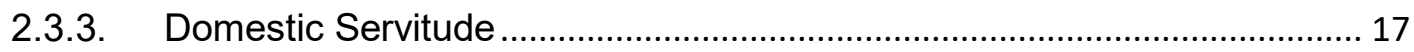

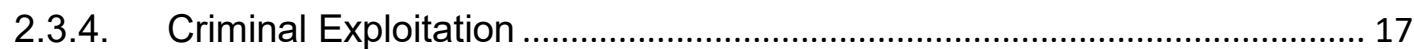

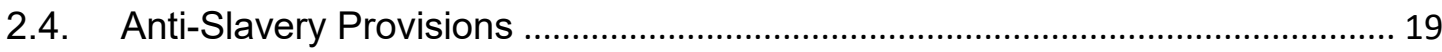

2.4.1. The National Referral Mechanism ............................................................. 19

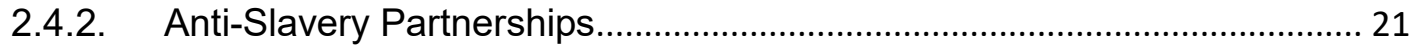

2.5. Modern Slavery in Gloucestershire and Localised Studies .............................. 23

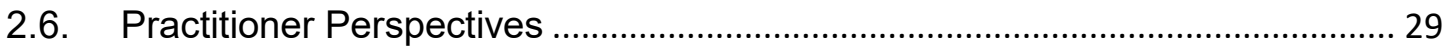

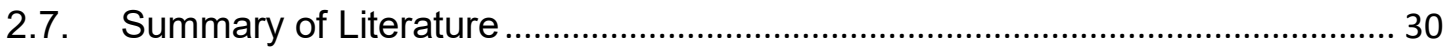

Chapter 3: Developing a method to research practitioner perspectives.......................... 31

3.1. Philosophical Assumptions ………………....................................................... 31

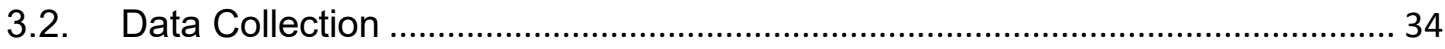

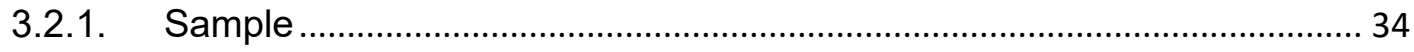

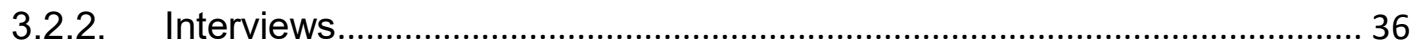

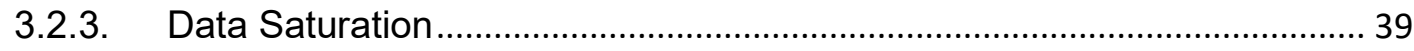

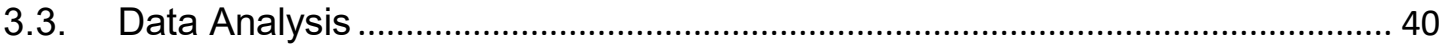

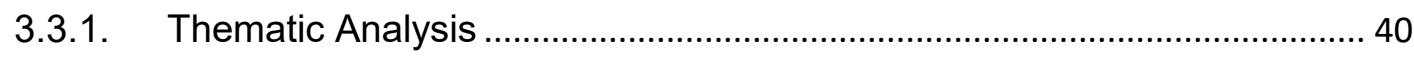

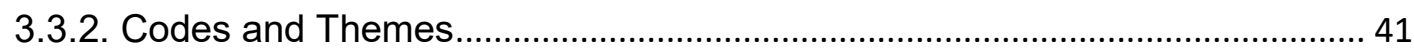

3.3.3. Summary of How NVivo was Used to Aid Analysis ....................................... 45

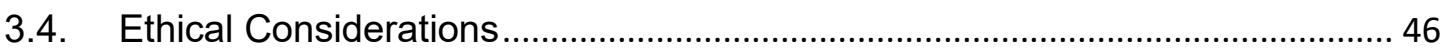

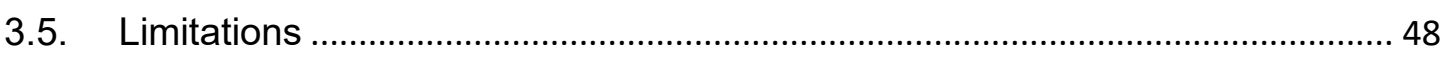

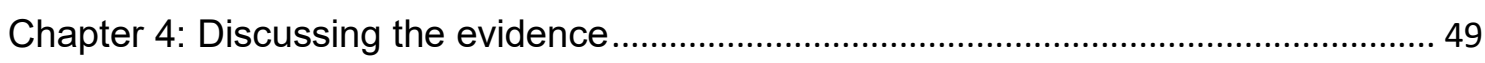

4.1. Practitioner Understanding and Awareness of Modern Slavery ...................... 49

4.1.1. Differing Perceptions of the Term 'Modern Slavery' ................................... 49

4.1.2. Underreporting of slavery in Gloucestershire........................................... 53

4.1.3. Conflicting Understandings Regarding Extent of the Problem................... 55

4.1.4. The Perception of 'Not in Gloucestershire' Recognised by Local Practitioners 
4.2. The Numerous Types of Modern Slavery Offences 'Known' to Take Place in Gloucestershire.

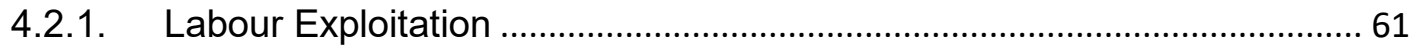

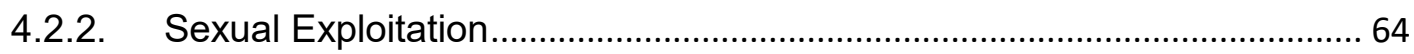

4.2.3. Exploitative Practices During Cheltenham Race Week .............................. 66

4.2.4. Criminal exploitation in the form of county lines and forced begging....... 68

4.3. Local anti-slavery practices and disputed impact............................................... 72

4.4. Several major barriers hindering local progress.............................................. 75

4.4.1. Victim reluctance to cooperate with practitioners ........................................ 75

4.4.2. Not seeing themselves as victims............................................................ 77

4.5. Practitioner concern over current local provision ............................................... 79

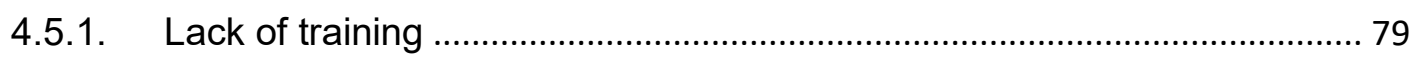

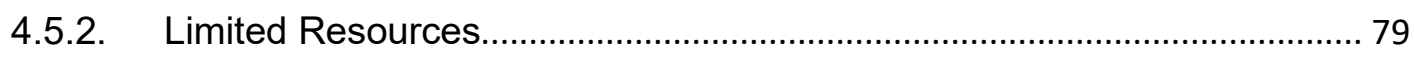

4.6. Limitations and concerns regarding the National Referral Mechanism process

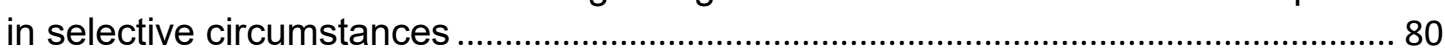

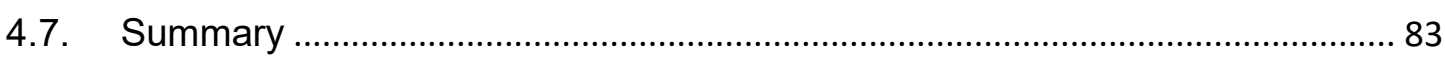

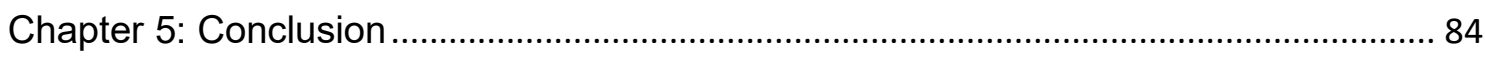

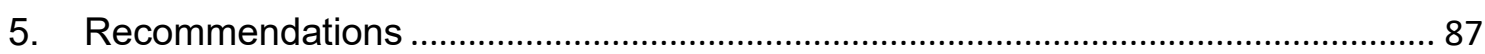

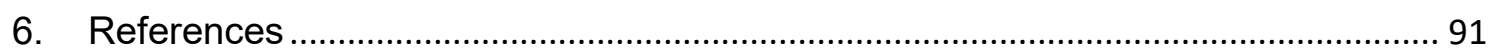

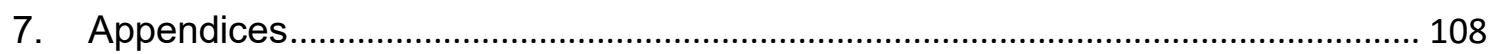

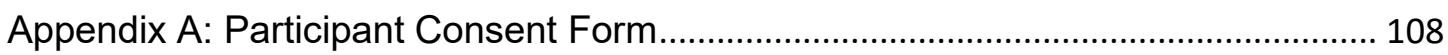

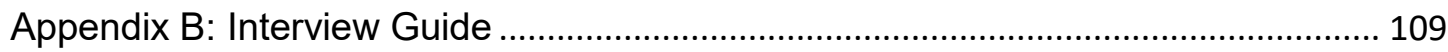

Appendix C: Participant Information Sheet .............................................................. 110

\section{List of Tables}

Table 1: National Referral Mechanism Statistics UK (2015-2018) ............................. 12

Table 2: 17 Typologies of modern slavery offences in the UK (Cooper et al. 2017) .... 13

Table 3: Prosecutions and convictions for modern slavery UK (Crown Prosecution

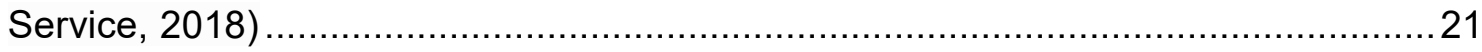

Table 4: National Referral Mechanism Statistics Comparison (2015-2018)................. 24

Table 5: National Referral Statistics with recorded exploitation type- Gloucestershire

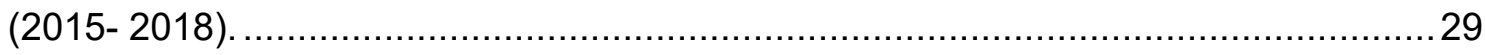

Table 6: Participants with corresponding profession/professional role ....................... 35

\section{List of Figures}

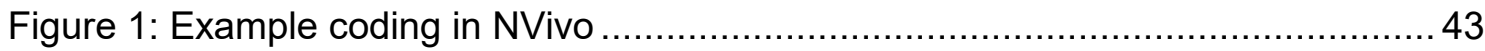

Figure 2: Diagram showing the development of themes.......................................... 44

Figure 3: Sources and references lists in NVivo............................................ 45 


\section{Chapter 1: Introduction; researching local perspectives on modern slavery in the UK}

\subsection{Background}

Historically, exploitation through slavery has existed across many societies (Lovejoy, 2012). A range of manifestations of slavery have occurred during ancient societies, for example the Roman Empire was dependent upon slavery for economics (Burks, 2008). Slavery served many social and economic roles and slaves themselves were often entirely under the control of another, as possessions (Wiedemann, 1981) of low status and with few legal rights. Slavery frequently occurred from spoils of war in the ancient world and were sentenced to manual labour in rural areas, in mines, farms etc. Others fulfilled domestic roles, which often varied and according to Burks (2008), wealthy citizens commonly used slaves to show family prestige and demonstrate affluence. According to Heuman \& Burnar (2010) those who benefitted from slave ownership attempted to imprint upon their human chattels a sense of humiliation, inferiority and worthlessness, which often involved physical coercion and psychological oppression.

Nicholson, Dang and Trodd (2018), analysed present day survivor accounts of slavery and identified a sense of inferiority, status gap, shame and fear inflicted by perpetrators onto victims. This suggests that despite action to combat slavery, such as legislative endeavours and societal improvements in equality, there are similarities between the testimonies of present-day survivors and descriptions of historical slavery. This supports the argument that some elements of slavery have remained constant (see Bales, 2009). Substantiating this theory, Bales (2006) outlines slavery as a form of relationship, the core aspect of which in both contemporary and historic slavery relates to the potentially violent control of a person(s) by another.

According to Bales (2000), slavery remains present in society but has undergone change over the years, which has caused the issue to become more hidden compared to previously recognised forms (see also Bales, Hesketh \& Silverman, 2015; Slavery Working Group, 2013; Black 2011). Additionally, 
Meltzer (1993) argues that slavery is deeply rooted in the history and economy of most countries and that human bondage for profit has never been completely eradicated.

In the United Kingdom, legislation has been implemented as a means to abolish slavery and prevent profiting from such oppression. For example, the Slave Trade Act 1807, prohibited the trade in slaves for the British Empire. Another example is the Slave Trade Consolidation Act 1824, which declared it unlawful to take part in the purchase, trade, sale or barter for slaves (Slave Trade Act, 1824). These Acts of Parliament did not officially ban slave ownership until the Slavery Abolition Act (enacted in 1834), which expanded the 1807 Act. Despite this, it remained commonplace for some people (including children) to be subjected to forced labour under the regime of workhouses, for which appalling working and living conditions are well documented (see Strauss, 2012). This remained the case until the implementation of the Factory Act 1844, which improved the working conditions and rights for child workers. This Act was the first health and safety Act in Britain, which made it a criminal offence if factories and workshops did not supply safety provision for dangerous machinery. The Act also limited the number of working hours for children and young people, and was praised for leading to the decline for child labour and improving the welfare of children (Nardinelli, 1980). This was a significant step away from exploitative working conditions at the time. Slavery remains a human rights issue despite attempts to abolish it (Landman 2018) such as Wilberforce's 1807 Slave Trade Act. However, legal regulation, then and now, has resulted in a shift towards the issue being pushed underground (Butler-Sloss, Field \& Randall, 2013), making it less visible compared to historical and regulated forms of slavery (Bales 2000).

Gaps in evidence-based knowledge regarding modern slavery are present across the UK and in some localised communities remains absent altogether. The growing concern regarding contemporary slavery in business (see Christ and Burritt, 2018), prompted further legislative intervention in the UK. Landman (2018) argues that legal policy is based on what is currently known about the topic and the knowledge base is widely understood to be underdeveloped (Cockbain \& Brayley-Morris, 2017; Crane, 2013; Craig et al 2007). In addition, it 
is widely acknowledged among scholars that previous attempts to investigate this topic have largely focussed on specific aspects or manifestations of the topic, such as sexual exploitation and human trafficking, rather than looking at the broader picture (Gregoriou, 2018; Scott, 2017; Chuang, 2015; Andrees and Van der Linden, 2005). Furthermore, scholars have highlighted that modern slavery in business in particular, as compared to domestic or sexual servitude, is a relatively new topic area (see Gold, Trautrims and Trodd, 2015 and Crane, 2013). Christ and Burritt (2018) highlight that the underdeveloped evidencebase regarding contemporary slavery can be linked to a general lack of consensus associated with addressing the problem effectively.

The absence of research-based attention allows gaps in knowledge to be neglected, resulting in a lack of understanding about key aspects of the topic. It is important to develop research for localised communities that includes incidences and prevalence of modern slavery, perceptions of the issue and local provision. This can support the operational responses of these communities and strengthen the local response. Localised studies also contribute to addressing the misconception that these types of human exploitation only take place in cities or developing countries (Anti-Slavery International, 2019a). Research can also serve as a useful tool in raising local awareness of the different types of offences taking place, which encourages reporting of these crimes. Conducting research on modern slavery can also encourage and aid future research enquiry, further developing the evidencebase. This helps to develop the research-based understanding of this issue and also encourages research enquiry for other localities.

Kiss and Zimmerman (2019) state that in order to make progress in addressing this issue, researchers and practitioners should seek co-operation to develop evidence-based understandings and suitable interventions, which are grounded in that evidence. Evidence-based responses from academics have an important role in increasing the knowledge surrounding modern slavery in the UK, which informs critical practices, designed to eradicate this issue (Bales, Hedwards and Silverman, 2017). 
There remains a lack of literature taking into consideration the perceptions of local practitioners that work to address the modern slavery. It is critical that perspectives and social worlds are recognised and evaluated as local groups such as police forces, charity and faith-based organisations and healthcare professionals often work close to this problem. This can be in the form of prevention, providing support for victims and raising awareness. Scholars have recognised growing public, academic and practitioner interest in this topic, specifically in developing knowledge surrounding slavery, in order to contribute to eradicating it (Landman, 2018; Craig et al. 2007). Bales, Hedwards and Silverman (2017) further highlight the importance of academic, nongovernmental and governmental research in developing a knowledge-base, which can inform policy and practice. This highlights the need for research to include practitioner insights into the developing body of research and evidence associated with this topic.

For this study, the focus is directed to Gloucestershire as a case study of localised modern slavery. Gloucestershire has seen an increase in cases of exploitation over the years (see Tables 4 and 5, presented later in the thesis) and has a range of practitioners and organisations responsible for dealing with modern slavery. This study is an opportunity to identify new information and develop findings that take these informed perceptions into account. As research regarding this topic in Gloucestershire is absent, this study ensures that local practitioner perceptions of modern slavery are incorporated in the first piece of academic literature for this locality. This contributes to the justification for Gloucestershire as the chosen case study.

\subsection{Research Aims \& Objectives}

The aim of the research was to produce evidence on practitioners' perspectives regarding modern slavery, focusing on the case study of Gloucestershire. Specifically, the objectives were:

1) To review the literature regarding the nature and responses to modern slavery, focusing on the UK and other relevant areas e.g. Gloucestershire. 
2) To gather and analyse practitioner perceptions of modern slavery in Gloucestershire focusing on key aspects of the topic such as, types of slavery offences, complexities faced by practitioners working in the area and role of the local anti-slavery partnership.

3) To develop modern slavery research recommendations for localised areas, including Gloucestershire, and suggestions for improved policy and practice.

This thesis is organised thus: the next section outlines the literature review, which provides context and further background relating to the subject. This includes relevant literature regarding the case study Gloucestershire, the types of slavery known to take place in the UK as well as the development, implementation and impact of UK legislation and provision. Following this, the methodology chapter provides a detailed account of how the study was conducted, including data collection and analysis. The findings of the empirical research are then presented and interpreted in the discussion chapter. The final sections include the conclusion and recommendations for future research, policy and practice. 


\section{Chapter 2: Reviewing the research on modern slavery}

This section addresses objective 1 by reviewing literature surrounding modern slavery, including key areas such as contemporary knowledge about modern slavery in the UK and Gloucestershire, anti-slavery provision and the impact of legislation. This chapter firstly reviews the definitions relating to modern slavery and provides necessary context regarding terminology used by organisations and scholars when outlining this topic. Attention is then paid to literature regarding the various forms of exploitation that are known to occur within the United Kingdom. Following this, the chapter covers literature surrounding antislavery provision locally and nationally, specific works related to Gloucestershire and other local communities, as well as outlining the use of practitioner insights in contemporary slavery research.

\subsection{What is Modern Slavery?}

In recent years, the UK government has further pushed the modern slavery agenda through both legislation and collaborative action, with the aim of becoming a world leader in fighting this issue (Butler-Sloss, Field and Randall, 2013).

In the UK, the term Modern Slavery is broadly defined by the Modern Slavery Act 2015, subsection 1 (a) and (b), as being where a:

person holds another person in slavery or servitude and the circumstances are such that the person knows or ought to know that the other person is held in slavery or servitude, or the person requires another person to perform forced or compulsory labour and the circumstances are such that the person knows or ought to know that the other person is being required to perform forced or compulsory labour (Modern Slavery Act, 2015).

The Act includes and defines various exploitative practices including, but not limited to, human trafficking, labour exploitation, sexual exploitation, domestic servitude and criminal exploitation and most provisions apply to England and Wales. Additionally, the Act sets out the broader features of slavery and encapsulates them in this legislation (Kidd and Manthorpe, 2017). The Act requires businesses with an annual turnover of more than $£ 36,000,000$ to 
produce an annual statement detailing procedures taken to ensure slavery is not present within supply chains.

The Act's impact has been assessed by both academics and government. Advocates of the Act have described it as 'world-leading' (Craig, 2017, p.16) as the first national legislation to use the term 'modern slavery' to explicitly target 'slavery', rather than exclusively 'human trafficking' or 'forced labour.' (Broad \& Turnbull, 2018). This terminology is important because the Modern Slavery Act 2015 states: it is designed to combat all forms of slavery in the UK and consolidates previous offences relating to trafficking and slavery. It has reportedly contributed to an increase in awareness and anti-slavery practices among UK practitioners including law enforcement (Machura et al. 2018) and this has arguably contributed to modern slavery becoming more prominent within academic debates, international law and society (Mende, 2018). In 2016, Haughey (2016) conducted an independent review of the 2015 legislation, addressing several key questions regarding implementation and effectiveness. The report highlighted provisions associated with the Act but identified gaps in both training and appropriate intelligence regarding the nature of modern slavery across the UK (see Haughey, 2016). The report found an increase in both awareness and training being put into place at a judicial level (Haughey, 2016). This has reportedly increased the number of police investigations and consequently the number of victims being identified (in 2015 a $40 \%$ increase on the previous year) (Haughey, 2016).

Critics have found evidence highlighting potential gaps in current policy intervention. For example, in relation to how anti-slavery policy is enforced on the frontline (Gardner, 2018). Furthermore, some police inspection reports have stated that responses have not significantly improved as a result of the Modern Slavery Act 2015 (HMICFRS, 2017). This lack of enforcement was found despite the presence of a legal framework for human trafficking, modern slavery and labour exploitation, suggesting these criminal-legal agendas are often inadequate or unenforced (Scott, 2017). In addition, during the review of the legislation, Haughey (2016) reported absent and partial training for police officers and investigators as well as a lack of intelligence, both locally and nationally, regarding the extent of modern slavery. Gardner (2018) reinforces 
these findings, reporting that implementation gaps are present between modern slavery legislation and front-line practice on both national and local scales, highlighting evidence of failure to reproduce national slavery policy at a local level resulting in little or no action in some areas of the UK.

The development of the UK's anti-slavery legalisation has international comparisons that provide useful insights regarding complexities associated with enactment. This includes California's (USA) Transparency in Supply Chains Act 2010 which requires manufacturers to reveal necessary steps taken to eliminate slavery from supply chains (Crane, 2013) and the Brazilian Ministry of Labour's Lista Suja ('The Dirty List') which identifies and publicly names modern slavery offenders (Pinheiro, Emberson and Trautims, 2019). The approach of 'The Dirty List' was suspended in Brazil between 2013 and 2016, after the Supreme Federal Tribunal deemed it unconstitutional (Scott, AndradeBarbosa and Borlido-Haddad, 2017). This is important because the Brazilian 'Dirty List', Californian Transparency in Supply Chains Act and UK's Modern Slavery Act all rely on businesses to act based on the threat of potential reputation damage. Research by Pinheiro, Emberson and Trautims (2019) on how laws and regulations shape supply chains concluded that the process in which companies actively police their supply chains is limited and complex. This is because legislation and regulation only cover partial and individual sections of the supply chain (Pinheiro, Emberson and Trautims, 2019).

Furthermore, there are concerns that the blacklisting of suppliers in Brazil could have negative legal implications in providing some companies significant power over others who are suppliers, some of which may not be equipped to carry out these policing roles (Pinheiro, Emberson and Trautims, 2019). This example sets out that agendas aimed at tackling slavery in supply chains often prove troublesome to implement and are associated with a host of complexities.

Problems have been identified with the shape of human trafficking policy and the nature of the response (Broad, 2013; Danailova-Trainor and Laczko, 2010). Due to this, the shape of current policy has been questioned, particularly by groups that interpret it within the context of their professional, political and institutional experiences (Cockbain \& Brayley-Morris, 2017). According to Broad \& Turnbull (2018) the increased international policy focus 
was not matched with research that would have provided a more robust evidence base. This is supported by Craig (2017) who stated that current evidence suggests the provisions of the Modern Slavery Act are not implemented or understood across many organisations. According to Craig (2017) this point was clearly demonstrated when six police forces across England and Wales reportedly identified zero potential victims of modern slavery in their areas in 2017. Furthermore, Harvey et al. (2015) argues there is a disjointed service relating to provision for child trafficking in the UK and reported failing of inter-agency communication reinforcing Haughey's (2016) argument that the Act remains a work in progress, particularly regarding consistency in how specific agencies approach modern slavery.

Varying descriptions of modern slavery exist within academic literature, it is essentially a "terminological umbrella" (Piotrowicz, 2018; Kiss and Zimmerman, 2017), which incorporates a range of activities such as human trafficking, forced labour, sexual exploitation and forced marriage (Christ and Burritt, 2018). The variety of definitions related to modern slavery not only highlights the wideranging nature of the topic but also demonstrates the broadness of the subject in a developing field of research. Bales, Hesketh and Silverman (2015) outline that the present-day crime is known as involuntary servitude, human trafficking and modern slavery. It comes in many forms, but is essentially the complete control of a person by another. This can be based on potential factors such as coercion, deception, violence or the threat of violence and typically has the aim of economic exploitation. Assault, rape, torture, sleep and food deprivation, dangerous and demeaning work and psychological coercion are common experiences for modern day slaves (Bales, Hesketh and Silverman, 2015).

The Modern Slavery Act clearly distinguishes human trafficking separately as "An offence if the person arranges or facilitates the travel of another person ("V") with a view to V being exploited." Although distinct legal definitions of modern slavery exist, the term 'enslavement' is often intertwined with the terms 'human trafficking' and 'exploitative practices,' which are often collectively labelled 'modern slavery' (Siller, 2016). Nicholson, Dang and Trodd (2018) highlight that the growing debate regarding the parameters of slavery often exclude the survivor testimonies and experience-based definitions of slavery 
thereby primarily framing definitions of slavery from a perpetrator perspective. Using semi-structured interviews with survivors of slavery, Nicholson, Dang and Trodd (2018) found that survivors emphasised the impact of control (e.g. destruction of identity as a result of objectivism), rather than the purpose of the control (e.g. forced labour for the purpose of economic gain), when defining slavery.

Scott (2017) acknowledges the progress made by both slavery and labour exploitation agendas but expresses criticism in stating that definitions often used to capture these sorts of problems often fall short in recognising the full extent of the issue. The meaning of the term 'modern slavery' and whether this single concept effectively captures the vast forms that this can take, has been brought into question (Mende, 2018). Additionally, The Anti-Trafficking Monitoring Group (2018) highlights concern regarding the term "modern slavery" as an umbrella concept, as this limited view does not recognise historical perspectives or past experiences of slavery (The Anti-Trafficking Monitoring Group, 2018).

\subsection{Extent of Modern Slavery}

Crane (2013) states that on every continent modern slavery has been identified, however empirical data is lacking in relation to the number of slaves present in the global workforce. Bales, Trodd and Williamson (2009) previously argued that there could be 27 million people in slavery across the world, more than at any other point in history. More recently, research by the International Labour Organisation (ILO) and the Walk Free Foundation argue that the number of contemporary slaves worldwide is closer to 40 million (ILO, 2019). Human trafficking is one aspect of contemporary slavery and said to be the world's fastest growing crime (Roundy 2019). Additionally, worldwide slavery in modern society is understood to generate approximately $\$ 150$ billion per year (Bales, Hesketh and Silverman, 2015)

The UK is widely recognised as a destination for victims of human trafficking, yet Craig et al. (2007) argue that there are no reliable estimates relating to 
trafficked individuals in the UK. Despite this being a well-established issue in the UK, victim identification, crime reports and other research often underestimate the number of people in slavery in any one country (Bales, Hedwards and Silverman, 2017). According to the National Crime Agency (2017), the scale of modern slavery across victims, offenders and incidences has increased over the years and is expected to continue burgeoning. Supporting this assertion, Crane (2013) states that the practice of slavery is growing and highlights the evidence regarding this is assisted by the vast trafficking networks both formal and informal, which are used to move people between and within countries (Crane, 2013; Robinson, 2013). The increasing trend in statistics can be observed via the National Crime Agency's National Referral Mechanism statistics, shown in Table 1. However, the accuracy of statistics surrounding the topic is widely criticised due to the illicit nature of the issue (Gold, Trautrims and Trodd, 2015; Slavery Working Group, 2013) as modern slavery is often hidden and operates underground (Craig 2017; Stevenson and Cole 2018). Furthermore, Bales (2012) highlights the veiled nature of modern slavery where perpetrators keep their activities hidden and where slavery has often been concealed by ignorance in the form of public assumption that slavery is an historic issue that no longer exists.

In 2013, sources suggested that 10,000 - 13,000 slaves existed in the UK (Cooper et al. 2017; HM Government, 2014). Silverman (2014) reported this estimation was the result of exploratory analysis, which built on the 2013 National Crime Agency (NCA) data relating to potential victims of human trafficking. Additionally, the analysis attempted to consider the "dark figure" of cases that remained unknown to the authorities (Silverman, 2014). In recent years, new evidence from the NCA, has indicated the issue is more extensive across the UK. The original figure 10,000-13,000 was deemed an underestimation by the National Crime Agency, which was supported by frontline investigators from anti-trafficking NGO, Hope for Justice (Hope for Justice, 2017). This supports the view of Craig et al. (2007) that accuracy regarding the extent of modern slavery victims in the UK remains absent. Supporting this further, according to Slavery Working Group (2013, p16), agencies responsible for gaining an understanding of the extent of the issue are "groping in the dark for a sense of scale." Slavery Working Group (2013) 
reported that their research shows a lack of acknowledgement of cases as well as reporting and therefore statistics do not accurately measure the true scale of the problem. This insight provides context regarding the statistics in relation to challenges that arise during interpretation.

\begin{tabular}{|c|c|c|}
\hline Year & $\begin{array}{l}\text { Number of Referrals } \\
\text { recorded in the UK }\end{array}$ & $\begin{array}{l}\text { Percentage increase on } \\
\text { previous year }\end{array}$ \\
\hline 2015 & 3266 & $40 \%$ \\
\hline 2016 & 3805 & $17 \%$ \\
\hline 2017 & 5145 & $35 \%$ \\
\hline 2018 & 6993 & $36 \%$ \\
\hline
\end{tabular}

Table 1: National Referral Mechanism Statistics UK (2015-2018)

According to the National Crime Agency (2019), the most common claimed nationality of potential victims referred to the NRM during 2017 and 2018 was United Kingdom. This was followed by Albania, Vietnam, China and Romania (National Crime Agency, 2019).

\subsection{Types of Modern Slavery Offences}

Academics and governments have discussed and disputed the various ways that slavery and exploitation manifests within modern society and the most prominent forms of exploitation. A 2017, Home Office research project devised a typology of modern slavery offences to improve the understanding of the different ways that modern slavery manifests in the UK. 17 modern slavery types were identified (see Table 2) based on 328 confirmed cases of modern slavery offences that had taken place across the UK. 


\begin{tabular}{|l|l|l|l|}
\hline $\begin{array}{l}\text { Labour } \\
\text { exploitation }\end{array}$ & $\begin{array}{l}\text { Sexual } \\
\text { exploitation }\end{array}$ & $\begin{array}{l}\text { Domestic } \\
\text { servitude }\end{array}$ & $\begin{array}{l}\text { Criminal } \\
\text { exploitation }\end{array}$ \\
\hline $\begin{array}{l}\text { Victims exploited } \\
\text { for multiple } \\
\text { purposes in } \\
\text { isolated } \\
\text { environments }\end{array}$ & $\begin{array}{l}\text { Child sexual } \\
\text { exploitation- } \\
\text { group exploitation }\end{array}$ & $\begin{array}{l}\text { Exploited by } \\
\text { partner }\end{array}$ & $\begin{array}{l}\text { Forced gang- } \\
\text { related criminality }\end{array}$ \\
\hline $\begin{array}{l}\text { Victims work for } \\
\text { offenders }\end{array}$ & $\begin{array}{l}\text { Child sexual } \\
\text { exploitation- } \\
\text { single exploiter }\end{array}$ & $\begin{array}{l}\text { Exploited by } \\
\text { relatives }\end{array}$ & $\begin{array}{l}\text { Forced labour in } \\
\text { illegal activities }\end{array}$ \\
\hline $\begin{array}{l}\text { Victims work for } \\
\text { someone other } \\
\text { than offenders }\end{array}$ & $\begin{array}{l}\text { Forced sex work } \\
\text { in fixed location }\end{array}$ & $\begin{array}{l}\text { Exploiters not } \\
\text { related to victims }\end{array}$ & Forced begging \\
\hline & $\begin{array}{l}\text { Forced sex work } \\
\text { in changing } \\
\text { location }\end{array}$ & $\begin{array}{l}\text { Trafficking for } \\
\text { personal } \\
\text { gratification }\end{array}$ & $\begin{array}{l}\text { Trafficking for } \\
\text { forced sham } \\
\text { marriage }\end{array}$ \\
\hline
\end{tabular}

Table 2: 17 Typologies of modern slavery offences in the UK (Cooper et al. 2017)

According to Cooper et al. (2017) modern slavery typologies enhance understanding of the framework for classifying and recognising different modern slavery crimes in the UK. This relates to how these offences manifest in society, which can aid the response for frontline agencies and increase familiarity regarding the indicators and how best to tackle each type (Cooper et al. 2017). The research project developed 17 types of modern slavery offences, which are categorised into 4 main groupings; Labour Exploitation, Domestic Servitude, Sexual Exploitation and Criminal Exploitation (see Table 2). In the report, human trafficking is not a separate category but rather acknowledged as a factor that could be present within any of the 17 types of exploitation (Cooper et al. 2017). For example, an individual may be trafficked locally for the purposes of labour or sexual exploitation. It is worth noting that the report states the typologies listed represent the types of modern slavery offences that have come to the attention of the authorities and therefore do not represent the whole scope, due to the hidden nature of this issue (Cooper et al. 2017). 
Typically, sexual and labour exploitation have often been the most prominently detected and reported forms (UNODC, 2016). It is argued that much of the attention surrounding this topic has previously focussed on sexual exploitation and human trafficking (Chuang, 2015; Scott, 2017) which has caused misrepresentation of the other offences (Andrees and van der Linden, 2005; Gregoriou, 2018). It can however be argued that in recent years the focus of the topic has undergone a shift, whereby other forms of slavery are now being considered (LeBaron, 2014).

\subsubsection{Labour Exploitation}

Based on the four groupings of the 17 types of modern slavery offences that have occurred in the UK (as outlined by Cooper et al. 2017), labour exploitation includes, but is not limited to, victims working for offenders in business or sites controlled by the perpetrators, sites controlled by others or work in multiple, isolated locations. This is an extensive category itself, which includes the occurrence of exploitative circumstances in car washes, construction, and agriculture and food industries. According to ILO and Walk Free Foundation (2017) 24.9 million people worldwide are subjected to forced labour, 16 million of which, are exploited in private sectors such as agriculture or construction. Victims have been found to live in overcrowded and poor conditions, working long hours; be unpaid and controlled through the use of threats, violence and debt bondage (Cooper et al. 2017; Mantouvalou, 2005). The focus on labour exploitation has been well documented in recent years (Scott, 2017; Gold, Trautrims and Trodd, 2015; Crane, 2013 and Bales, 2009). Labour exploitation can also be tied to other areas referred to as 'less extreme labour exploitation' as outlined by Davies (2018) who states that this area has seen less attention compared to more extreme forms of labour exploitation. These 'less extreme forms' are still considered exploitative and harmful and can include routine labour abuses such as occupational hazards (Davidson, 2015). According to Kiss and Zimmerman (2019) in order to make progress in preventing labour exploitation it is necessary to further develop the evidence regarding what this entails. Developments in legislation, media and academic attention have caused a spike in research which has adopted multiple focuses in the hope of shedding light on the breadth of modern slavery offences (Home Office, 2018). 
Turner-Moss et al.'s (2014) research on the health of 35 men trafficked for labour exploitation in the UK reported that seven of the 35 men were exploited through the construction industry and were subject to extremely poor living and working conditions, violence and abuse.

\subsubsection{Sexual Exploitation}

This is a broad category that includes child sexual exploitation (CSE), forced sex work in both fixed and changing locations and can link to trafficking for financial gain or personal gratification (Cooper et al. 2017). Cases have consisted of both prolonged exploitative circumstances and single incidents but the element of control is evident in observed cases as perpetrators often used physical violence in order to gain control over the individual(s) (Cooper et al. 2017). According to ILO and Walk Free Foundation (2017) 4.8 million people suffer sexual exploitation worldwide of which $99 \%$ of victims subjected to exploitation in the sex industry are women and girls. According to Finkel \& Finkel (2015) the existence of human trafficking and sexual exploitation on a global scale cannot be denied, yet attempts to quantify it prove difficult due to the hidden and often underground nature of the problem.

According to Coy (2016) topics such as, CSE have gained prominence as a policy concern across the UK due to high profile cases and the development of research evidence. For example, ILO and Walk Free Foundation (2017) estimated that 1 in 4 victims of modern slavery are children including; labour, sexual and criminal exploitation. Furthermore, Mason-Jones and Loggie (2019), state that CSE has shifted from being an unrecognised form of child abuse to a widely discussed topic, gaining significant political and public consideration. Coy (2016) states that the increased attention surrounding CSE can be linked to a paradigm shift whereby CSE is viewed separately from other forms of exploitation in prostitution and the sex industry. Despite the increase in attention surrounding this topic, progress in tacking CSE remains plagued with concern. During a studying involving thematic analysis of reports of CSE in England, Mason-Jones and Loggie (2019) reported a lack of communication, lack of appropriate action and reluctance to apply relevant polices were key themes in their study. The study concluded that CSE is a complex issue, one that requires awareness, intervention and training (Mason-Jones and Loggie, 2019). 
In addition, another area related to sexual exploitation that has gained attention in recent years is the connection between human trafficking and exploitative practices during sporting events (Finkel and Finkel, 2015; Matheson and Finkel, 2013; Ham, 2011). An example of this comes from the United States Congress et al. (2014) stating that sexually exploited human trafficking victims were undoubtedly being transported into the country for the American Football Super Bowl. Similarly, Matheson and Finkel (2013), in relation to the 2004 Olympics in Athens, argued that the temporary increase in population during the event resulted in greater demand for sexual services with traffickers meeting the demand with exploited individuals. This supports Smith \& Vardaman's (2010) argument that demand causes trafficking for sexual exploitation to increase and as demand increases, traffickers increase their supply of victims. Another challenge regarding this topic is the use of genuine travel routes being used for trafficking purposes (Musto, 2009) which causes difficulty when attempting to distinguish victims of trafficking from both legal and illegal immigrants (Bowersox, 2016). Additionally, Matheson and Finkel (2013), found the presence of human trafficking victims in the area increased by $95 \%$ during the lead up to the sporting event and decreased by $24 \%$ a year after, to which they concluded that there is a causal link between human trafficking offences and the sporting event. Despite these studies, the relationship between sexual exploitation and sporting events remains difficult to establish due to the hidden nature of the offences involved and the limited research evidence (Finkel and Finkel, 2015). In support of this, Ham (2011) highlights the lack of evidence to support the correlation between human trafficking and sporting events, arguing that this has been promoted by prostitution abolitionist groups.

The potential connection between the commercial sex industry and exploitation is yet another discussion related to this topic. This link has been investigated in recent years, yet the connection remains disputed (Bowersox, 2016; Coy, 2016; Finkel \& Finkel, 2015; Ham, 2011). According to Chase and Statham (2005) many published works have focused on the exploitation of young people through prostitution, indicating this industry is exploitative. Bowersox, (2016) states that a theoretical link can be drawn between the sex industry and exploitation due to the opportunistic environment, yet this topic remains heavily 
disputed and controversial, partially due to wider debates regarding social and gender equality.

\subsubsection{Domestic Servitude}

As a category of modern slavery, domestic servitude is a form of exploitation that is known to manifest in many ways in the UK, making it a broad topic area. According to Cooper et al. (2017) based on the reported cases of domestic servitude in the UK, this type of exploitation is often associated with sexual exploitation or another form of abuse such as, being forced to undertake household chores and can include forced marriages. Other tasks include cleaning, cooking, taking care of children and elderly (Anti-Slavery International, 2019b). Anti-Slavery International, (2019b) stated that in some cases, 'employers' prevent domestic workers from leaving the property, refuse to pay wages and use threats or violence as well as withholding documentation as a way to control the individuals. In some instances, domestic workers are not paid at all but instead receive basic human needs of food and accommodation as payment (Anti-Slavery International, 2019b). Additionally, in the observed cases, perpetrators have had control over a victim via psychological coercion and threats and this exploitation can take place by either a partner, relatives or by someone not related to the victim(s) (Cooper et al. 2017). Mantouvalou (2005), referred to a 2001 study by non-governmental organisation, Kalayaan, which was based on a sample of 1,000 domestic workers in the UK. This study showed that $84 \%$ had suffered psychological violence, $54 \%$ experienced being locked up and $38 \%$ had been beaten.

\subsubsection{Criminal Exploitation}

In recent years, criminal exploitation has become a growing focus in the UK, particularly due to police forces targeting areas of criminality such as county lines drug offences (National Crime Agency, 2019c). County lines is the term used for gangs from urban areas that transport drugs to suburban areas (Cooper et al. 2017). Offenders are often adaptable in the recruitment and exploitation of vulnerable individuals (National Crime Agency, 2019b). This type of exploitation can impact a broad range of victims as the offenders often target 
individuals with any vulnerability (National Crime Agency, 2019c). According to the National Crime Agency (2016) these gangs often use children to transport the drugs for two primary reasons; to avoid police detection and because children are typically more vulnerable to intimidation and control (Home Office, 2018).

The types of criminal exploitation observed in the UK include, but is not limited to, forced begging, financial fraud and forced gang-related criminality (see Cooper et al. 2017). County lines can include gang related instances whereby children or adults are groomed, exploited and used to transport drugs from urban to suburban areas (National Crime Agency, 2019; HM Government, 2018). In 2018, the government published a Serious Violence Strategy which highlights an approach to tacking various crimes, including county lines exploitation (see HM Government, 2018). The report highlighted that this form of exploitation can affect any child or adult however, there is evidence indicating that the most prominent age range of victims is children aged 15-17 years. According to HM Government (2018) this exploitation can appear as a consensual agreement whereby some form of exchange is present, for example clothing, drugs money etc. and victims often do not realise they are victims of a crime (see National Crime Agency, 2019). One reason for the growing attention in this area is the 2018 prosecution of a Birmingham drug dealer who faced five allegations of human trafficking and according to West Midlands Police (2018), is the first perpetrator to be convicted under the Modern Slavery Act for child trafficking offences related to county lines (see also Stone, 2018). A qualitative practitioner study by Robinson, McLean and Densley (2018) found evidence of Child Criminal Exploitation (CCE) linked to County lines in Glasgow and Merseyside. The study reported that in some cases, young people would willingly take part in drug distribution in order to gain status and financial benefits. In some instances, evidence was found of debt bondage being used as a means of controlling children into carrying out these offences (Robinson, McLean and Densley, 2018).

The previous sections outline the recognised forms of exploitation known to have taken place in the UK, all of which can be dealt with under the Modern Slavery Act 2015. Since the implementation of the Act, these offences are 
becoming increasingly recognised as accounts of slavery, which arguably causes change in the way the term 'slavery' is used and applied in modern society. Additionally, these offences often overlap, which creates challenges in distinguishing between nuances such as, labour exploitation and criminal exploitation.

\subsection{Anti-Slavery Provisions}

\subsubsection{The National Referral Mechanism}

The National Referral Mechanism (NRM) framework was implemented in 2009 to provide support and protection for survivors of slavery whilst the evidence for trafficking/modern slavery is assessed (Broad \& Turnbull, 2018). In 2018, 6,993 potential victims were referred to the NRM from across the UK for support, and this total has increased annually (see Table 1). In recent years, the NRM has received increasing amounts of attention and scrutiny across academic literature, due to the paralleled development in research regarding modern slavery. According to the Anti-Trafficking Monitoring Group (2013) in addition to identifying victims and ensuring survivors get assistance, since implementation, the NRM has increased awareness of trafficking among frontline practitioners.

The NRM provides 45 days as a reflection and recovery period for survivors of modern slavery or human trafficking (National Crime Agency, 2018). This reflection period takes place whilst victim cases progress from provisional acceptance to final agreement (Craig, 2017). Haughey (2016) reported findings from Police Forces highlighting 45 days is insufficient and recommended implementing an extension to this period of rest and recovery for potential victims. After this assessment period, the individuals are given either a positive or negative finding of trafficking or modern slavery. Roberts (2018) states that if a person receives a negative decision, this means that there was not enough evidence to confirm the claim at that time rather than a decisive conclusion that the individual is not a victim of exploitation. Schweppenstedde (2016), on behalf of the Human Trafficking Foundation, followed up potential victims that been referred to the NRM. The investigation found that 18 trafficking victims were uncontactable and could have been re-trafficked (Schweppenstedde, 2016). Bokhari (2008) highlighted similar concerns prior to the implementation of the 
NRM regarding the lack of specialist protection, which leave children in these situations vulnerable to further harm. These concerns indicate an underlying problem exists regardless of changes to practice, suggesting the execution or effectiveness remains limited.

According to Schweppenstedde (2016) there is little reliable evidence regarding what happens to survivors after the 45-day recovery period and no provision to prevent repeat victimisation. Furthermore, during an attempt to assess effectiveness of the provision in the UK, Craig (2017) reported that survivors are not provided with sufficient time to plan for community integration in the UK, leaving them potentially vulnerable to poverty and re-trafficking (see also Manouvalou 2018). Additionally, Craig (2017) reported that the Independent Anti-Slavery Commissioner (2016) argued that the NRM is ineffective and requires significant improvement with regards to confirming claims made by potential survivors of slavery and providing necessary support (Roberts, 2018). Bulman (2020) reinforces this point reporting that 605 potential victims have been waiting more than two years for a decision from the Home Office, which is causing more people to fall back into exploitation. According to Craig (2017) the NRM has been widely criticised by a range of NGOs, who claimed that the mechanism was racist, arguing that potential victims from countries outside of the EU had only one quarter of the chance of their claim being accepted (see Anti-Trafficking Monitoring Group, 2014). Mantouvalou (2018) reported that a lack of suitable support for potential victims is tied to the lack of prosecutions for these crimes, in the UK. This highlights a negative cycle whereby victims' participant in the prosecution process to then face family and self-danger however, if they choose not to cooperate they risk deportation, potential retrafficking and enslavement. These points highlight the limitations of the NRM, which contribute to the extent of the problem remaining unclear. The extent of modern slavery in the UK has been the source of much debate in recent years (Craig, 2017). One reason for this debate is due to the NRM receiving 6,993 referrals across the UK in 2018 , more than $50 \%$ of the government estimated 13,000 victims. This is another piece of evidence that suggests these statistics are significantly underestimated, which is generally considered to be the case (Craig, 2017). Additionally, Bales, Hesketh and Silverman (2015), argue that 
estimating the extent of modern slavery from known accounts of the issue is likely to be an underestimation of the true scale of the problem.

Table 3 shows statistics from the Crown Prosecution Service regarding prosecutions and convictions for modern slavery offences, in the UK. These can be compared with the estimated extent of modern slavery in the UK and with the victim referral statistics (see Table 1). The total number of prosecutions per year is significantly lower compared with the number of referrals being made to the NRM, as well as compared with the estimated figure of 13,000 victims in the UK. Additionally, Table 3 shows that the prosecution and conviction rates between 2014 and 2018 fluctuate but do not consistently increase annually compared with the total number of victim referrals (see Table 1). Furthermore, the conviction rate percentage decreases between 2014 and 2017, even though the NRM found a 35\% increase in potential victims in 2017. This indicates that despite the increase in victims being identified and referred to the NRM, significant challenges consistently remain in relation to successfully convicting perpetrators.

\begin{tabular}{|l|l|l|l|l|}
\hline & $\begin{array}{l}\mathbf{2 0 1 4 -} \\
\mathbf{2 0 1 5}\end{array}$ & $\mathbf{2 0 1 5 - 1 6}$ & $\mathbf{2 0 1 6 - 1 7}$ & $\mathbf{2 0 1 7 - 1 8}$ \\
\hline Convicted & 130 & 192 & 181 & 185 \\
\hline $\begin{array}{l}\text { Conviction rate } \\
(\%)\end{array}$ & $69.5 \%$ & $65.1 \%$ & $61.4 \%$ & $65.1 \%$ \\
\hline Not Convicted & 57 & 103 & 114 & 99 \\
\hline $\begin{array}{l}\text { Total } \\
\text { prosecutions }\end{array}$ & $\mathbf{1 8 7}$ & $\mathbf{2 9 5}$ & $\mathbf{2 9 5}$ & $\mathbf{2 8 4}$ \\
\hline
\end{tabular}

Table 3: Prosecutions and convictions for modern slavery UK (Crown Prosecution Service, 2018)

\subsubsection{Anti-Slavery Partnerships}

Alongside the introduction of the Modern Slavery Act 2015, Anti-Slavery Partnerships are becoming more commonplace as a means of ensuring a more consistent and effective local response to modern slavery (Van Dyke, 2017). 
The intended role of these partnerships is that of raising awareness and providing appropriate training for practitioners. This has led to Anti-Slavery Partnerships being viewed as a vital aspect of a more coordinated and collective response to modern slavery in the UK (HM Government, 2014). Cockbain \& Brayley-Morris (2017) reported the importance of coordinated efforts and improved information sharing both within police and outside agencies. HM Government (2014) stated the importance of effective multiagency working and suggests that making use of the local partnerships across the UK by sharing information will strengthen local responses. Reinforcing this, Beadle and Davison (2019) recommended that for practice to improve, information sharing should be increased along with networking with government bodies and NGOs.

Gardner (2018) argues that evidence of good practice among local partnerships remains difficult to establish due to the lack of local data and longer-term monitoring of partnership activity. This remains another area of the topic currently lacking research-based knowledge associated with determining the effectiveness of these partnerships locally. Brewster (2019) highlights that these partnerships are not mandatory across the UK despite there being some evidence that Anti-Slavery Partnerships have an important role to play in providing suitable training, awareness raising and identification of slavery victims. Independent Anti-Slavery Commissioner (2017) stated that multiagency collaborative working such as anti-slavery partnerships are frequently highlighted as a key element in the UK's response to modern slavery. Despite this, there is evidence of little monitoring, guidance and dedicated funding to promote local anti-slavery partnership activity efforts (Independent Anti-Slavery Commissioner, 2017). Supporting this argument, ATMG (2018) stated that training and quality control was inconsistent across the UK and these gaps in the national response also have a negative impact on local areas. However, ATMG (2018) did report increased initiatives targeting training and awarenessraising in the UK, indicating improvement in specific geographic areas. Despite these developments, initiatives such as these are not always assessed or evaluated, resulting in problems when attempting to monitor the potential impact (ATMG, 2018). 


\subsection{Modern Slavery in Gloucestershire and Localised Studies}

Research that focuses on modern slavery in localised communities is lacking, which contributes to uncertainty regarding the prevalence of this issue. According to Beadle and Davison (2019) current gaps in knowledge continuously leave individuals vulnerable to trafficking and exploitation. This also results in many areas of the issue remaining unclear therefore it is important to take local cases into account in order to develop the body of research that increases both the evidence, wider discussion and contributes to improving local awareness.

Gloucestershire is predominantly an agricultural county in South West England. The county comprises the city of Gloucester as well as towns such as Cheltenham, Tewkesbury, Cirencester and Stroud. This rural community includes the Forest of Dean and areas of the Cotswolds. Besides the lack of research relating to modern slavery for this county, Gloucestershire was selected as the study location firstly to address a common misconception that modern slavery only happens in large cities or developing countries (AntiSlavery International, 2019a). Furthermore, it is important to evaluate local accounts of the issue in order to identify any unique characteristics or manifestations of the problem for every locality. This can be compared with other areas and the national scale, which further aids in developing the understanding surrounding this issue. This highlights the reasoning behind selecting Gloucestershire as the study location.

The evidence that slavery occurs locally can be found via Gloucestershire Constabulary (2019), which specifically acknowledges the occurrence of these crimes in Gloucestershire and the rest of the UK. Additionally, Gloucestershire County Council (2019), outlines measures that aim to tackle modern slavery through the local anti-slavery partnership. Furthermore, evidence regarding the occurrence of slavery can be found via the national referral mechanism statistics (shown in Table 4 and 5) and in the local media (see Boobyer, 2018 and Gibbon, 2017). 


\begin{tabular}{|c|c|c|c|c|c|c|c|c|c|c|c|c|c|c|}
\hline Year & \multicolumn{2}{|c|}{$\begin{array}{l}\text { Number of } \\
\text { Referrals } \\
\text { recorded in } \\
\text { Gloucestershire } \\
\text { and \% increase } \\
\text { on previous year }\end{array}$} & \multicolumn{2}{|c|}{$\begin{array}{l}\text { Number of } \\
\text { Referrals } \\
\text { recorded in } \\
\text { Warwickshire } \\
\text { and \% increase } \\
\text { on previous year }\end{array}$} & \multicolumn{2}{|c|}{$\begin{array}{l}\text { Number of } \\
\text { Referrals } \\
\text { recorded in } \\
\text { Devon and } \\
\text { Cornwall } \\
\text { and \% } \\
\text { increase on } \\
\text { previous } \\
\text { year }\end{array}$} & \multicolumn{2}{|c|}{$\begin{array}{l}\text { Number of } \\
\text { Referrals } \\
\text { recorded in } \\
\text { West Mercia } \\
\text { and \% } \\
\text { increase on } \\
\text { previous year }\end{array}$} & \multicolumn{2}{|c|}{$\begin{array}{l}\text { Number of } \\
\text { Referrals } \\
\text { recorded in } \\
\text { Suffolk and } \\
\% \text { increase } \\
\text { on previous } \\
\text { year }\end{array}$} & \multicolumn{2}{|c|}{$\begin{array}{l}\text { Number of } \\
\text { Referrals } \\
\text { recorded in } \\
\text { North } \\
\text { Yorkshire and } \\
\% \text { increase on } \\
\text { previous year }\end{array}$} & \multicolumn{2}{|c|}{$\begin{array}{l}\text { Number of } \\
\text { Referrals } \\
\text { recorded in } \\
\text { Cambridgeshire } \\
\text { and \% increase on } \\
\text { previous year }\end{array}$} \\
\hline 2015 & 0 & $0 \%$ & 1 & $0 \%$ & 11 & $0 \%$ & 2 & $0 \%$ & 6 & $0 \%$ & 3 & $0 \%$ & 29 & $0 \%$ \\
\hline 2016 & 5 & $\begin{array}{l}500.00 \\
\%\end{array}$ & 9 & $900.00 \%$ & 22 & $\begin{array}{l}100.0 \\
0 \%\end{array}$ & 20 & $\begin{array}{l}900.0 \\
0 \%\end{array}$ & 8 & $\begin{array}{l}33.33 \\
\%\end{array}$ & 7 & $\begin{array}{l}133.3 \\
3\end{array}$ & 13 & $-55.17 \%$ \\
\hline 2017 & 16 & $\begin{array}{l}220.00 \\
\%\end{array}$ & 8 & $-11.11 \%$ & 22 & $\begin{array}{l}00.00 \\
\%\end{array}$ & 23 & $\begin{array}{l}15.00 \\
\%\end{array}$ & 16 & $\begin{array}{l}100.0 \\
0 \%\end{array}$ & 7 & $\begin{array}{l}00.00 \\
\%\end{array}$ & 25 & $92.30 \%$ \\
\hline 2018 & 41 & $\begin{array}{l}156.25 \\
\%\end{array}$ & 11 & $37.5 \%$ & 54 & $\begin{array}{l}145.0 \\
0 \%\end{array}$ & 21 & $\begin{array}{l}- \\
8.69 \\
\%\end{array}$ & 30 & $\begin{array}{l}87.50 \\
\%\end{array}$ & 29 & $\begin{array}{l}314.2 \\
8 \%\end{array}$ & 18 & $-28.00 \%$ \\
\hline
\end{tabular}

Table 4: National Referral Mechanism Statistics Comparison (2015-2018) 
Table 4 shows the NRM statistics of Most Similar Force Groups (MSGs). This refers to groups of localities that are statistically most similar to Gloucestershire in terms of demographic, economic and social factors linked to crime (HMICFRS, 2017b). The purpose of MSGs is to enable reasonable comparisons between different areas (HMICFRS, 2017b). Comparing referral statistics from similar areas can provide insights into how Gloucestershire is responding to modern slavery.

With the exception of Cambridgeshire, all locations show an increase in referrals in 2016 (one year after the Modern Slavery Act was implemented). This is evidence that the legislation caused an increase in the number of referrals for most locations within this Force Group. Out of the seven locations, Gloucestershire and Suffolk were the only areas to consistently increase their referrals year on year between 2015 and 2018. In 2017, Warwickshire shows a minus percentage increase in referrals, as does West Mercia in 2018 and Cambridgeshire being the only location to show a minus in referrals during 2016 and 2018 (see Table 4).

The referrals for Gloucestershire have increased consistently each year, whereas Warwickshire had fewer referrals in 2017 compared with the previous year while Devon and Cornwall had the same number of referrals for 2016 and 2017. Furthermore, Gloucestershire shows the highest percentage increase in referrals during 2017 and the second highest during 2018 (see Table 4). This is evidence that Gloucestershire is consistently making progress in terms of increasing referrals each year, which can be tied to modern slavery now being a priority for the local constabulary (Gloucestershire County Council, 2018). Despite this, Gloucestershire, Warwickshire, Devon and Cornwall, West Mercia and North Yorkshire had a lower percentage increase in referrals during the year 2017 compared to the previous year. This decrease indicates a regression in progress post 2016 for most of the localities. Devon and Cornwall and North Yorkshire and Suffolk are the only localities to have a higher percentage increase of potential victims in 2018, post the spike shown for 2016 after the implementation of the Act. 
Two recent pieces of literature have included modern slavery in Gloucestershire and have provided rare insights regarding this topic. Cockbain and BrayleyMorris (2017) took a qualitative approach analysing data from three police investigations across the UK regarding Irish Traveller Offending Groups. This included analysis of operational data and interviews with the Senior Investigating Officers (SIO) in each of the three cases. The cases in the study included operations from the Bedfordshire, Hampshire and Gloucestershire Constabularies. The case in Gloucestershire (known as Operation Tundra), began in 2010 after a suspected victim was found dead and intelligence consisted of numerous allegations of labour exploitation taking place in Gloucestershire. Cockbain and Brayley-Morris (2017) reported that Operation Tundra led to a number of arrests over eight locations in the UK leading to five successful convictions of conspiracy to hold people in servitude and conspiracy to require them to perform forced labour. Additionally, six survivors were removed from the sites (Cockbain and Brayley-Morris, 2017). The study carried out by Cockbain and Brayley-Morris (2017) identified key challenges faced by the SIOs associated with investigating modern slavery and human trafficking cases. These included; difficulties with prosecutions, securing and maintaining victim co-operation due to fear of retribution, police-related trust issues and victim's initial reluctance to perceive themselves as such. Although the study has a specific concentration on Irish Traveller Offending Groups with a wide geographical focus, it contributes to the development of research regarding offences occurring in Gloucestershire. This study also highlights the value of incorporating local areas as cases studies, as this can be a source of important insights regarding the topic. This could relate to differences in local provision or specific factors that encourage slavery offences to take place which are unique to the local region.

The other example of evidence-based knowledge regarding slavery in Gloucestershire is the 2013 Scrutiny Task Group Report conducted by Reeves (2013) on behalf of Gloucestershire County Council. This report focused on the trade in sexually exploited young or vulnerable people in Cheltenham. The report reviewed evidence from a variety of sources, including Gloucestershire Constabulary. Information was gathered specifically in relation to the approach to trafficking and sexual exploitation in Gloucestershire and details regarding 
the extent of the problem. The report included specifics collected from the local police relating to the unlicensed sex trade and the undisputed participation of young vulnerable individuals (Reeves, 2013). The report stated that whilst a low percentage of individuals involved in the sex trade in Cheltenham were unwilling victims, a higher percentage would at one time have been coerced into the trade prior to reaching Cheltenham (Reeves, 2013). The report also presents potential risk factors associated with seasonal events such as the Cheltenham Race Festival. The festival is an annual event that takes place in March, which results in an increase in visitors to the area. In 2018, approximately 262,637 people visited Gloucestershire during the four-day event (BBC, 2018).

Most of the wider literature surrounding sex trafficking and sporting events is focused on global events such as the Superbowl and Olympics (United States Congress House et al. (2014); Matheson and Finkel, 2013). It has been argued that the temporary population increase due to sporting events can result in heightened demand for sexual exploitation (Bowersox, 2016; Finkel, \& Finkel, 2015). Although a significantly smaller event, according to population statistics, reported by Gloucestershire County Council (2019), the population of Cheltenham is approximately 117,128 , meaning an estimated $224.23 \%$ temporary increase in the population during the festival period. Bowersox (2016) claims that logically, demand on the local sex industry can be driven up during large sporting events that attract large numbers of visitors to an area, which creates an opportunistic environment for exploitation and human trafficking to occur.

Reeves (2013) recommended that due to concerns regarding Race Week and the negative potential impacts, the council should raise awareness among local hotel managers of potential sexual exploitation and prostitution, in preparation for the Cheltenham Race Week. Additionally, Reeves (2013) reported that in response to Race Week, measures are put into place such as raising awareness and increasing officer presence. The local council and police also carry out inspections of alcohol and adult entertainment venues to ensure rules and regulations are followed (Cheltenham Borough Council 2019). However, the report stated that sexual exploitation in the area is not highly visible supporting recent literature that the problem is predominately hidden. According 
to Rutland (2017), this lack of visibility can cause assumptions such as the idea that modern slavery is not an issue, particularly in local communities across the UK.

There is a lack of research regarding the experience of specific individuals or groups, which may have critical complementary insights into the issue at a local level such as, how different forms of exploitation occur (Bales, Hedwards and Silverman, 2017). Reeves (2013), stated that gaps in knowledge are present as are challenges related to understanding the extent of trafficking and sexual exploitation in the area.

The NRM statistics for Gloucestershire (see Tables 4 and 5) show the increase in potential victims of modern slavery recorded in the local area. When compared with the national statistics (see Table 1), it is clear they both show an increasing trend as the percentage of referrals has increased annually in the previous four years. Table 5 shows the range of recorded exploitation types in Gloucestershire. When comparing exploitation recorded locally with the national scale (see Cooper et al. 2017), it becomes clear that the same offences are occurring and are also increasing annually. According to Gloucestershire County Council (2018), in 2016 police efforts regarding modern slavery increased and this area of policing became a force priority. This increased police effort, along with the development in anti-slavery practices in recent years, can provide some context for the increases in reported slavery instances, however, due to the lack of research-based evidence currently available, an accurate explanation for the increases remains indefinite.

Table 5 also shows that the most frequently reported type of exploitation in Gloucestershire, is labour exploitation. This is also true for the UK statistics (see National Crime Agency, 2019a). 


\begin{tabular}{|l|c|c|c|c|c|}
\hline $\begin{array}{l}\text { Claimed } \\
\text { exploitation type }\end{array}$ & 2015 & 2016 & 2017 & 2018 & $\begin{array}{c}\text { Total by } \\
\text { exploitation } \\
\text { type across } \\
\text { last 4 years } \\
(2015-2018)\end{array}$ \\
\hline $\begin{array}{l}\text { Labour } \\
\text { exploitation }\end{array}$ & 0 & 3 & 7 & 37 & $\mathbf{4 7}$ \\
\hline $\begin{array}{l}\text { Sexual } \\
\text { exploitation }\end{array}$ & 0 & 2 & 8 & 2 & 12 \\
\hline $\begin{array}{l}\text { Domestic } \\
\text { servitude }\end{array}$ & 0 & 0 & 1 & 0 & 1 \\
\hline $\begin{array}{l}\text { Unknown } \\
\text { exploitation }\end{array}$ & 0 & 0 & 0 & 2 & $\mathbf{2}$ \\
\hline Total & $\mathbf{0}$ & $\mathbf{5}$ & $\mathbf{1 6}$ & $\mathbf{4 1}$ & $\mathbf{6 2}$ \\
\hline
\end{tabular}

Table 5: National Referral Statistics with recorded exploitation typeGloucestershire (2015-2018).

\subsection{Practitioner Perspectives}

Practitioner perceptions regarding modern slavery can contribute to the broader understanding of this topic, however they have not been utilised enough in research. This is partially due to being a relatively new, yet growing topic area of research in the UK. Generally, local regions have received very little academic attention regarding this issue and there have been very few, if any, academic research enquiries conducted using Gloucestershire as a case study. This points to a gap in literature and absence of experienced and critical-based perceptions related to the topic at a local level.

Rutland (2016) successfully conducted a localised study in Leicester that focussed on practitioner perceptions of modern slavery, which contributed to the wider evidence and knowledge-base. For example, the study identified that 12 out of the 20 local practitioners used terms such as "hidden" or "discrete" to describe it. The study also acknowledged gaps in communication between organisations and practitioners at a local level, which resulted in under-reporting and missed opportunities to assist victims. 
In Australia, Christ and Burritt (2017) investigated business stakeholder perceptions related to modern slavery finding that more tools were required for businesses to manage the issue, particularly if exploitation extended to suppliers. The study concluded that directors in business should acknowledge the perspectives of stakeholders, NGOs, employee representatives etc. regarding the approach to tackling modern slavery in global supply chains (Christ and Burritt, 2017). The study contributed to a wider discussion regarding the potential impact of legislation in reducing modern slavery practices. This study is another example of practitioner insight being used to discuss modern slavery concerns, which then contribute to a wider discussion regarding the means of addressing the problem.

Another area that is currently lacking in research is the focus on the collaborative anti-slavery practices and prevention efforts in the UK. This applies to Gloucestershire as academic literature for this area has remained scarce altogether. Gaps therefore remain regarding understanding how practitioners tackle the issue locally (Reeves, 2013). Practitioner focused research offers an opportunity to develop knowledge on the subject, from individuals that have worked closely to the issue. This focus allows for insights regarding types of exploitation witnessed as well as critical insights regarding current provision.

\subsection{Summary of Literature}

It is clear that the growing field of research related to modern slavery has sparked discussion regarding the nature, scale and new manifestations of slavery in society. The literature reveals a vast amount of modern slavery offences evidenced within the UK but it is clear that few research enquiries have adopted a local focus. This has resulted in little evidence regarding how different localities are affected by modern slavery and a lack of recommendations for strengthening and developing local response.

The reviewed literature points to gaps in current policy implementation across the UK, including the Modern Slavery Act's ability to provide efficient support to victims. Additionally, the role and effectiveness of anti-slavery partnerships 
requires research-based attention as it remains unclear how these initiatives impact modern slavery and the local response.

This research enquiry aims to address these gaps by gathering evidence regarding modern slavery at a local level and considering the perspectives of experienced individuals in this field. The suggested research enquiry offers an opportunity to develop evidence regarding localised modern slavery via informed insights into this issue and bridging these gaps in knowledge.

In conclusion, even though research regarding modern slavery is developing, gaps still remain particularly research that focuses on local areas for example, interpretation of local statistics. Additionally, very few studies include the perspectives of local practitioners, which offer unique experienced-based perceptions of the issue and the local provision.

\section{Chapter 3: Developing a method to research practitioner perspectives}

This chapter firstly outlines the philosophical assumptions for this research, followed by sections relating to data collection techniques and analysis. This section also outlines potential limitations with the approach to this research enquiry, in order to critically assess the validity of the study, and to suggest improvements for future studies.

\subsection{Philosophical Assumptions}

Each piece of research contains underlying beliefs and philosophical assumptions, which have been widely acknowledged and debated within the scholarly community (Antwi and Hamza, 2015; Creswell, 2013). These assumptions and beliefs relate to ontology which, Crotty $(2003$, p. 10) refers to as the 'study of being' whereas Creswell (2013, p. 20) states that ontology relates to the nature of reality. Crotty $(2003$, p. 8$)$ outlines epistemology as 'how we know what we know'. According to Maynard (1994, p.10) epistemology is associated with 'providing a philosophical grounding for deciding what kinds of knowledge are possible and how we can ensure that they are both adequate 
and legitimate'. Philosophical assumptions allow the researcher to understand what kind of knowledge can be obtained by the proposed research (Crotty, 2003). This informs the researcher's choice of methodology and methods (Creswell, 2013; Scotland, 2012). This research adopts the assumption that reality is multiple and socially constructed, which can only be understood through attempting to gain access to the participant's worldviews and realities related to the subject area. This refers to the interpretivist theoretical perspective, which includes understanding specific individuals and their perspectives related to modern slavery such as professionals working in the field. For this study an inductive approach is taken, rather than starting with a hypothesis, which refers to building theory through observations and patterns in the data (Smith and Davies, 2010). It is also worth noting that the research was not conducted with a specific agenda beyond seeking practitioner perceptions and allowing them to be the focus of the enquiry.

For this research enquiry, multiple perceptions, opinions and experiences related to modern slavery are being sourced, collected and analysed to construct knowledge regarding the phenomenon. During this approach individual views and experiences are highlighted as key sources for data collection (Creswell, 2013). Furthermore, an interpretivist approach, was adopted as it relies upon the perspectives of participants and conclusions that derive from the interpretations of these responses, rather than the abstract theories of the researcher (Creswell \& Creswell, 2013). This approach rejects absolute fact and objective truth and instead focuses on perceptions, which relates to the position that reality is multiple (Creswell, 2013). This highlights the reasoning behind utilising an interpretivist paradigm and qualitative methods that rely on the seeking experiences, perceptions and understandings from participants in order to uncover reality (Thanh and Thanh, 2015). Cohen et al. (2002) states that in this case human perceptions and situations are examined through the lens of participants rather than the researcher. This provides context to the ontology and epistemological assumptions appropriate for this research enquiry.

A qualitative approach was taken because the aim of this study is to gain an understanding of participant perspectives, experiences and opinions regarding 
localised modern slavery. For this research enquiry qualitative data analysis was used as a process to bring structure and meaning to the collected data (Marshall and Rossman, 1990). In this case, the aim of qualitative research is to develop understanding of the topic under study, through recognising the value of participant viewpoints. These unique viewpoints can be critical to understanding the topic as they are based on experiences of the individuals and different realities of the subject through working in various areas of the field. These perspectives can only be understood in the context of the participant's worldview, as stated by Castleberry and Nolen (2018).

According to Crotty (1998) a methodology is a comprehensive strategy which reflects the researcher's choice of specific methods. Noor (2008) states that these methodological choices differ depending on the type and features of the research. In this case, the following methodological approach aims to address the research objective in gaining insights into the topic via semi-structured interviews with local practitioners. This aims to develop the current researchbased evidence regarding modern slavery in Gloucestershire focusing on key aspects of the topic. The key aspects include, but are not limited to, perceptions of modern slavery as a concept and how this relates to the way in which the problem is viewed and how it potentially manifests locally.

Localised research enquiries utilising practitioner perceptions of modern slavery have been successfully executed and are becoming an increasingly popular research focus (Cockbain, \& Brayley-Morris, 2017; Christ and Burritt, 2017; Rutland, 2016 and Reeves, 2013). Additionally, the report conducted by Cooper et al. (2017) regarding modern slavery typologies for the UK utilised the consultation of experts e.g. frontline staff, NGOs and police officers. These previous research studies have effectively highlighted key factors regarding the social phenomenon by evaluating perceptions of the issue through the lens of practitioners in the field. The precedent for including first hand practitioner evidence demonstrates appropriateness for this study, which was tailored to the study site of Gloucestershire. 


\subsection{Data Collection}

\subsubsection{Sample}

Participants were recruited via a purposive, snowball sampling approach, based on their professional roles and their different professional backgrounds, which informed the phenomenon under study (Sargeant, 2012; Creswell \& Creswell, 2013) and allowed a broad range of perspectives to be sourced for this study. Purposive sampling recruitment techniques were utilised because the study required specific, well informed individuals who have expertise in the subject area (Palinkas et al. 2015). Initial respondents were recruited from local NGOs, faith-based organisations and public services by discussing the aim of the research project with individuals in these targeted professional sectors. Following this sampling technique, a snowball sampling approach was then implemented that involved participants referring additional individuals among their connections to expand the recruitment of suitable participants. This sampling approach was necessary for this research due to the sensitivity surrounding the topic which, has been known to cause challenges when accessing participants (Browne, 2005).

Initial concerns regarding professionals' reluctance to take part in the study due to modern slavery being a sensitive subject and lack of availability were mitigated through the snowball sampling approach as it allowed introductions to be made by other professionals, which gained trust and the interest of other potential participants. Participants for this research were sourced from various professional roles in order to gain wide-ranging experiences, opinions and perspectives. The full list of participants interviewed for this study is shown in Table 6. 


\begin{tabular}{|l|l|}
\hline Participant number & Professional Role \\
\hline 1 & Human Trafficking NGO \\
\hline 2 & Gloucestershire Constabulary \\
\hline 3 & Safeguarding Officer, Faith-Based \\
\hline 4 & Safeguarding Officer, Faith-Based \\
\hline 5 & Cheltenham Borough Council \\
\hline 6 & Faith-Based Non-governmental relief agency \\
\hline 7 & Gloucestershire Constabulary Detective \\
\hline 8 & Healthcare Professional \\
\hline 9 & Gloucester Council Representative \\
\hline 10 & Anti-slavery partnership representative \\
\hline 11 & Crimestoppers \\
\hline 12 & Business Procurement \\
\hline 13 & Asylum seeker case worker \\
\hline 14 & Asylum seeker support worker \\
\hline
\end{tabular}

Table 6: Participants with corresponding profession/professional role

As mentioned previously, the nature of the participant experiences differed, for example; some worked directly with survivors of modern slavery via NGOs, some came into contact with victims/potential victims during work as police officers or healthcare professionals. Some participants had no experience working directly with victims or survivors and were associated with raising awareness, working with the legislation or other areas related to the issue e.g. the anti-slavery partnership. This allowed multiple perceptions from a variety of informed individuals to be collected regarding key areas of the topic. The Gloucestershire Anti-Slavery Partnership served as a means of networking and recruiting research participants. According to Gardner (2018), these partnerships provide valued sources of information regarding localised engagement with modern slavery policy. It was therefore important to acknowledge the role of the partnership as a potential source of research participants, which resulted in the recruitment of $57 \%$ of the research participants. It is worth noting that $43 \%$ of the participants were recruited outside of the Partnership, mitigating repetition of data or biases, because a key role of these partnerships is information sharing. This approach also served as an opportunity for voices critical of the anti-slavery partnership itself to be considered if present. The majority of intended participants responded positively 
to the invitation and agreed to take part in the study, demonstrating eagerness to contribute to the research.

Researching modern slavery by interviewing a range of individuals such as Council members, Law Enforcement and NGOs is useful in highlighting many aspects of this issue (Cockbain \& Brayley-Morris, 2017; Christ and Burritt, 2017; Rutland, 2016). Examples of key areas of the topic included in the interview guide (see Appendix B) were; forms of exploitation, impact of local and national provision and contributing factors specific to Gloucestershire. These key areas were covered during the interviews to allow a broad overview of the topic. This contributes to the growing body of qualitative interview research, which illuminates the complexity and variability of modern slavery. This approach offers an opportunity to develop the evidence-base, using the perspectives of individuals who have experience with the subject. The details from experienced individuals provide a unique take on the subject, allowing this study to present modern slavery as viewed by the professionals that work alongside it.

\subsubsection{Interviews}

Semi-structured interviews were appropriate for addressing the aim of this research as they allow participants to express their individual accounts, understandings and experiences (King et al. 2019). For example, this interview technique is acknowledged as a powerful means of generating description and interpretation of individuals' social worlds (Majid et al. 2017; Robson and McCartan, 2016; Richie and Lewis, 2014; Warren, 2002). In support of this approach, Merriam, (2006) states that the interpretivist paradigm involves data that is often collected via interviews, with the purpose of gaining an understanding of the phenomenon from detailed accounts of experienced individuals. This addresses objective 2 in collecting practitioner perspectives regarding modern slavery in Gloucestershire. In this case, qualitative interviews were appropriate for this research enquiry due to the effectiveness associated with observing and identifying an individual's perspectives (Patton, 2002). They were an ideal choice for this research because they result in rich descriptions of the individual's discussed social world (Warren, 2002). Another reason for using semi-structured interviews is the naturalist means of interaction, which can be used to uncover information often inaccessible to questionnaires and 
observations (Blaxter et al. 2006). This approach allowed the perspectives of multiple practitioners to be collected and produced detailed accounts associated with the broader topic.

According to King et al. (2019) the critical aspect in qualitative interviewing is building rapport with the research participants. Rapport-building carried out in many ways before and during the interviews. For example, meeting the participants prior to the interview and discussing the research in detail and answering any questions they had provided reassurance and built trust. This pre-interview preparation was also carried out to encourage participants to feel comfortable during the interview in order to mitigate potential changes in responses when being recorded. King et al. (2019) highlighted this approach as useful, particularly regarding sensitive topics and encouraging a positive relationship between researchers and participants. While there is no exact method of developing rapport it is advisable to allow participants to decide the location of the interview (Doody and Noonan, 2013; Elwood and Martin, 2000). Where possible this study followed that advice and interviews were conducted in locations of the participants' choosing in order to allow both physical and psychological comfort during the interview, to mitigate participants feeling unsettled which could negatively impact results (King et al. 2019). This was intentionally carried out as a measure to create a positive environment for the interviews to take place. An example of this is when possible, private rooms were acquired for the interviews, in order to provide privacy and maintain confidentiality, while limiting interruptions. Additionally, participants were invited to attend the interviews at their convenience, with the intention of reducing pressure and to avoid potential rushing during the interview. This approach also encouraged honest responses rather than participants feeling the need to make comments they perhaps felt the research was searching for.

An interview guide containing prompt questions was utilised during the interviews (see Appendix B), which is an organised list of questions and topics used to influence the interview in the appropriate direction for the research purpose (DiCicco-Bloom \& Crabtree, 2006). The interview guide covered the main topics of the study but this was not strictly adhered to because the purpose of the semi-structure was to allow exploration of the research area as 
outlined by Holloway and Wheeler (2010). The questions asked during the interviews were broad and at times varied as some questions were inappropriate to ask certain individuals. For example, when interviewing an individual from the Anti-Slavery Partnership, it was not necessary to ask 'are you aware of the local Anti-Slavery Partnership?' The questions were kept broad to allow room for individual interpretation and response rather than asking leading questions, which carry assumptions (King et al. 2019). This allowed participants to discuss a variety of areas of the topic and focus on key aspects they felt were important. Giving participants this flexibility during the interviews prevented excessive reinforcing of their opinions, which can often direct the interview unnecessarily (King et al. 2019), while ensuring relevant desired areas of the topic were discussed.

The interview guide was piloted in order to ensure the questions being asked aligned with addressing the research aim and objectives. This was also done to identify areas of the interview process that required improvement. During this process, the researcher acknowledged the interview protocol refinement framework as discussed by Castillo-Montoya (2016) which involves four steps: ensuring interview questions are linked to the research question(s), helping to form an inquiry-based conversation with participants; receiving feedback regarding the interview, and piloting (Castillo-Montoya, 2016). According to Jones, Torres and Arminio (2014), this approach aids the researcher to develop a research method appropriate for both the research aims and the participants involved in the study. Piloting the interview resulted in minor changes being made to the interview guide and allowed the researcher to improve interview skills, enabling future interviews to be conducted under improved circumstances.

Each interview was audio-recorded rather than solely relying on notetaking alone. Although notes were taken during the interviews, this is typically deemed unreliable as important information could be missed (Jamshed, 2014). The reason for audio-recording was because thorough analysis of the data was later required and therefore an accurate record of each interview was necessary. Tessier (2012) states that producing transcripts from audio-recordings incurs several key benefits including; accessing the event itself in greater detail 
compared to field notes. Note taking was also utilised as a contingency, for example; to include additional details for the researcher to refer to if needed. This relates to information that the audio could have missed and was also used as a precaution in the event of the recording device failing or corrupting. Furthermore, in the event of a participant requesting the interview not be audiorecorded, note taking was an alternative option. It is worth noting that despite this precaution, all participants consented to audio-recording, which was preferred for this study due to the lack of detail capture associated with note taking (Tessier, 2012).

\subsubsection{Data Saturation}

Initially there was a preliminary target of 15 to 20 participants, however this changed to a sample size determined by reaching data saturation. Faulkner and Trotter (2017) refer to this as the point in which there is no new information being discovered during data analysis. This is commonly taken to indicate that further data collection is unnecessary and is a process that has attained acceptance as a methodological principle within qualitative research (Saunders et al. 2017). Data saturation was indicated in several ways within this study. For example, the absence of new codes emerging and categories stabilising (Smith and Davies, 2010; Urquhart, 2013). Additionally, the lack of new themes deriving from the data is another indication that data saturation had been achieved, deeming further data collection at this point was unnecessary (Birks and Mills, 2015). For these reasons, the researcher could be reasonably assured that further data collection would produce similar results, which would confirm emerging themes (Sandra, Faulkner and Trotter, (2017). Furthermore, whilst sourcing participants it became clear that a sufficient number of representatives from Gloucestershire had been recruited for this study. This was indicated towards the end of the data collection process as many of the participants had referred the researcher to individuals that had already been invited to take part in the study. Observing this repetition in referrals suggested that a suitable number of relevant participants had been sourced. At this point it was necessary to test this assertion and ensure the study had not simply included participants known to each other, as this would not represent the intended sample. This was tested by seeking additional participants for the study from another avenue, which was the Anti-Slavery Partnership and another 
NGO. This resulted in repetition in referrals further indicating that an acceptable sample had been collected.

\subsection{Data Analysis}

According to AlYahmady and Alabri (2013) qualitative data analysis is pursuing the relationship between themes of data and attempting to increase the understanding of the topic by interacting with the data in a flexible manner. For example, observing patterns in the data and constantly comparing them, all of which are coded, which generate categories (Smith and Davis, 2010). Once the data had been collected, it was manually transcribed from the interview recordings. This ensured familiarity and closeness with the data (Castleberry and Nolen, 2018; Smith and Davis, 2010). Even though manually transcribing data is known to be time-consuming (Smith and Davis, 2010) the associated benefits outweigh the option to have the recordings externally produced. Smith and Davis (2010) highlight additional benefits of the transcription being conducted by the researcher including; it being easier to understand what is being said if the transcribing takes place soon after each interview.

Furthermore, the process of listening to the recordings and typing out each word encourages the researcher to become immersed in the data. This process also allowed for thorough checking of errors and inaccuracies, which were corrected during this approach (Smith and Davis, 2010). Tessier (2012) highlights that a key benefit of producing transcripts from digital files is the researcher's ability to search for specific excerpts in the interviews.

\subsubsection{Thematic Analysis}

The interviews were then analysed thematically using an inductive approach based on observing patterns, resemblances and regularities in experiences in order to reach conclusions or to generate theory (Saunders, Lewis and Thornhill, 2016). This relates to a 'bottom-up' process that involves using evidence in the data as the origin of developing conclusions (Ritchie, 2014). The alternative, deductive processes, test evidence from the data against hypothesises derived from pre-existing theories (Ritchie, 2014). However, there are very few current theories and concepts related to modern slavery at a local level that could be applied to draw contrast and comparisons. While this area has seen an increase in research, it remains limited and patchy (Cockbain et al. 
2018) and therefore supports the generation of knowledge from the data up. An inductive approach was, therefore, more appropriate for this type of enquiry as it seeks to gain multiple perceptions of modern slavery in order to develop new knowledge. This approach to this area of research attempts to address the criticisms by Cockbain et al. (2018) that scientific research (related to human trafficking and labour exploitation) often had conclusions not properly grounded in data. This approach links to Grounded Theory Methodology (GTM), which consists of systematic, flexible guidelines for collecting and analysing qualitative data in order to construct theories from the data (Charmaz, 2014). GTM originates in the work of Glaser and Strauss (1967) and has been used extensively in social science. For GTM it is important to collect rich and detailed data from a range of perspectives in order to aid the development of theory (Maher et al. 2018).

Blaikie (2007) argues there is no such thing as 'pure' induction or deduction due to the inability to approach the interpretation of data with a blank mind even if when not testing a hypothesis. Blaikie (2007) argues that in each case the data that has been generated through the questions asked will have been influenced by assumptions derived from previous works in that field. In response to this limitation, the semi-structured interview guide allows space for the participants to direct the interview and therefore discuss their own perception of the key areas of the topic.

This inductive approach allows conclusions to be drawn from the data offering the opportunity to contribute to the literature regarding suitable professional practice. Additionally, this approach provides an opportunity to identify significant broader patterns of meaning in relation to key research questions. By establishing these patterns, it is possible to gain insights into the types of offences taking place, how they occur, the role of current policy and the perspectives surrounding future intervention.

\subsubsection{Codes and Themes}

Coding in qualitative research involves identifying similarities and differences in the data (Sutton and Austin, 2015). According to Maher et al. (2018) coding is the main analytic process linked to GTM, which requires categorising data 
segments using codes with the aim of developing an understanding of what is happening in the social situation being studied (Charmaz, 2006). Auerbach and Silverstein (2003) stated that the coding method is a procedure for organising sections of large text and discovering patterns to develop theory. Once the data was transcribed, sections of the transcripts were separated using the Node feature in NVivo and formed categories and groupings. Castleberry and Nolen (2018) refer to this process as disassembling, which leads to reassembling when later the codes are brought together to form themes in a hierarchy (otherwise known as thematic hierarchies).

The coding process for this research can be divided into three main sections. The purpose of conducting analysis in this manner is to identify key patterns and/or differences between transcripts. In doing this, it is then possible to identify significant similarities and/or differences regarding the perceptions related to the topic. This offers an opportunity to establish a base-line of knowledge regarding the practitioner's perceptions and experiences, associated with the study.

Stage one of coding consisted of reading each transcript and highlighting relevant material that directly linked to the research aim or objectives. This approach addressed a common challenge associated with interview coding where the researchers fail to establish a direction to take; assuming that everything covered in the data is important for the study (Auerbach and Silverstein, 2003). This challenge was mitigated by maintaining the initial focus linked to the research aims providing a clear starting point for the coding process.

Initially, coding took place manually and involved single words, phrases or sentences. For example, initial descriptive codes were applied throughout the transcripts such as 'types of slavery practices', 'prevention measures', 'policy intervention'. NVivo was also used to ease this process by allowing the researcher to interact and apply coding to all the data, as shown in Figure 1. This allows for greater links and comparisons to be drawn later in the analysis process. 
The next stage was the development of themes across the transcripts. Themes developed through the repetition of ideas were then organisation into larger abstract ideas and concepts (Auerbach and Silverstein 2003; shown in Figure 2).

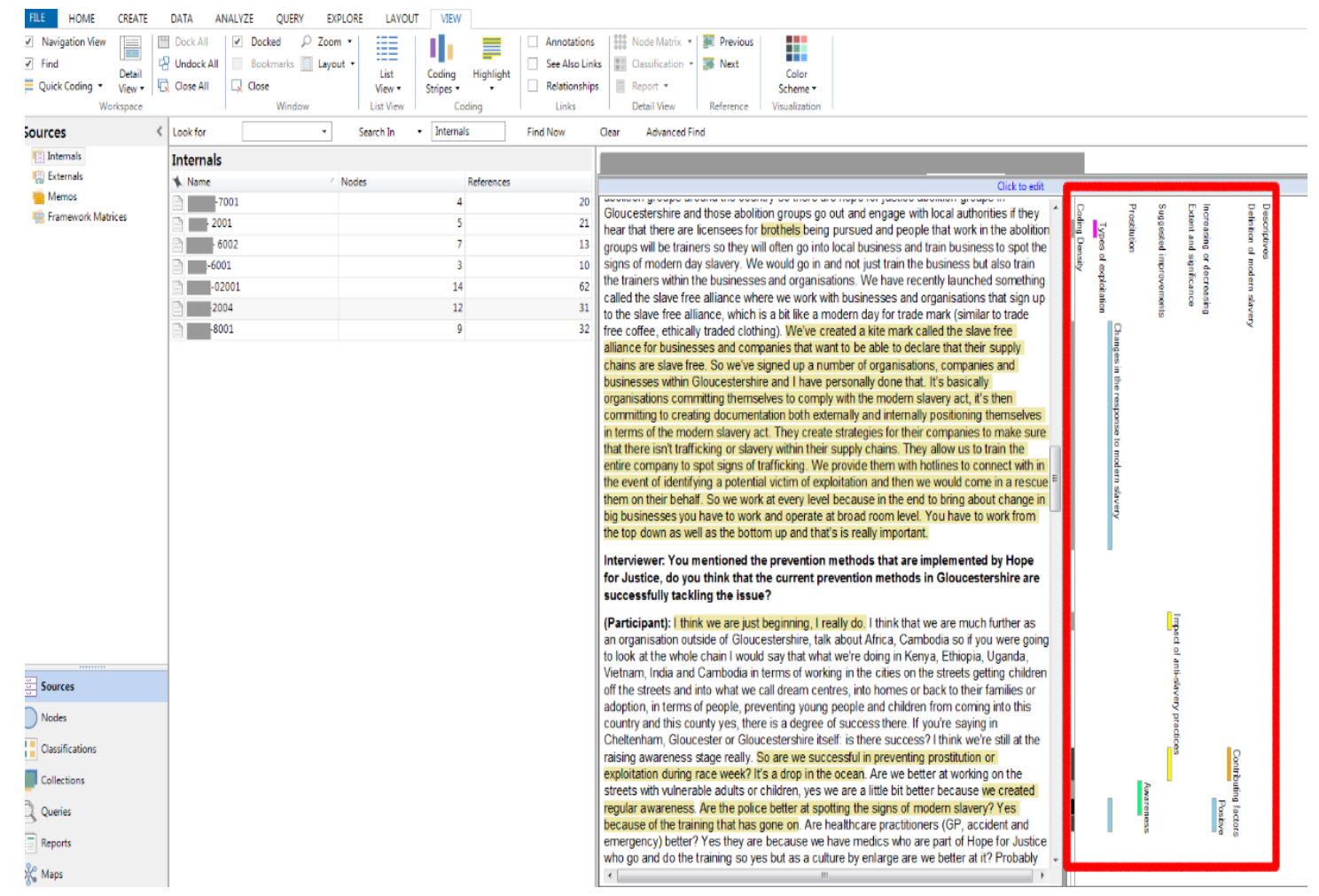

Figure 1: Example coding in NVivo 
Stage one:

Examples of initial codes highlighted across raw data. At this stage, sections of the data are labelled with a code or code word. This process is about identifying features of the data that link back to the research objectives.

\section{Stage two:}

Grouping together/organising codes that have a common theme. Some themes interrelate, which creates different levels of themes i.e. subtheme.

\section{Stage three:}

The identification of organised and global themes that derived from initial codes. Basic and organising themes can link together to form Global themes.
- Sexual Exploitation

- Exploitation in agriculture

- Labour exploitation

- Car washes

- Nail bars
Several forms of exploitation highlighted by participants

Figure 1: Diagram showing the development of themes

During this process, it was appropriate to merge or split themes to aid in the development of theme hierarchy. This was carried out using the Node feature and monitored in the codebook in NVivo. For example, the primary theme 'extent of the problem' could be broken down into three specific subthemes e.g. growing, declining or stable. It is important that coding was undertaken across all the transcripts to form themes, which avoids relying heavily on single responses to key topic areas. Using NVivo also simplified this process by allowing constant monitoring of the sources and references as analysis took place (as shown in Figure 3). These features allowed progress to be observed and careful monitoring of the analysis process. From here similarities and contrasts could be observed, which formed the basis of the discussion chapter of the research project. 


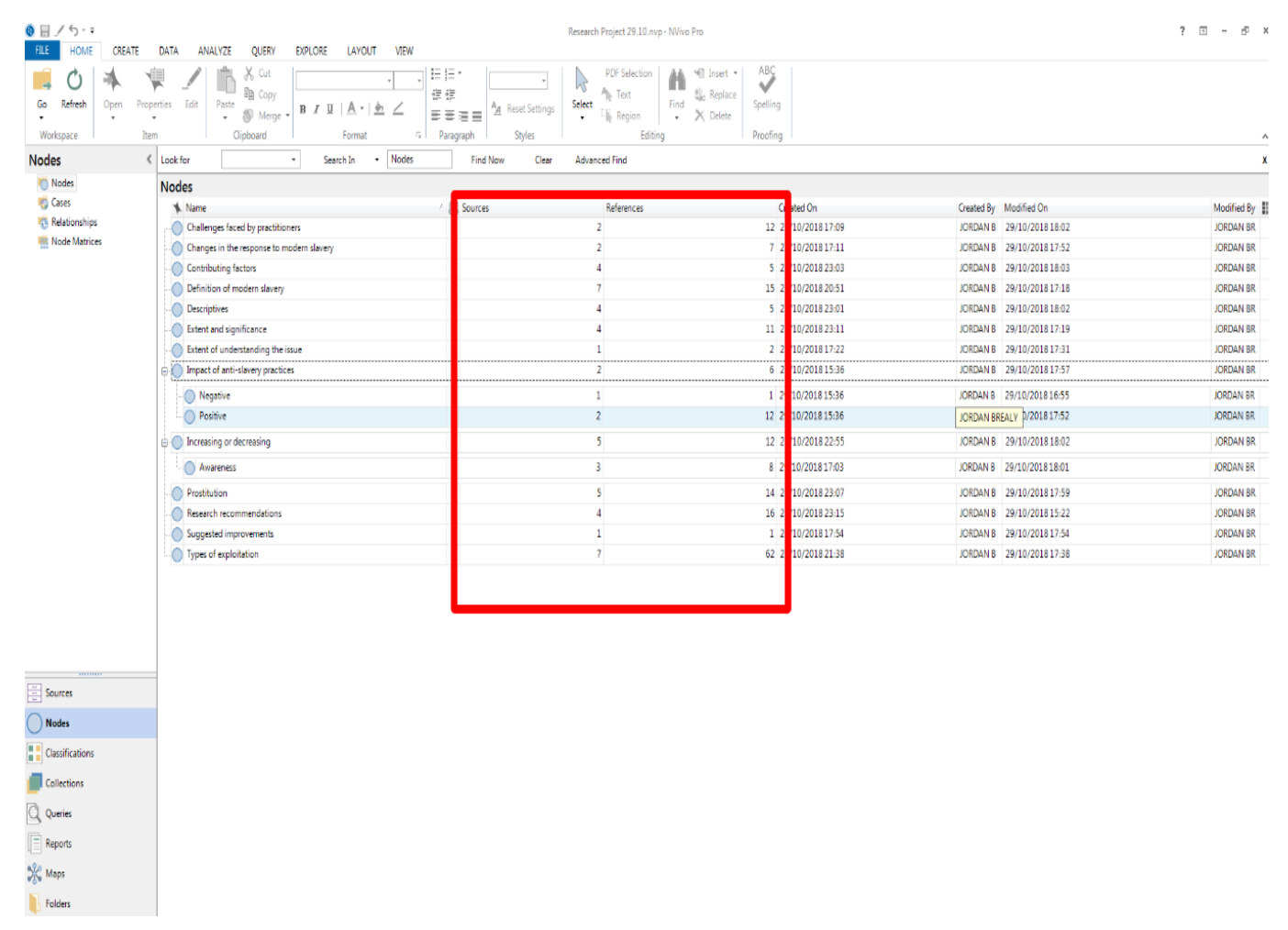

Figure 2: Sources and references lists in NVivo

\subsubsection{Summary of How NVivo was Used to Aid Analysis}

For this study NVivo was primarily used as an organising tool, which addresses the criticism regarding computer-based software packages taking over the role of the researcher. Computer Assisted Qualitative Data Analysis (CAQDAS) has been criticised due to concerns regarding researchers being guided in a particular direction (Seidel, 1991). Another concern associated with utilising this software is the argument that is causes separation between the researcher and the data, resulting in quantitative analysis of qualitative data (Barry, 1998; Hinchliffe et al. 1997). Welsh (2002) argues that CAQDAS has its place in qualitative research and that a researcher should recognise the value of both manual and electronic tools (Welsh, 2002). In addition, Maher et al. (2018) recognises the benefits of NVivo as well as traditional techniques, stating that the use of NVivo supports data analysis by providing enhanced management during the coding process, particularly when accompanied with traditional tools e.g. highlighter pens during manual coding. In this study, traditional coding techniques and NVivo software were used in addition to CAQDAS, in order to benefit from both the management benefits associated with CAQDAS, which 
has also been found to reduce errors associated with traditional methods. This was reinforced previously by Richards (2002), who highlighted features such as character-based coding, rich text capabilities and functions of NVivo that are crucial for qualitative data management. Traditional methods were incorporated via hard copies and highlighters, predominantly to ensure rigour and suitable interaction with the data.

Interviewing as a research method typically results in dealing with large quantities of data, which can be both time consuming and labour intensive (AlYahmady and Alabri, 2013). In order to mitigate these challenges, CAQDAS has become an increasingly popular method which, according to Zamawe (2015), researchers should become aware of CAQDAS as an option for aiding transcript analysis. AlYahmady and Alabri (2013) declare the software reduces the manual tasks and gives the researcher more opportunity and time to discover tendencies, recognise themes and derive conclusions. For example, when using NVivo, one way that accuracy is achieved is by using the search feature, which is seen by the product designers as one of its main assets for facilitating interrogation of the data (Welsh, 2002). Carrying out such a search electronically is arguably more effective, less time consuming and can result in greater accuracy and reliable results compared with a manual search. According to Zamawe (2015), there are misconceptions associated with CAQDAS but a criticism of software use is reduced data interaction, (see Maher et al. 2018). This criticism was addressed during this study by ensuring the interviews were manually transcribed by the researcher which, as stated previously, encouraged data interaction.

\subsection{Ethical Considerations}

The data obtained was only accessible to the researcher and project supervisors to ensure a high level of confidentiality. The participants were informed that any raw data collected will be appropriately destroyed after the study concludes, unless permission was given to archive. For ethical purposes, each participant was briefed prior to the interviews, whereby they were informed that answering all questions was not mandatory. This was done to acknowledge the potential for upset during the discussion of sensitive and possibly 
distressing topics. It is also worth noting that during data collection, to the researcher's knowledge, no victims of modern slavery were interviewed for this study. Of the 14 participants recruited for this study, 11 gave consent to have the transcript data archived and none of the participants decided to withdraw from the study. Additionally, each participant was reminded that their participation in the study was entirely voluntary and that they could withdraw at any time up to January 2019 (see Appendix A and Appendix C), (Alshenqeeti, 2014).

Once the participants were sourced, each individual was presented with an information sheet containing all relevant information regarding the study (see Appendix $\mathrm{C}$ ). This included details regarding the purpose and significance of the research, data handling information and duration of study. The information sheet also provided contact numbers of the researcher and research supervisors for follow-up questions regarding the study. Participants were also asked to read and sign a consent form (see Appendix $A$ ), which, included indicating permission for the interview to be audio-recorded and to provide consent regarding archiving the data after the research concludes. Obtaining informed consent is an ethical and legal requirement for research involving human participants (Musmade et al. 2013).

Interviews are considered an intrusion into respondent's private lives therefore, a high standard of ethical consideration should be maintained (Cohen et al. 2007). Additionally, for this research, due to the sensitive nature of the topic, the research methodological approach adheres to the guidelines outlined by The University of Gloucestershire concordat to support research integrity. For example, any information collected during the interviews relating to a third party was suitably broadened e.g. if a participant mentioned the name of a potential victim or colleague, this would be changed or broadened for confidentiality purposes. Furthermore, for data handling and security purposes, the data was stored on a password protected computer, facilitated at the University of Gloucestershire.

Prior to the interviews, the participants were given the opportunity to request anonymity and a level of confidentiality that suited them. To ensure this, when 
presenting the interview data, each quote was accompanied with a tag relating the individual's profession rather than personal information relating to their identity, as shown in Table 6 . The level of anonymity was strictly adhered to throughout the duration of the study. Participants were also informed that breaching confidentiality would only be necessary in the event of an individual being at risk of harm, as stated in Appendix A. Although all necessary precautions to provide anonymity for the research participants was provided, it is said that interviews are never $100 \%$ anonymous (Alshenqeeti, 2014). An example of when this is out of the researcher's control is during situations when participants reveal their participation in the study to third parties.

\subsection{Limitations}

Hammersley and Gomm, (2008) stated that qualitative research using interviews should acknowledge that participants will be influenced by what they think the interviewer wants to hear. This is therefore a potential limitation with the methodological approach for this study. Furthermore, research participants respond to questions in a different manner when aware the conversation is being recorded. The potential for this bias argues against the conversations taking place in a natural environment. With regards to audio-recording, the lack of visual aid limits the ability for the research to recall factors that could impact the data such as, facial expressions, emotions and body language. In order to mitigate this in future research, the use of both audio and visual recording should be explored. 


\section{Chapter 4: Discussing the evidence}

This section presents and discusses the themes which emerged from the analysis of interviews with local practitioners in modern slavery related fields in Gloucestershire, thus addressing objective 2.

\subsection{Practitioner Understanding and Awareness of Modern Slavery}

\subsubsection{Differing Perceptions of the Term 'Modern Slavery'}

A range of opinions and perceptions regarding the term 'modern slavery' within individual fields were acknowledged in the data of this study. These insights contribute to the idea that participant perception of modern slavery can be influenced by practitioner experiences with victims/survivors and professional roles. Practitioners basing their perceptions of modern slavery on victim experiences will mean great variation in perceptions due to the extremely variant nature and forms of slavery (Bales, 2004).

Some participants, typically those professionals who had either experience implementing legislation or a policing background, referred directly to the Modern Slavery Act to define the term. For example, participant 12 discussed having responsibility for preparing a slavery and human trafficking statement under section 54 of the Act, for a local establishment.

"Modern slavery is as defined in the legislation, fully adopted by the organisation and it's basically people who are in summary, people who are forced into labour or are in labour not at their own free will."Participant 12, Business Procurement

"I define it by the 2015 modern slavery legislation."- Participant 2, Gloucestershire Constabulary

This definition indicates that professionals with responsibility regarding law and experience implementing the legislation tended to focus on the legal definitions and factors that could lead to prosecution under the Act. Other participants in this study defined modern by the experiences of victims, including types of exploitation and how it takes place, these were often professionals who worked 
for the council or for faith-based organisations. Participants 4 and 10 used the term "exploitation" in their definitions and, in doing so, indicated this was a key component related to their perception of modern slavery.

"It's exploitation of vulnerable people in different ways"- Participant 4, Faith-Based Safeguarding Officer

"I think fundamentally it's just exploitation of an individual for personal or commercial gain"- Participant 10, Anti-slavery Partnership Representative.

Participants 6 and 9 focussed their definitions on their opinions related to victim experiences' such as: "being forced to do something" such as labouring or: "having their movement restricted" by removing travel documents.

"I think it would be people being forced to work for very low wages, being either imprisoned or having their movements very much restricted by means of having money taken away or documents removed or the removal of people's freedom and liberty and being forced to do something that they maybe would not choose to do."- Participant 6, FaithBased Non-governmental relief agency

"Anyone generally that's in a situation against their will where they're being forced to do something."- Participant 9, Gloucester Council Representative

"It's about the dehumanising of an individual and converting them from a person to a commodity." - Participant 5, Cheltenham Borough Council

The focus on exploitation is embedded within both the Modern Slavery Act 2015 and wider literature such as Machura et al. (2018), who states that modern slavery encompasses forms of extreme labour exploitation.

"Control" was another key phrase used by the research participants when asked to define modern slavery.

"The control of one person by another or others and I try and keep it simple as that because firstly, legislation can be complex, it can confuse people and I talk about it as very broad, as I've already mentioned, a broad threat and actually a very useful legislative tool therefore to deal with other issues, such as CSE and County Lines." - Participant 7, Gloucester Constabulary 
"It's the wider public sector and the public at large to kind of see it when they go to a carwash when someone looks like they're under the control of someone"- Participant 9, Gloucester Council Representative

"We just feel something is not right and then it's asking those further questions of, is anyone trying to control you?"- Participant 8 , Healthcare professional

"The control of one person by another or others" - Participant 7 (Gloucestershire Constabulary)

The data in this study shows that the control element is mentioned across agencies, for example; the local constabulary, healthcare and council sectors. This suggests that in some cases, the perception of modern slavery was influenced by experiences of potential victims. This is unsupportive of findings from Nicholson, Dang and Trodd (2018), who stated that practitioners do not take victim experiences into account when discussing the parameters of slavery. An example of this is participant 7 stressing that if a "controlling element" was present, this is an area where policing efforts would be focused as it is a key indicator of exploitation. This reinforces Bales (2006), who claimed that a core attribute of both past and present slavery is the condition of potentially violent control of one person by another.

Many research participants indicated that the trafficking or movement of a person was key in defining the term modern slavery. In some instances, this definition was expected due to organisational roles, for example; participants 13 and 14 represent an asylum-seeking organisation that provides support for potential victims of human trafficking. This explains why these participants referred specifically to the movement of people or 'trafficking', as this is their professional focus. Additionally, during the interview, participant 8 discussed how they also worked for a charity specifically focused on human trafficking and reported to have come into contact with a trafficking victim while working as a local GP. Participant 11 also highlighted 'trafficking' as a key aspect in defining modern slavery as she indicated that human trafficking and modern slavery definitions could be merged together.

"My clients are generally trafficked into the UK or have been trafficked from their country across Europe and then escaped and may end up in the UK. But as long as they've been trafficked it's all across Europe or 
into the UK then they're classified as being victims."- Participant 13, Asylum seeker, Case Worker.

"I just used the definition of trafficking. For my work its children so they just have to be moved essentially for exploitation."- Participant 14, Asylum Seeker Support Worker.

"For my definition is the kind of the movement of people by means of force, fraud, coercion or deception with means of exploiting them. Now that's the definition of the charity I work for so that's probably why I've got that my head." - Participant 8, Healthcare Professional

"The way that I would look at it is I would normally put together modernday slavery and human trafficking. I think the misconception is that people assume that human trafficking has to happen from either one country to another or one county to another without the recognition that it can just be from someone moving to a house next door or even to a room in the same, you know, family home for example." - Participant 11, Crimestoppers

It is widely acknowledged that the terminology surrounding this subject can often be confusing. This confusion is evident in this study and in Rutland's (2016) study in Leicester and Siller (2016) who argued that despite distinct legal definitions, slavery is consistently being intertwined with human trafficking. This research also finds evidence of this intertwining with many participants expressing that movement and trafficking are key factors in defining the term modern slavery, indicating similarity with the term human trafficking. However, as outlined in the Modern Slavery Act 2015, human trafficking is a separate offence relating to facilitating the travel or movement of another person. A reason for the terminological confusion identified by the participants in this study, is the overlap between these different offences. Haughey (2016), demonstrates this confusion through stating slaves rarely experience just one form of abuse. For example, if an individual is sexually assaulted and forced to work, and they are driven to the labour location, this is both sexual exploitation and human trafficking for the purpose of labour exploitation, under the Modern Slavery Act. This demonstrates the misconception highlighted in this study relating to the two different terms being used by local practitioners to refer to the same issue.

Professional roles and experiences with potential victims' impact how the topic is perceived by practitioners. This is shown by the multiple perceptions of 
modern slavery discussed by the research participants, which are likely linked to factors such as participant experiences with survivors and perpetrators, experience and awareness regarding legislation, professional roles and agency representation. This reinforces the claims that modern slavery is an umbrella term that encompasses the offences of human trafficking and slavery and forced labour (Cooper et al. 2017; Piotrowicz, 2018; Reed et al. 2018; Zimmerman, 2017). The different perceptions described by the participants suggest only a partial understanding of the overall topic, which is negative for factors related to identifying potential victims locally and awareness raising.

The ineffectiveness of the legislation is highlighted by Gardner (2018), yet this study finds evidence of its use and implementation. The key terms typically used in this study to define modern slavery such as; exploitation, control, force and movement, are embedded within the national legislation. Therefore, this study indicates that these phrases are important aspects of practitioner perceptions of modern slavery and, although these components are accompanied with individual accounts, their presence denotes awareness of the legislation. In most cases, the participants in this study expressed perceptions that reflect their individual organisations and experiences, whilst including key factors related to the national legislation. This, therefore contradicts claims regarding the ineffectiveness of the legislation and how policy has been implemented at a local level (Gardner, 2018). It is unclear exactly why these responses had different focuses, but the data does indicate that professional roles have some influence over how the topic is perceived by the professionals locally.

\subsubsection{Underreporting of slavery in Gloucestershire}

In this study, half the research participants used terms such as "hidden" or "underground" to describe the occurrence of modern slavery in Gloucestershire. These terms were used by participants across different organisations indicating the prominence of this perspective.

"It's something that's very hidden"- Participant 4, Faith-Based Safeguarding Officer 
"So, it's quite a hidden issue"- Participant 8 , Healthcare professional

"We've noticed quite a significant change in the understanding of modern-day slavery and also the crimes that are usually very hidden within it."- Participant 11, Crimestoppers

"Obviously the whole point is that it's underground and therefore is not easily quantifiable."- Participant 6, Faith-Based Non-Governmental Relief Agency

This hidden nature impacts statistical evidence for understanding of the extent of the problem in Gloucestershire. As Gardner (2018), highlighted there is limited information at local level and as a result, the true extent of the problem in Gloucestershire remains unknown. Indeed, this is what was concluded by Reeves (2013) during an investigation in Cheltenham. Participants 4 and 6 suggested that current NRM statistics for Gloucestershire represented only the "tip of the iceberg".

"I think the truth is anyone that's working in this field will freely admit that there's a pretty significant chance that what we're seeing is just the tip of the iceberg." - Participant 6, Non-Governmental Relief Agency

"So, I think slavery is a really hidden issue and we don't know the severity of it nationally let alone in Gloucestershire." - Participant 11, Crimestoppers

"I would imagine because it's such an underreported crime because people feel so threatened like with domestic...in a similar way to domestic abuse in terms of the controlling and coercion. So, I imagine it's an underrepresentation more than an overrepresentation." - Participant 4, Faith-Based Safeguarding Officer

"For so long and still to a large part it remains such a hidden thing and often very well coordinated by criminal organisations and gangs. It seems to me that the police are really just starting to scratch the surface and other agencies are trying to stay up to speed with what the police are doing in terms of information gathering and picture building."- Participant 3 , Faith-Based, Safeguarding Officer

The hidden or underground nature of modern slavery is well established throughout the wider literature (Stevenson and Cole, 2018; Craig, 2017). Nationally, the NRM (2018) statistics reported 6,993 potential victims across the UK have been referred, a much lower amount than the current "tens of thousands" estimated by the National Crime Agency (Christ and Burritt, 2018). Furthermore, a year after the introduction of the Modern Slavery Act 2015, Haughey (2016) found that slavery across the UK was under-reported and 
previous government estimates regarding the extent $(13,000)$ was widely established to be an underrepresentation (Craig, 2017; Hope for Justice, 2017). Stevenson and Cole (2018) also expressed this view regarding the extent of modern slavery worldwide. Additionally, statistics do not take into consideration the number of potential victims waiting prolonged periods of time to receive their decision form the Home Office, which is a rising problem in the UK (Bulman, 2020). Therefore, data sources must be viewed as underrepresentations (Bales, Hesketh and Silverman, 2015), only representative of modern slavery that is known to the authorities (Cooper et al. 2017) and unreliable (Craig et al. 2007).

The research participants suggested that the hidden nature of modern slavery is both a cause and a symptom of underreporting. As quantification of problems is required as evidence for funding, there is a consequent and problematic lack of funding regarding modern slavery at a local level. This dichotomy prevents additional resources for aiding the discovery of victims. Consequently, there is a cycle of limited information and under-funding meaning there could be undiscovered victims in local communities across the UK (Gardner, 2018). Bulman (2020)

\subsubsection{Conflicting Understandings Regarding Extent of the Problem}

The participants in this study expressed contradictory opinions regarding the National Referral Mechanism statistics and what they potentially represent. These disparities resulted in different opinions regarding the extent problem in Gloucestershire.

Most of the participants suggested the increasing trend in referral statistics in Gloucestershire shown in Table 4 and 5, represent the positive development and impact of local anti-slavery practices, including increased action from the police. This was a key interpretation of the current statistics regarding victim referrals for Gloucestershire. The participants suggested that more cases are coming to light due to factors such as increased efforts to tackle the issue, developing awareness as a direct result of the legislation and coordinated agencies. Additionally, some participants suggested reasons for the increase in referrals in Gloucestershire such as, the result of "correct pressure on the 
police" to make modern slavery a priority and to start implementing the provision.

"So, figures are increasing. That will be to a degree as a result the correct pressure brought about policing and other agencies to sort themselves out and start using the legislation available, as well as improved recording"- Participant 7, Gloucestershire Constabulary Detective

"We're now seeing more action from the police. It's recognised more within the police and we've also seen some legislation come forward which has helped with that."- Participant 9, Gloucester Council Representative

This perception highlights the increased efforts from the local constabulary since the implementation of the Act in 2015. Some participants also stated that the police are now better prepared to tackle the issue locally. This contradicts the finding of HMICFRS, (2017a) stating that improvements in police responses to modern slavery and human trafficking were found lacking.

Participants 13 and 14 expressed a different perspective and indicated that based on their experiences with their organisation, modern slavery is a frequent issue. Participant 14 claimed that slavery is a "growing problem" in terms of observed child trafficking cases over the years. Additionally, participant 13 described their work with human trafficking survivors as "constant" across the last 10-15 years. This suggests that, despite increased efforts to tackle these issues, some areas of modern slavery in Gloucestershire are being addressed less than successfully others. This is evidenced by participant 7 describing the occurrence of CSE cases as "relatively routinely", further suggesting the perception that this is a common occurrence in their professional role.

Participant 4 also reflected this view by suggesting that modern slavery "worldwide is on the increase", implying that local areas such as Gloucestershire is no exception to this.

Interviewer: "Do you view modern slavery as a growing or declining problem in Gloucestershire?"

Interviewee: "Growing. I've been in Gloucestershire for eight years. As I say, when I came here I don't recall that there were any unaccompanied asylum-seeking children who were trafficked. I can't remember any. And now, there's quite a lot." - Participant 14, Asylum Seeker Support Worker 
"I thought the trafficking side has pretty well stayed quite constant regarding numbers."- Participant 13, Asylum Seeker Case Worker

"We have CSE cases where we seek charging advice for trafficking relatively routinely" Participant 7 , Gloucestershire Constabulary Detective

"I'd say generally worldwide it's definitely on the increase"- Participant 4, Safeguarding Officer, Faith-Based

These responses suggest an increase in modern slavery locally, specifically in relation to localised human trafficking cases. These perspectives therefore indicate that offences involving human trafficking are putting strain on particular services, causing this to become an increasing area of local responsibility. Despite participant insights regarding the extent and scale of the problem locally, identifying the breadth of the problem remains a troublesome area of the topic. This is further demonstrated by Haughey (2016) who described the intelligence regarding the nature and scale of the issue for the UK as insufficient.

\subsubsection{The Perception of 'Not in Gloucestershire' Recognised by Local Practitioners}

Another critical discussion point in this study was developed from participant accounts relating to the idea that modern slavery in Gloucestershire has not been fully recognised or accepted by the general public. Furthermore, during the interviews, some participants acknowledged their own obliviousness about the subject prior to working in their current professions. The following quotes from the participants in this study reflect these perceptions:

"Unfortunately like many crimes people...are blinded by it not being an issue because a lot of people say 'it doesn't happen here'. We recently did a campaign called On Your Doorstep, purely because people will say 'it doesn't happen'. I speak to friends and they'll say 'nah it doesn't happen here' 'Beautiful old Cheltenham doesn't have that or Gloucestershire hasn't got that'..." - Participant 11, Crimestoppers

"I also think that the Gloucestershire public are probably not as aware as they could be. That's not a criticism against anyone in particular. I think we probably haven't utilised raising awareness of cases that we've had and try to yeah let them know that it really is happening here. To get people to report." - Participant 11, Crimestoppers 
"I think and I put myself in this that I moved from London and kind of thought actually you know that couldn't possibly happen here. But absolutely it does."- Participant 4, Faith-Based, Safeguarding

“I had no knowledge before at all."- Participant 9, Gloucester Council

This sentiment also reflected by participant 9, who claimed to have no knowledge of modern slavery occurring in Gloucestershire until working with the local council. This is evidence of the view that the occurrence of modern slavery in Gloucestershire is still disputed, despite awareness campaigns, media reports (see Boobyer, 2018 and Gibbon, 2017) and statistics related to the identification of potential victims (see Table 4 and 5). This reinforces Bales (2012) who stated that public opinion regarding slavery can include the strong assumption that slavery only exists in the past.

This, therefore, presents evidence indicating that the general public is not being engaged enough locally through awareness raising efforts. This validates Gardner (2018) who identified minimal incentives for local engagement and found that the public had little interest locally. Additionally, HMICFRS (2017a) reported that in some cases frontline professionals had the view that modern slavery occurrences are rare or are a non-issue altogether within their locations. This is contradictory to recent evidence that indicates modern slavery being an issue across all communities, in the United Kingdom (National Crime Agency, 2018)

Evidence from this research portrays increasing awareness in Gloucestershire, however better awareness of the issue was also described as a key recommendation for improving the local response to the problem (see also Haughey, 2016). The following excerpts from this study reflect the view that local awareness has increased, but still requires further development in order to engage a more impactful response:

"I think the biggest change has been awareness. The anti-slavery partnership, seems to have continued to grow quite a lot. Which is a good thing. It's something we see a bit more in the media as well. Not massive changed but I think more generally both within in the work we do within the Church of England but also on a multi-agency kind of level I think there is more awareness and 
more conversation about it really." - Participant 3, Safeguarding Officer, Faith-Based

"I do think again it's about awareness raising so you know the growth of anti-slavery partnerships across the country, the continued work of charity organisations that have got the specialism around modern slavery, campaigning, awareness raising, creating another route for people to go to raise concerns."Participant 3, Safeguarding Officer, Faith-Based

"Our role has been to try and promote awareness of modern-day slavery but also providing anyone with information, the understanding of the signs to look out for as well as, what kind of information they can pass on either to ourselves or other people."Participant 11, Crimestoppers

"I would suggest that because some of the work that a whole load of people are doing around raising awareness I would hope that that's having some kind of effect in giving people the opportunity to be freed."- Participant 6, Faith-Based Non-governmental relief agency

"We've got 53 county councillors and there are another 250 district councils and many more parish councillors and town councils they're eyes and ears in the community so if we can and it's not an easy job but to raise awareness amongst those people so they actually see these things going on and they know what to do."Participant 9, Gloucester Council Representative

This supports claims from Haughey (2016), who reported an increase in police investigations and operational responses indicating a rise in awareness and improving processes to deal with slavery offences. Despite this, awareness was also a factor outlined by Haughey (2016) as an area in need of improvement within specific areas.

This study demonstrates local professionals believe that efforts to increase public awareness have not been entirely successful as there is a remaining perception that locals are unaware of the occurrence of slavery in the county. It is suggested by participant 11 that this is partially a result of Gloucestershire being renowned as a safe place to live and therefore many individuals are "blinded" to criminal activity in the county. Participant 2 also expressed this perception by claiming the local public still remains "naïve" to the occurrence of slavery practices in Gloucestershire. Participant 6 suggested that people in 
Gloucestershire would not expect modern slavery to occur and claimed that this is a reason why the county is a good target for potential traffickers.

"I think the other thing is where Cheltenham is good for the trafficker is that it is a very respectable town and therefore things like you know car washing, nail bars, agricultural work and all of those kind of things people would never suspect a place like Cheltenham or Gloucestershire more widely to be a place where people would be trafficked. And therefore, I think it's easier to hide. You know whereas in perhaps some of the bigger cities people are perhaps more aware. So, you know maybe on the lookout so yeah awareness is a big issue here because it is relatively easy to put it underground."- Participant 6, Non-governmental Relief Agency

"They come to target the Cotswolds and Gloucestershire because there are a lot of naive people living here and they're seen as easy to take advantage of, there's a lot of money here and due to the low population, there aren't many police so for them its easy pickings."- Participant 2, Gloucestershire Constabulary

These perspectives indicate that awareness in Gloucestershire remains partial, which is highlighted as a potential barrier for tackling the problem proactively at a local level. Many participants expressed the opinion that a greater level of awareness across the county is not only beneficial for developing the level of understanding but also for increasing the reporting of potential victims.

\subsection{The Numerous Types of Modern Slavery Offences 'Known' to Take Place in Gloucestershire}

Currently there is little information regarding the specific forms of slavery taking place in Gloucestershire, with the exception of NRM reports and media coverage (see Boobyer, 2018 and Gibbon, 2017), which focus on high profile, individual cases. This current information provides categorised types of exploitation e.g. labour and sexual exploitation but little information exists regarding specific forms of exploitation such as, forced agricultural work, car washes, etc.

The practitioners in this study described a wide range of exploitative crimes that can be dealt with under the Modern Slavery Act. These included; human trafficking, sexual exploitation, various forms of labour exploitation and criminal exploitation e.g. forced cannabis cultivation and county lines. Most participants 
highlighted the occurrence of labour exploitation, sexual exploitation and human trafficking offences. The detail and context regarding specific ways these crimes are manifesting in Gloucestershire is a significant finding and contribution of this research. Christ and Burritt (2018) and Cooper et al. (2017) demonstrated that modern slavery incorporates a range of activities. The specific types of offences outlined by the participants in this study were inconsistent across all 14 practitioners. This indicates either a partial understanding of the broader problem across the participants in this study or that different professionals come across different sorts of modern slavery.

\subsubsection{Labour Exploitation}

In this study labour exploitation was outlined by the majority of participants and was accompanied by a range of references related to economic sectors whereby offences are manifesting. Several participants claimed that modern slavery offences are likely to be taking place within agriculture in Gloucestershire. Exploitation in this sector was also recognised by Gold, Trautrims and Trodd, 2015; New, (2015); Bales, (2009) and Crane, (2013). As Gloucestershire is largely a rural area, it can be argued that it is more susceptible to this form of exploitation.

"There are events in Gloucestershire that bring it, but also obviously in terms of the summer months you're more likely if there is and we don't know in terms of the agriculture. That's when you see a bigger influx of immigrant people coming in. But that is still an area where we're trying to ... we're trying to get to grips with."- Participant 9, Gloucester Council Representative

"We have more to learn around how labour exploitation may be manifesting itself in rural areas, perhaps in relation to seasonal crop picking for example. We have focused for some time on sexual exploitation and have done some excellent work. We've needed to prioritise our resources and we can only do so much at any given time"Participant 7, Gloucestershire Constabulary Detective

"People being forced into sort of agricultural work, laying driveways and that kind of thing which flies under the radar a little bit."- Participant 6 , Faith-Based Non-governmental relief agency

"Within anything that's seasonal, it's quite difficult for anybody to monitor who those people are so we also looked to work with the rural community 
to ensure that they were aware that they have got the ability to have a voice if they got concerns for any potential slaves within agriculture." Participant 11, Crimestoppers

"I think Gloucestershire has got a problem probably more within the agricultural industry because it's such a large area and it's very widely known within the agricultural areas for the county."- Participant 11, Crimestoppers

"Then you also have people potentially getting exploited on farms, which are often very isolated and cut off so nobody is aware of the exploitative situations"- Participant 2, Gloucestershire Constabulary

The frequent mention of labour exploitation by the majority of participants reinforces the notion of the 'shift' in focus, which has resulted in the recognition of other forms of slavery (LeBaron, 2014).

The research participants describe how local knowledge and evidence regarding this issue is lacking. In relation to exploitation in a rural setting, participant 7 stated there is "more to learn" in order to improve the intelligence in this area. Furthermore, participant 11 highlights the "large area" and it being "quite difficult for anybody to monitor who those people are", indicating current challenges with addressing agricultural exploitation in Gloucestershire. Participant 2 and 6 reinforce this by expressing that rural areas are "very isolated and cut off so nobody is aware of the exploitative situations" and exploitation in agriculture "flies under the radar a little bit." In some instances, participants indicated that immigrant workers are being targeted in specific economic areas such as in agriculture. In support of this view, New (2015) found that in the UK, migrant workers had been subject to exploitation in agriculture.

The evidence from this research highlights the need for further provision and resources in order to make additional progress in this area. Mantouvalou (2018) supports this by stating that despite the implementation of the Modern Slavery Act, measures for tackling labour exploitation require improvement. This further highlights the hidden nature of modern slavery in this specific economic area, 
indicating the occurrence of slavery practices manifesting within agriculture in Gloucestershire and going unnoticed.

Another common theme described by the participants in this study was the occurrence of labour exploitation within car washes in Gloucestershire. The following excerpts show the participants' views regarding this occurrence of labour exploitation:

"You have people being exploited in car washes. I know that officers in Gloucestershire are looking into this. I have contacts that are looking into this problem in the area, so it is happening."- Participant 2, Gloucestershire Constabulary.

“There's also been a number of cases around labour exploitation and some of those have been in the media more in recent times, for example car washes being raided and closed down and people being safeguarded"- Participant 3, Safeguarding Officer, Faith-Based.

Interviewer: What are the signs of modern slavery, to look out for? Interviewee: "People that are working and just really don't look very happy. People that can't speak English maybe even so you know in a car wash. People that look really dishevelled, can't communicate well, look really nervous. So, language issues and people that suddenly just appear."- Participant 6, Faith-Based Non-governmental relief agency.

"I think you know someone that may look frightened, someone else that's giving instructions to them, they may look malnourished, they're not wearing the right equipment...can't speak English"- Participant 9, Gloucester Council Representative.

The excerpts from the research participants show phrases such as "poor working conditions", "low wages" and "language issues" when describing potential cases of forced labour within car washes. Additionally, when discussing potential indicators of modern slavery, participants stated that victims within car washes "may not be able to speak English", further indicating that migrant workers are being targeted within this specific area of exploitation. Again, this highlights the perception that migrant workers are being targeted for this type of exploitation. This relates to the argument regarding foreign nationals being labelled 'good workers' and 'better motivated' and therefore, are more likely to accept unsafe working conditions and low wages, compared to British nationals (Findlay and McCollum, 2013; McCollum and Findlay, 2015; Anderson and Ruhs, 2010). 


\subsubsection{Sexual Exploitation}

Many participants in this study highlighted the occurrence of sexual exploitation in Gloucestershire and described forms this can take. In most instances, sexual exploitation was discussed in relation to the local sex industry, particularly in reference to Cheltenham Race Week. CSE was also a key talking point outlined by participants in this research. Additionally, controlled prostitution was also described to a lesser extent. The following quotes demonstrate these key areas described by the research participants.

"We've had a number of examples. So, one individual...Chinese again, relating to last year's operation was involved in controlled prostitution over a number of addresses in Cheltenham and Gloucestershire, using Chinese nationals to do it. He was arrested and prosecuted and deported. The evidence was supportive of the controlling of prostitution though I know he was committing a trafficking offense too. The evidence was strong for controlling prostitution for gain, less so for trafficking." Participant 7, Gloucestershire Constabulary Detective

"We have CSE cases where we seek charging advice for trafficking relatively routinely" Participant 7 , Gloucestershire Constabulary Detective

"There is certainly sexual exploitation and forced labour, we've definitely got cases and they're becoming more frequent because the police are identifying them earlier." - Participant 8, Healthcare Professional

"We also know that we have pop-up brothels especially in Cheltenham as well as in Gloucester." - Participant 8, Healthcare Professional

"I think labour exploitation and sexual exploitation have also been quite high" - Participant 10, Anti-slavery partnership representative

"A great one is Cheltenham races. You know, because of the increase in the population in Cheltenham, people with quite a lot of money you find that you get pop-up brothels." - Participant 9, Gloucester Council Representative

Many of the participant responses regarding sexual exploitation included an element of movement or trafficking, for example; "pop-up brothels" and "controlled prostitution over a number of addresses." Cooper et al. (2017) reported that survivors of sexual exploitation in the UK had often been forced into sex work across a variety of locations. This indicates that movement and trafficking are critical factors involved in locally observed sexual exploitation. 
Participants 7 and 9 further highlighted the trafficking element by discussing their knowledge regarding sexual exploitation in the county, including disruption activity carried out on potential traffickers in the area. Participant 7 described a number of victims as being trafficked. Participant 9 also discussed a police operation that was connected to Gloucestershire, in which perpetrators were transporting potential victims who were "being moved around through the rail networks", for the purpose of exploitation. Additionally, several participants highlighted the presence of temporary or, as practitioners refer to them 'pop-up' brothels in Gloucestershire, further demonstrating that the movement of potential victims is present.

"We carried out an operation last year where we...for safeguarding purposes focused on making appointments with sex workers, after reviewing online adverts in the county, and attended these appointments with Safeguarding teams. Last year, at any given time, there were around 250 to 280 adverts providing services in Gloucestershire every single day - though this has now been brought down. And a number of those people are transient, moved into the area. They provide the services for three or four days - the term pop-up brothels - that's what that's linked to and then they move onto a different area. So, l've described movement and organised sexual activity. So that could amount to trafficking and if there's a controlling element, that's where we would look to target our efforts."- Participant 7, Gloucestershire Constabulary Detective.

"In Gloucestershire the police are quite proactive in that area and have been for a while. In fact, they've recently had a campaign and there was quite a significant prostitution ring that was based out of Cheltenham but was operating in other parts of the UK. And the women were being moved around through the rail network as it turned out. And this is from actually from a few years ago. But the money was being laundered out of a bank account in Cheltenham back to a country of origin. So, Cheltenham was right at the centre of that."- Participant 9, Gloucester Council Representative

These quotes also describe the occurrence of trafficking for the purpose of sexual exploitation in Gloucestershire. This supports Cooper et al. (2017) who stated that victims are often advertised online and then later transported to clients' residences or hotels or clients visited victims in locations that regularly change ('pop-up' brothels and short-term rented properties). Additionally, the data supports the claims of Crane (2013) and Robinson (2013), who highlighted the impact of formal and informal trafficking networks that aid the growth of the problem as they are used to move potential victims within counties. Participant 
9 also indicates the global scale of these crimes by highlighting the international flows of money, which is often associated with modern slavery. Participant 9 also states that: "money was being laundered out of a bank account in Cheltenham back to a country of origin" indicating that, even though exploitation is taking place in Gloucestershire, the perpetrators and beneficiaries could be located in another part of the world.

\subsubsection{Exploitative Practices During Cheltenham Race Week}

Many of the participants described the Cheltenham Races as a contributing factor to sexual exploitation and trafficking in Gloucestershire. A prominent argument made by the participants references the influx of people during the event resulting in higher demand on the local sex industry. Participant 6 and 8 highlighted the "clear and open increase in pop-up brothels and sexual entertainment venues" during the event and expressed it was their opinion that "it could be argued that this is tightly linked to people being brought in against their will." Participant 4 stressed this point further by claiming that it's: "obvious there is a link between that industry and modern slavery." The following excerpts further demonstrate this argument:

"I think Race Week does increase the chances although we've got no statistical evidence of that yet, but it does seem to be that around that time the culture it is happening of pop-up brothels, more strip clubs, more violence on the streets and therefore sadly these things generally follow. So, I think that's a contributing factor."- Participant 8 , Healthcare Professional.

"In Gloucestershire like I was saying, there's a big issue around what happens during the race week in Cheltenham and that's definitely one of those issues that highlights one strand of modern slavery in the county." - Participant 3, Safeguarding Officer, Faith-Based

"A great one is Cheltenham races. You know, because of the increase in the population in Cheltenham, people with quite a lot of money you find that you get pop-up brothels, you get pole dancing clubs and sometimes people are doing that in a legitimate way in terms of applying for a license but you know that that's not always the case."- Participant 9, Gloucester Council Representative

"There is a very clear increase in things like pop-up brothels, sexual entertainment venues and all of that kind of thing during those few days of like Gold Cup and all of those kinds of things. So certainly, there is a very obvious and when I say obvious...on the streets of sexual 
entertainment and prostitution being openly offered. It could be argued that that is tightly linked to people being brought in against their will." Participant 6, Faith-Based Non-Governmental Relief Agency.

"If you were to look on maybe the council's websites around the time of March horse racing you'll notice that there is a push for an understanding that there are more individuals that are offering those services. It will back it up for you. For Cheltenham you'll see that there is a push for people to be aware that they may not be legitimate." - Participant 11, Crimestoppers

The discussed link between the sex industry in Gloucestershire and modern slavery was also reported by Reeves (2013), who argued there will always be perpetrators willing to use vulnerable individuals to maintain demand because of the vast financial benefits. This is supportive of the concerns raised by the research participants. Additionally, Participant 11 outlined that evidence of sexual exploitation during the local event can be found via Cheltenham Borough Council raising concern regarding the legitimacy of businesses "offering those services".

The excerpts indicate exploitation in changing locations, hence the mention of pop-up brothels. It can therefore be argued that measures such as licensing checks in bars and adult entertainment premises (see Cheltenham Borough Council, 2019) are insufficient to ensure exploitation is not taking place. This is because only known establishments are checked. Whereas, the participants raised concerns regarding sexual exploitation taking place outside of these establishments in the form of pop-up brothels and in changing locations.

Despite these claims regarding a connection between the Cheltenham Races and sexual exploitation the majority of research participants also expressed an awareness regarding the lack of evidence to corroborate these views, as highlighted by Bowersox (2016) and Ham (2011). The suggested connection between localised sporting events and increased sexual exploitation requires additional research that focuses specifically on this topic as currently, this remains an under-researched focus. However, it is argued within the wider literature, there is evidence of this occurring at larger global sporting events (United States Congress et al. 2014; and Matheson and Finkel, 2013). 
Participant 12 indicated that professionals are informed by the police of the potential link between the Cheltenham Races and modern slavery. This suggests that in some cases, this link is being made by the police then passed on to other professionals and adopted as their own view. This provides another potential reason for the vast responses regarding the link between this event and sexual exploitation.

"We're told...there's potential for it to increase around Race Week in March, in Cheltenham because of the...particularly around the sex industry side of it. The police are particularly vigilant then." - Participant 12, Business Procurement.

The majority of participants that referred to the occurrence of prostitution during Race Week and the suspected link to slavery, acknowledged that "not all prostitutes are slaves" and referred to terminology outlined in the legislation as a means of distinguishing between "an individual's choice" and exploitation. The participants used terms such as "exploited", "not working for themselves", "lack of control over the situation", "no ability to leave that situation", "transient". Such terms indicate awareness regarding how to recognise sexual exploitation under the Modern Slavery Act 2015 and distinguish this from other activities related to the sex industry such as, consensual prostitution.

A significant finding of this study relates to cross-agency claims regarding the link between a localised sporting event and modern slavery offences. Although, there is a current lack of quantitative evidence (Bowersox, 2016), this study indicates many of the local professionals reflect the view that concern regarding the potential impact of the local event, in relation to sexual exploitation is logical (Hayes, 2010). Additionally, the responses observed in this study regarding the potential link between the sex industry and exploitation contributes to the wider academic debate on this subject (see Coy, 2016).

\subsubsection{Criminal exploitation in the form of county lines and forced begging}

The research participants discussed criminal exploitation and different manifestations of this in Gloucestershire. The following excerpts demonstrate 
participant's views regarding the occurrence of different types of criminal exploitation in the county.

"And then there's transport. Made to sit in parks with bags and look like a child playing in a park. When someone comes to pick it up. Then you're taken away and... that's your job. I've been told that happened to a young person and I think it was in Gloucestershire but he doesn't know exactly where. So that sort of thing. The young person I spoke to you about who was doing cannabis production, I think it was cannabis." Participant 14, Asylum Seeker Support Worker.

"I think the current picture of criminal exploitation is really increasing especially linking with County lines and dangerous drug networks"Participant 10, Anti-Slavery Partnership Representative.

"Forced begging, that definitely happens in Gloucestershire as well. Representatives from an NGO have gone out and asked homeless people why they are begging and many claim they're not begging for themselves but for someone else that has forced them to do so by threatening them."- Participant 1, Charity Sector

According to the research participants, these offences are taking place locally as forced begging, cannabis cultivation and county lines drug activity. The occurrence of these offences across the UK, is supported by Cooper et al. (2017) as well as the classification of these offences under criminal exploitation, as opposed to labour exploitation. Additionally, the presence of these offences in the UK is supported by HM Government (2018) and the National Crime Agency (2019), indicating that this takes place nationally and within local communities such as Gloucestershire.

Participant 7 highlighted the occurrence of county lines drug activity and forced begging in Gloucestershire and offers an insight regarding how these offences have been categorised in the NRM statistics. The following excerpts from the interview provide illustrative examples of such cases provided by the respondent:

"We've seen examples of a guy who... basically, went into the house of two individuals and got them to beg for him and he took advantage of them in terms of their substance misuse issues. So, he supplied them with small amounts of drugs. Got them out to beg and got the money off them when they came back. And... he was charged under the Modern Slavery Act for... labour exploitation." Participant 7, Gloucestershire Constabulary Detective. 
"We've had examples of county lines drug activities and movement of young people by drugs gangs to exploit them in terms of the movement and selling and the movement and the harbouring of drugs in our area." Participant 7, Gloucestershire Constabulary Detective "We've referred lots of kids to the NRM and recorded lots of cases under county lines" Participant 7, Gloucestershire Constabulary.

These excerpts raise questions regarding how offences are categories through the NRM. Participant 7 stated that "we've referred lots of kids to the NRM and recorded lots of cases under county lines" yet these offences appear to be absent in the NRM statistics, (see Table 5). According to the National Crime Agency (2019) this is because cases of criminal exploitation, in the UK are categorised under labour exploitation. This contrasts with the categories outlined by Cooper et al. (2017), in Table 2. A county lines victim would be classified under criminal exploitation if the offence either relates to drug networks or if victims are forced to provide labour for offenders for illegal purposes or both (Cooper et al. 2017). It is unclear why offences are categorised in this manner; however, a potential explanation is the overlap between criminal and labour exploitation whereby an offence can be linked to both categories. Merging the statistics for both labour and criminal exploitation makes the data unclear and difficult to interpret and as stated previously, are already said to be unreliable (Craig et al. 2007). This reinforces the need for further detailed information regarding the specific types of offences taking place in Gloucestershire. Cooper et al. (2017) reported that developing the typology for modern slavery offences was intended to improve understanding of the offences taking place so that informed, tailored operational responses can take be implemented. By merging labour exploitation with criminal exploitation, the statistics are less reliable and do not accurately represent the true extent of these different types of offences in Gloucestershire and across the UK. This accounts for the partial awareness relating to criminal exploitation. This is demonstrated in this study by participants expressing awareness regarding sexual exploitation and forced labour but fewer outlined the occurrence of criminal exploitation taking place such as, county lines and forced begging.

County lines offences were only described by a few participants, in most instances this was due to their experiences within their professional role. This shows that some areas related to criminal exploitation are not commonly known 
across all practitioners in this study. Differences in professional roles is one explanation for this as only a select few professionals specially work with the criminal aspect of modern slavery or with child exploitation. For example, participant 14 described their primary role is working with trafficked children and therefore has a professional focus, which would make her more likely to be aware of issues such as county lines, as the offence typically involves minors. This reinforces the point regarding how professional roles and responsibilities can alter an individual's perception of modern slavery and how it manifests in society.

The limited understanding of county lines, identified in this study carries connotation regarding awareness of this issue locally. For example, due to little context alongside the NRM statistics, they current indicate that criminal exploitation is not occurring altogether, in Gloucestershire. This hinders awareness-raising efforts in the county and across local practitioners, which is reflected in this study as only select participants mentioned criminal exploitation i.e. county lines, forced begging and forced cannabis cultivation. The limited mention of county lines offences shown in this study, reflects a partial understanding of this specific area. This is an important finding because it further reinforces the hidden nature of the offence, despite Gloucestershire having several specialists and a focused proactive approach in this field. In addition, the following excerpts highlight the low prosecution rate for these crimes, which further suggests that the partial understanding shown in this study, is impacting the ability to tackle the problem effectively.

"We've referred lots of kids to the NRM and recorded lots of cases under county lines. But there's been one reported of prosecution in the country."- Participant 7, Gloucestershire Constabulary.

"When you look at the bare statistics in terms of the number of prosecutions, they don't look particularly high."- Participant 9, Gloucester Council Representative.

This is supportive of Cooper et al. (2017) who highlighted that across England and Wales, official data for modern slavery and human trafficking offences show few prosecutions taking place. The data from this study further highlights the challenges outlined in Chapter 2.4.1, in regards to convicting perpetrators and 
therefore more is required improve the prosecution and convictions rate for modern slavery offences locally as well as nationally.

\subsection{Local anti-slavery practices and disputed impact}

Improving areas related to localised modern slavery were highlighted by many of the participants in this study e.g. in relation to victim support and police activity. Most participants highlighted that there are currently anti-slavery partnership meetings held quarterly in Gloucestershire, which are made up of approximately 20 different organisations. Additionally, participant 5 highlights the positive impact of the legislation in giving law enforcement greater power and means to tackle the issue and provide support for victims.

"It's transformed the UK's response to modern slavery on a national and international level. It gives the police and law enforcement agencies power to bring perpetrators to justice. It gives greater protection to victims. And as I said before it's led to significant uplift in law enforcement activities." - Participant 5, Cheltenham Borough Council

The study highlights the presence of a range of organisations working to tackle the issue of modern slavery or provide support for victims. The participants in this study outline the benefit of the Anti-Slavery Partnership meetings and how they enable local professionals to exchange intelligence related to modern slavery such as, information regarding potential victims and disruption activities, carried out by the local constabulary. This therefore highlights practitioner efforts to increase their awareness of modern slavery in the county. The following excerpts provided detailed accounts of the partnership and the positive impact it has in rising awareness and its role in addressing modern slavery locally.

"It is more about information sharing and that kind of thing between agencies. If there are initiatives so that we're all aware so that there's not duplication and all of that kind of thing and just trying to work together in the most coherent way"- Participant 6, Faith-Based Non-governmental relief agency.

"I think the key thing that we also do is kind of making sure that everyone is on the same page. Everyone's collaborating and knows what each other is doing." - Participant 10, Anti-slavery partnership representative. 
"The chief executive of the council chairs it, you have the head of child services and you have the adult safeguarding lead and you have the assistant fire chief and the correct level of strategic interest comes along from other partner agencies"- Participant 7, Gloucestershire Constabulary.

"They have on their members of the fire service, local charities, medical professionals, social services, child welfare, Anglican church and Catholic Church. They have a bit of a mixture and they meet quarterly to see what kind of problems are going on, increase education within that. The idea is then that spanned out into their services that they look after and if there's a problem within a service and they think they need resources then hopefully the anti-slavery partnership can help resource that in terms of teaching or education or improving pathways."Participant 8, Healthcare Professional

"Representatives are really widespread kind of from public sector, charitable sector, faith-based organisations. So, there's us, Church of England and Roman Catholic dioceses are involved, Salvation Army who are also key in terms of national referral mechanism as well, victim support. Quite a number of local charities, one being Nelson Trust who have had quite a lot of dealings with individuals that have been identified as potential victims of modern slavery. Yeah so, I think it's a really healthy kind of membership."- Participant 3, Safeguarding Officer, FaithBased.

"We've got social services, Children's Services, different parts of the NHS, we've got the Gangmasters Association, we've got ourselves so it's all organisations like that who meet together and share intelligence and give briefings to each other basically and training they provide training as well."- Participant 12, Business Procurement

"I've worked with the anti-slavery partnership, I created some resources nationally, which I brought to the Gloucestershire anti-slavery partnership." - Participant 11, Crimestoppers

"So obviously, everyone is doing their own thing to fight the issue. But it's just making sure that it's all centrally coordinated and we all can help out where we can and make sure that we're lending a hand."- Participant 10, Anti-slavery partnership representative.

"I think just the networking aspect of lots of different people sitting on a partnership is things get done much more quickly and if people as a central point of contact people can come to me and I can link them with someone I'll think 'oh that person's working on that.' I'll put you in touch with them. It just makes a much smoother process so that things can actually get done." - Participant 10, Anti-slavery partnership member.

These excerpts reinforce the findings of Haughey, (2016), who highlighted the potential significance of partnership contribution at a local level. Furthermore, 
the research data stressed the importance of information sharing among partnership members, as this was viewed as a key benefit, which allows for multiple organisations to become increasingly aware of the broader situation, in Gloucestershire. Furthermore, participants referred to the communication and networking benefits associated with the partnership as well as training opportunities. This is reinforced by wider literature that suggests anti-slavery partnerships are increasingly viewed as crucial in developing a more coordinated response to modern slavery in terms of the identification of victims and addressing training gaps (HM Government, 2014; Gardner, Brickell, \& Gren-Jardan, 2018). Despite this, evidence of good practice among local partnerships remains difficult to establish due to the lack of local data and longer-term monitoring of effective partnership activity (Gardner, 2018).

The previous excerpts highlight the positive impact of the partnership in bringing agencies together to share intelligence, which demonstrates awareness raising within the partnership. This contradicts the findings of Harvey et al. (2015) who identified a lack of communication and information sharing amongst practitioners during a study related to child trafficking and multi-agency provision. However, participant 14 did discuss areas where communication is potentially lacking, reinforcing the view that gaps in relevant knowledge in specific areas of the topic are leaving people vulnerable to trafficking (Beadle and Davison, 2019). This was in relation to instances of dealing with child trafficking and exploitation in Gloucestershire.

Interviewer: "So do you think there's perhaps a lack of communication between some organisations?"

Interviewee: "Yeah and a lack of working together because I mean I guess they're just all so overstretched. I imagine... they just haven't got time to try and sort this out. It's just another difficulty. But I think it would help. I've been to a couple of strategy meetings but mostly as far as I'm aware there aren't strategy meetings for each child" - Participant 14, Asylum seeker support worker.

This indicates the need to improve information sharing and networking across government bodies and NGOs (Beadle and Davison, 2019). This study indicates that professionals outside of the local partnership, in some cases showed a limited view of the topic e.g. local occurrences of county lines and were unaware of training available in the area. This not only reinforces the 
importance of a collaborative approach but also indicates that information is not being passed on from the partnership, to external professionals. This further demonstrates the need for increased coordination of partnership work at national, regional and local levels (see Anti-slavery Commissioner, 2017).

The results from this research indicate that many of the practitioners believe that the local partnership is having an overall positive impact in terms of its coordination and awareness raising. Additionally, participants highlighted the importance of networking opportunities and empowerment of professionals to seek advice and training. This supports Cockbain \& Brayley-Morris (2017) and Beadle and Davison (2019) who stated the importance of coordinated efforts and improved information sharing both within police and outside agencies.

\subsection{Several major barriers hindering local progress}

A range of factors that impact local progress were highlighted by the practitioners in this study. A prominent issue highlighted in this study was the presence of a range of factors that prevent victims from coming forward and cooperating with local authorities.

\subsubsection{Victim reluctance to cooperate with practitioners}

Factors that prevent victims seeking help from the local provision were described by the research participants. Police presence was highlighted as being a deterrent in some cases for potential victims coming forward.

Participant 14 claimed that victims "tend not to cooperate or provide information to the police" due to fear of being sent back where they came from and potentially back into the hands of traffickers. Participant 11 highlighted similar concerns regarding some victims being unwilling to provide information to the police about their experiences due to negative practices with the authorities in their countries of origin.

"It's very difficult and... that means that people tend to, one; not cooperate or not provide information to the police to prosecute and also that they tend to have to go back into exploitation either here or be moved back to wherever they came from and potentially then trafficked 
back here or to somewhere else."- Participant 14, Asylum Seeker Support Worker.

"You can also have individuals that are being asked to complete these with a police officer in the room and they may have a corrupt police force back at home so the confidence that they've got in the service is going to be limited"- Participant 11, Crimestoppers.

Rutland (2016) also identified fear of authorities as a barrier for victims reporting, particularly individuals without immigration status, would fear deportation and therefore would be reluctant to seek assistance. Cockbain and Brayley-Morris (2017) also identified challenges during police investigations such as, securing and maintaining victims' co-operation and an initial lack of victim trust toward the police was present.

A common theme for this section was the perception of corruption within countries where victims originated. This emphasises Bales (2004) theory that governmental corruption is the most significant predictor of trafficking from a country. Additionally, many of these excerpts refer to barriers, which exclusively relate to victims who are foreign nationals. This offers insight into the high rate of British nationals being referred to the NRM, in comparison to other nationalities, as they might be more trusting towards British authorities.

The participants described other factors that hinder victims reporting such as, fear of negative consequences after reporting a crime, fear of perpetrators if a prosecution was not carried out, embarrassment, deportation back to where conditions may be worse than the exploitation they faced in the UK (Home Office, 2015). The practitioners in this study expressed that these factors contribute to the issue of underreporting and the scale of the problem being inaccurately represented.

"I think because of fear that if they do tell then they'll be pressured to give details of the traffickers, which would cause obviously threats or danger either to themselves or to their family members."- Participant 14, Asylum Seeker Support Worker

"In my experience, victims of trafficking are really really not happy to disclose any detail at all about their exploitation."- Participant 14, Asylum Seeker Support Worker 
"However the key thing is the national referral mechanism and I'm sure we still have a way to go because as I was saying to the chief executive of Anti-Slavery International only yesterday it remains an incredibly daunting thing to give evidence against people who've kept you in slavery or servitude because you must be worried that if you don't achieve that conviction you know they could come after you."- Participant 5, Cheltenham Borough Council

Cockbain and Brayley-Morris (2017) also reported that survivors of slavery feared retribution, which resulted in difficulties regarding attendance in court. This was often a key challenge, accompanied with an extensive questioning process during the trial, which survivors often found traumatic (Cockbain and Brayley-Morris, 2017). Additionally, the fear regarding repercussions from perpetrators after reporting further demonstrates the low conviction rate for these crimes, as outlined in chapter 2.4 .

\subsubsection{Not seeing themselves as victims}

Participants 7 and 9 highlighted that an additional reason why they believed victims are reluctant to come forward was the idea that some victims accept their exploitative circumstances. Participant 9 claimed that victims, particularly individuals involved in forced prostitution and forced labour have in some cases, chosen and accepted those exploitative circumstances. The reason for this opinion was the understanding that some victims have escaped worse circumstances, in their countries of origin and see their current situation as the lesser of two evils.

"But another thing that this is a really awkward aspect of modern slavery is for some of those women that have come to this country it's something that they are choosing to do and they're choosing to be controlled because their standard of life is sometimes a lot better than where they've come from. So, whilst we are trying to help them, they actually want carry on because it's actually to them it's to their benefit so they may work at you know not a significant salary, in poor conditions in an industry that they don't want to but it's an awful lot better than what they experienced before."- Participant 9, Gloucester Council Representative

"If somebody is being paid five pounds an hour, which is less than the minimum wage, to work in a car wash, are they being exploited? That individual is Romanian, they've been in the country for six months and they come from Romania where they were earning much, much less- for an 18-hour day. Do they think they're being exploited? And that's the challenge we face. - Participant 7- Gloucestershire Constabulary

Detective 
This further expresses the view that previous exploitation or mishap, results in some victims becoming disinclined to view themselves as victims. Bales, Hesketh and Silverman (2015) also highlighted this as a concern, as did Cockbain and Brayley-Morris (2017), during analysis of police investigation data and interviews with SIO's who identified that victims were often reluctant to see themselves as victims.

The excerpts suggest an aspect of choice, based on the alternative being worse, compared to the current type of exploitation being experienced. Scott (2017) echoes a similar point when discussing abuse in the work place whereby victims are not forced or coerced but simply attempt to choose the least damaging option available to them. This reinforces Haughey's (2016) point regarding how professionals can often miss indicators of exploitation due to a lack of awareness of the victim's background. This is another factor that causes only a partial picture of the issue to be presented in the statistics.

Participant 11 suggested that if the "basic needs of the victims are being met", they are often reluctant to view themselves as victims of a crime. This reinforces the National Crime Agency's (2019) point regarding minors involved in county lines offences being rewarded and therefore frequently are reluctant to view themselves as victims of exploitation.

"I think with modern day slavery, if you can meet the basic needs of a person who is the slave, they usually don't see themselves as a victim. So, when it comes to the sex industry and young girls are being prostituted out, usually their main needs of having a roof over their heads, you know some form of a meal and that feeling of safety to a degree... they're going to continue to do it." - Participant 11, Crimestoppers

This further supports the concept described by Nicholson, Dang and Trodd (2018) that the meaning of the term 'modern slavery' does not appropriately capture the vast forms or conditions of victims related to slavery. Nicholson, Dang and Trodd (2018) acknowledged this during a study with survivors of slavery and stated that current parameters of slavery often excludes the personal experiences of victims and found indications that current definitions are often linked to the perspective of the perpetrators. 


\subsection{Practitioner concern over current local provision}

\subsubsection{Lack of training}

Participants within safeguarding roles, business procurement and the local constabulary e.g. 12, 3 and 2 highlighted that training is available for local practitioners through the anti-slavery partnership as well as the local Diocese. However, some practitioners indicated that they had not yet received specific training relating to modern slavery and that the level of training currently available has not always been sufficient. This hinders the local response and contribute to the lack of referrals from other local agencies.

"It's now all on the safeguarding training that you have to have every year, there are sections on human trafficking. I think it can always be increased but that's the same with everything. So, I think it is being made aware of, I think we just need to promote it more." - Participant 8 , Healthcare Professional

"They've just released more training that's about to come out and so I think in that sense they have explored and asked people whether or not they need more training and you know people on the front line who are working with potential victims or those that are coming into contact with them." Participant 11, Crimestoppers

In Leicester, Rutland (2016) identified professionals were uncertain regarding how to access training locally. This was not the case for Gloucestershire as areas where training was accessible were frequently mentioned such as via the Diocese and avenues known to the anti-slavery partnership.

\subsubsection{Limited Resources}

Participant 14 claimed that agencies in Gloucestershire are "overstretched", highlighting the barrier of resourcing as a prominent issue in tackling the problem locally. Moreover, Participant 7 claimed that the local constabulary has had to "prioritise resources" and highlights "new challenges to consider", indicating that there's a limited amount of resources the police can point at the 
issue of modern slavery, which is an additional barrier to tackling the issue effectively.

"Policing has had a number of new challenges to consider in recent years, this would include modern slavery as a theme, though the criminality itself has been ever present."- Participant 7, Gloucestershire Constabulary Detective

"We've needed to prioritise our resources and we can only do so much at any given time"-Participant 7, Gloucestershire Constabulary Detective

"I think the police are overstretched. You know I know that they're running between different duties, there's not enough police and social services are absolutely overstretched." - Participant 14, Asylum Seeker Support Worker

The excerpts from the data reinforce the claims of Gardner (2018), who suggested that minimal funding was allocated to local police forces for additional investigatory resources. Furthermore, this links to findings from the Anti-slavery Commissioner (2017) that reported little dedicated funding to promote local anti-slavery partnership activity efforts.

\subsection{Limitations and concerns regarding the National Referral Mechanism process in selective circumstances}

Some participants questioned and criticised the role of the NRM and its effectiveness in terms of providing sufficient support for survivors at a local level. An example of this is when research participants highlighted that adult survivors must fill out the consent section of the NRM form. This was described as a barrier to the identification of victims in Gloucestershire, especially in situations where victims did not want the police involved, feared potential repercussions from perpetrators or if victims didn't see themselves as victims.

This further contributes the count of underreported cases, meaning less victims would be recorded. Participants expressed that this area is particularly challenging, especially when victims have a choice to enter the NRM yet, do not see themselves as victims. 
"Some of those victims that have come to this country ... it's something that they are choosing to do and they're choosing to be controlled, because their standard of life is sometimes a lot better than where they've come from. So, whilst we are trying to help them, they actually want to carry on because to them it's to their benefit. So, they may work for poor pay, in poor conditions in an industry that they don't want to, but it's an awful lot better than what they experienced before. And that's a really awkward aspect of modern slavery. That's not just the sex industry that ... that can be car washes. That can be restaurants."- Participant 9, Gloucester Council Representative.

"If somebody is being paid five pounds an hour, which is less than the minimum wage, to work in a car wash, are they being exploited? That individual is Romanian, they've been in the country for six months and they come from Romania where they were earning much, much less- for an 18-hour day. Do they think they're being exploited? And that's the challenge we face. So absolutely we may feel as a result of our legislation in this country and our society that that person has been exploited for their labour. But do they want to be rescued from that example? But we've got to consider their relative view compared to what they previously experienced. And that is a real challenge in terms of modern slavery and maintaining victim's support for prosecutions"Participant 7- Gloucestershire Constabulary Detective

"But we've recently looked at those people who perhaps don't want to enter the NRM and they are a victim and they need that support. And that's kind of a gap at the moment. We really are trying to work on and find out how to tackle that to make sure that all victims are provided support even if they do or don't enter the referral mechanism."Participant 10, Anti-Slavery Partnership Representative

This study revealed concerns regarding the effectiveness of the legalisation and the NRM in providing sufficient support for victims. This links to reported criticisms of the Act in failing to support and protect survivors once they've been identified (House of Commons Work and Pensions Committee, 2017).

Participant 14 stated that during cases involving child victims, current provisions in place offer little long-term support for victims, making re-trafficking more likely. Bokhari (2008) acknowledged these concerns prior to the NRM, stating that children are at risk of being influenced by their traffickers and in some cases have disappeared without a trace. This is significant because the NRM was implemented in 2009, yet concerns with victim safety and support still remain today. This reflects the growing concerns regarding a potential lack of long-term and systematic support for survivors across the UK (Murphy, 2018; House of Commons Work and Pensions Committee 2017). 
"They tend to have to go back into exploitation either here or be moved back to wherever they came from and potentially then trafficked back here or to somewhere else. So, it's a bit of a washing machine, it seems to me really. Sort of clean them up a bit and then send them back in." Participant 14, Asylum Seeker Support Worker

Participants 11 also highlighted concern regarding the effectiveness of the NRM process, specifically the 45-day reflection and recovery period for survivors of human trafficking or modern slavery (National Crime Agency, 2017;

Schweppenstedde, 2016). This is reinforcing of Craig (2017), who stated that victims are not offered sufficient time to prepare for community reintegration after receiving a decision through the NRM.

"I don't think the NRM system works necessarily because people have a choice so there are many victims that don't go into the National Referral Mechanism. I think also the day process, I think it's 60 days that they've got. The system doesn't work. A lot of people disappear, so I think with those statistics for Gloucestershire ...l'd be interested to know how many of those victims actually went through the whole system and then were actually supported at the other end "- Participant 11, Crimestoppers

This study finds evidence of practitioner concern with the current level of protection the legislation provides for survivors and victims in Gloucestershire, particularly those that receive a negative trafficking decision. The research participants highlight issues such as, negative repercussions and backlash from perpetrators if a legitimate victim is found not to need support. Participants 11 and 14 suggest that this is one example of how the NRM system is flawed as victims fear that if they're given a negative trafficking decision, they may face retrafficking and further exploitation.

"I think at the moment, when I talk to the police it just seems like an awful lot of waste of time actually because you know they're pulling out all these victims of trafficking who are then processed, found not to need protection and sent back into trafficking." - Participant 14, Asylum Seeker Support Worker

"I think because of fear that if they do tell then they'll be pressured to give details of the traffickers, which would cause obviously threats or danger either to themselves or to their family members. My concern is that I think the Home Office is very difficult to give status. So most of those children will not get status so they'll be deported back to their country of origin from where they have been already trafficked so they will end up with a choice, 'do I go back?' I don't know what they're going back to. I know 
that they ended up here in some distress and having possibly been trafficked."- Participant 14, Asylum seeker support worker

The data highlights criticisms following a negative trafficking decision and indicates a potential risk of re-trafficking. Wider literature provides evidence validating these concerns such as, Craig, (2017) who suggested that after going through the NRM, survivors may be vulnerable to re-trafficking if their traffickers have not been identified and contained. This is reinforced by Schweppenstedde (2016), who reported that 18 potential victims who had gone through the NRM were uncontactable and highlighted re-trafficking as a potential reason.

Participant 14 raises concerns regarding potential victims who are minors and their efforts in gaining slavery status, claiming "I think the Home office is very difficult to give status, most of those children will not get status so they'll be deported." Bokhari (2008) further outlines these gaps by highlights the lack of specialist protection for children in these situations and the uncertainty regarding the immigration status of trafficked children in the UK. Craig (2017) also reports criticism regarding the treatment of those attempting to claim asylum, stating that immigration status can be confused with slavery status. This requires addressing to prevent victims from being discouraged from reporting, through fear of being deported and potentially re-trafficked (Craig, 2017).

This research identifies evidence that contributes to the criticisms of the Modern Slavery Act 2015 for not providing appropriate provisions for survivors that have been trafficked to, or within, the UK (Roberts, 2018). Additionally, this reinforces the recommendation of Nicholson, Dang and Trodd (2018) who argued that survivor-informed anti-slavery policy and practices should be utilised in order to shape a suitable response.

\subsection{Summary}

To summarise, objective 2 involved gathering a broad range of practitioner perspectives regarding modern slavery in Gloucestershire from different professional sectors e.g. police, healthcare, charity and NGOs. Objective 2 also 
included analysing these perspectives, which was carried out and produced evidence regarding the effectiveness of local responses to modern slavery. The interview data from this project demonstrates how the various types of slavery are manifesting in Gloucestershire from the perspective of local practitioners. Addressing objective 2 also revealed barriers regarding the local response including; resourcing, encouraging victims to come forward and awareness of all types of exploitation across practitioners and the public.

This enquiry demonstrates that a wide variety of organisations are acting to stamp out modern slavery offences and ensure that survivors receive necessary support, through the national provision and NGOs. Whilst the local constabulary take up a leading role in addressing this issue, the local anti-slavery partnership offers and facilitates a collaborative approach in terms of information sharing and raising awareness. The findings of this research enquiry highlight the wideranging perceptions related to this topic and how this differs between professionals and organisations.

\section{Chapter 5: Conclusion}

This research enquiry has addressed objectives 1 and 2 by reviewing relevant literature surrounding modern slavery and has contributed to filling knowledge gaps using practitioner perspectives. In addressing these two objectives, the aim of this enquiry is met, the extent and significance is outlined in this section.

The practitioner perspectives regarding modern slavery differ across individuals and organisations, which indicates a fragmented perception of the topic. This is partially due to the broad nature of the enquiry, as the topic tends to interlink with many other subject areas. This results in perspectives that refer to the topic broadly as well as perspectives that have a very specific focus. This partial understanding promotes the need for information sharing and a professional collaborative approach at local levels across the UK. Reinforcing the need for further information sharing, this study demonstrates that practitioners often have a specific or focused knowledge related to modern slavery, rather than a broad or complete understanding of the scale and scope of this issue. 
This enquiry found evidence that the 2015 legislation sparked an increase in attention regarding modern slavery in Gloucestershire, particularly within the local constabulary. This is evidenced in this study by the research participants highlighting local initiatives, awareness raising efforts, increased reporting in Gloucestershire, the introduction of the Anti-Slavery Partnership and the role this has locally. This insight is significant due to the scarce attention dedicated to research locally on this subject. Although this impact of the legalisation applies to Gloucestershire, this finding is not necessarily exclusive to this case study and may have wider implications regarding the impact of the 2015 legislation on broader localities across the UK.

Many practitioners in this study believe the increased attention through the legislation and the media has had a positive impact on raising awareness locally. The increased awareness was highlighted as having a positive impact on the reporting of crimes linked to the Modern Slavery Act, which provides context behind the increasing trend shown in the local NRM statistics. Despite the increase in awareness, this study indicates that local public awareness requires further attention as the perception that modern slavery does not occur in the county still remains prominent. As stated previously, this finding could have implications for other localities due to the lack of evidence-based literature across local communities in the UK. This awareness finding in Gloucestershire is significant because it allows slavery to remain hidden, causing a lack of reporting and impacts the statistics resulting in further misrepresentation of the true nature and scale of the problem locally. This was highlighted as a key concern by practitioners in this study and requires addressing in order to increase awareness and encourage reporting of these crimes.

Currently, statistics provide limited information regarding specific manifestations of slavery offences locally. This lack of context regarding statistics hinders local awareness further demonstrating the need for modern slavery research that applies to localities across the UK. This study contributes to bridging this knowledge gap by highlighting various ways slavery manifest locally from the perspectives of local professionals. This research evidences the occurrence of labour exploitation manifesting within agriculture, car washes and construction. Furthermore, the presence of sexual exploitation in Gloucestershire was 
evidenced as manifesting as CSE and taking place within pop-up brothels during Cheltenham Race Week. This research also contributes to the wider discussion regarding Cheltenham Race Week, specifically the impact a temporary population increase can have on localised modern slavery offences. Indeed, this finding has implications for other localities as the impact of specific events in relation to modern slavery remains under-researched at a local level. These findings highlight the need for further research regarding the types of offences taking place locally and the impact of localised events that encourage a population increase.

This study finds evidence that the Anti-Slavery Partnership has a positive presence in the county through facilitating information sharing, awareness raising and supporting a collaborative approach to localised modern slavery. However, this research enquiry highlights areas whereby information sharing regarding modern slavery could be improved and communicated more effectively across organisations and individuals. This is evidenced by a limited awareness of criminal exploitation found in this study, despite good practice from the local constabulary in addressing this issue locally. This emphasises the importance of a local collaborative approach as well as information sharing across practitioners and organisations, in order to develop a more complete picture of this problem. This is a key interpretation of the data and a significant policy-relevant finding that should benefit localities across the UK. Therefore, the locality it is likely to benefit from expanding the Anti-Slavery Partnership, incorporating more individuals and organisations. It is also important to ensure information is communicated within organisations by those attending the partnership meetings. This approach encourages cross-organisational awareness of local modern slavery related concerns and operations rather than only reaching individuals attending the partnership.

This research adds to the body of knowledge on this topic by contributing to the literature regarding localised modern slavery in the UK. This enquiry also demonstrates how practitioner perceptions in research can prove useful in highlighting local responses to modern slavery and gaining insights regarding the impact of these initiatives. In this case, research focusing on practitioner perceptions has revealed areas of the local response that require improvement, 
which will strengthen local provision and response. This was shown when practitioners identified challenges associated with reaching out to local victims of modern slavery, highlighting the complexities in addressing the needs of victims trapped in exploitative circumstances. In regards to this, evidence of concern was found relating to current provision for victims, which is limiting the effectiveness of support mechanisms. This study also indicates that current conviction rates of perpetrators prevents victim's seeking help from authorities. This is shown to be complicated further through potential victims not perceiving themselves as victims, which could be a contributing factor to the problem remaining hidden within other localities across the UK. The concealed nature of this issue also has a knock-on effective regarding the statistics inaccurately representing the extent of the problem in localised areas.

\section{Recommendations}

In relation to objective 3 of this research enquiry, recommendations for future research, policy and local practice are provided in this section. These recommendations derived from evidence highlighted in this study and relate to specific areas of the topic that warrant further action or enquiry.

Recommendations for policy and practice

1. It was indicated in this study that communication between practitioners could be improved. This was found to be the case regarding the nature of local modern slavery offences such as, criminal exploitation. The strongest evidence regarding information sharing acknowledged in this study was that within the local anti-slavery partnership, yet this does not include every organisation or practitioner and therefore, more is required to facilitate and develop information sharing in the county. Networking and information sharing between NGOs, government and the constabulary should aim to develop further in order to bridge gaps in knowledge and strengthen the local response. 
2. This enquiry indicates that coordinated efforts to tackle modern slavery should continue to develop through increases in personnel, connections and resources in order to expand. Modern slavery remains a relatively new area both within academia and policing yet, it is a growing subject area, gaining much attention in recent years. It is therefore essential that suitable resources and personnel are allocated in attempt address this issue further.

3. Local provision should increase efforts to reduce barriers and challenges to progress, particularly when dealing with potential victims that are foreign nationals. This study identifies evidence of barriers such as; victims being reluctant to cooperate with local authorities due to fear of negative repercussions and not perceiving themselves as victims. More frequent local awareness initiatives targeting both the public and potential victims would contribute to addressing this issue.

4. The NRM statistics should be reviewed, in relation to the categories being used. Currently, accounts of criminal exploitation are combined with labour exploitation, which creates additional challenges regarding interpretation. Despite there being overlap in some cases between these categories, the same can be said for others such as, sexual exploitation and domestic servitude- yet these remain separate categories. This study finds evidence supporting the requirement of a separate category for criminal exploitation to be implemented.

Recommendations for Research

5. Further developing the evidence-based knowledge regarding modern slavery provision and practitioner perspectives in other localities, should be a research priority. This allows for important insights associated with the topic to be collected and used to evaluate the effectiveness of current local provision. For example, this enquiry emphasised the role and effectiveness of the local anti-slavery partnership and highlighted areas for improvement. This demonstrates the benefit of developing research in this field, which promotes positive change that strengthens the response of the locality. 
6. Future studies should investigate localised events that cause a temporary population increase in Gloucestershire and other localities. Investigating these events allows further assessment regarding the impact they have regarding localised modern slavery. This study found evidence concerning the impact of Cheltenham Race Week on sexual exploitation, in Gloucestershire. Despite this, it is beyond the parameters of this study to comment on the extent of which this is having an impact, highlighting the need for additional research.

7. Future research enquiries should aim to assess the impact local anti-slavery partnerships to develop long-term monitoring of progress. Further research on local partnerships will contribute to the wider discussion linked to the impact of these partnerships as this is an underdeveloped area of the topic highlighted during this study. This assessment will promote improvement within the local response and provide information regarding how local partnerships in the UK can further develop. For example, this study highlighted how the effectiveness of the local partnership could be improved via expansion and ensuring information is further communicated within partnered organisations.

8. Make use of data archiving. Currently, research and data for this topic is scarce, therefore archiving serves to create a source of data that can be utilised by future research enquiries. Data archiving allows researchers to use the data for other enquiries and supports the development of the evidence-based for this topic. Archiving data also provides an opportunity to monitor long-term progress and perceptions regarding modern slavery. Data from this research will therefore be archived at the University of Gloucestershire as anonymous transcripts for future research.

9. Future research should include victim-based responses as well as practitioner perceptions. This would provide opportunity for critical voices to be included as well as additional discussion regarding the effectiveness of the support mechanisms currently in place for victims and survivors. 


\section{References}

AlYahmady, H. and Al Abri, S. (2013) 'Using NVivo for Data Analysis in Qualitative Research,' International Interdisciplinary Journal of Education, 2(2), pp.181-186.

Alshenqeeti, H. (2014) 'Interviewing as a Data Collection Method: A Critical Review,' English Linguistics Research, 3(1), pp. 41-44. doi:10.5430/elr.v3n1p39

Anderson, B. and Ruhs, M. (eds.) (2010) Who Needs Migrant Workers? Labour Shortages, Immigration, and Public Policy, Oxford: Oxford University Press

Antwi, S., K. and Hamza (2015) 'Qualitative and Quantitative Research Paradigms in Business Research: A Philosophical Reflection', European Journal of Business and Management, 7(3), pp. 217-225.

Andrees B. and Van der Linden M. N. J. (2005). 'Designing Trafficking Research from a Labour Market Perspective: The ILO Experience'. International Migration, 43 (1-2): pp. 55-73. doi:10.1111/j.0020-7985.2005.00312.x

Anti-Slavery International, (2019a) What is Modern Slavery? Available at: https://www.antislavery.org/slavery-today/modern-slavery/. (Accessed: 03 September 2019)

Anti-Slavery International, (2019b) Domestic slavery. Available at: https://www.antislavery.org/slavery-today/domestic-work-and-slavery/ (Accessed: 17 September 2019)

Anti-Trafficking Monitoring Group, (2018). Before The Harm is Done. Examining the UK's response to the prevention of trafficking. United Kingdom. ECPAT UK.

Auerbach, C. \& Silverstein, L. (2003) Qualitative Data: an introduction to coding and analysis, New York: New York University Press 
Anti-Trafficking Monitoring Group (2014) Proposal for a Revised National Referral Mechanism (NRM). Available at: http://www.antislavery.org/wpcontent/uploads/2017/01/atmg_national_referral_mechanism_for_children.pdf (Accessed 19 September 2019)

Anti-Slavery International, (2013) Hidden in Plain Sight. Available at: https://www.antislavery.org/hidden-plain-sight/ (Accessed: 17 September 2019)

Bales, K. (2012) Disposable People: New Slavery in the Global Economy, $5^{\text {th }}$ edn. London: University of California Press

Bales, K. (2009). 'Winning the Fight: eradicating slavery in the modern age,' Harvard International Review, 31(1), pp. 14-17.

Bales, K. (2006) Testing a Theory of Modern Slavery. Washington, DC. Available at: http://lastradainternational.org/lsidocs/bales_test_theory_0607.pdf (Accessed: 27 July 2019)

Bales, K., Hedwards, B. \& Silverman, B. (2017) Modern Slavery Research: The UK Picture. Available at:

http://iascresearch.nottingham.ac.uk/ResearchingModernSlaveryintheUK.pdf

Bales, K., Hesketh, O. \& Silverman, B. (2015) 'Modern Slavery In The UK: How Many Victims?' Significance', pp. 16-21. doi:10.1111/j.1740-9713.2015.00824.x

Bales, K., Trodd, Z., and Williamson, A. K. (2009), Modern slavery: The secret world of 27 million people. $1^{\text {st }}$ Edition. Oxford: Oneworld

Barry, C. (1998) 'Choosing Qualitative Data Analysis Software: Atlas/Ti and Nudist Compared,' Sociological Research Online, 3(3), pp. 1-13.

doi:10.5153/sro.178 
BBC. (2018) 'Cheltenham Festival: Record Crowds Attend Races', BBC News, $17^{\text {th }}$ March. Available at: https://www.bbc.co.uk/news/uk-englandgloucestershire-43442433

Beadle, D. and Davison, L. (2019) Precarious Journeys: Mapping vulnerabilities of victims of trafficking from Vietnam to Europe. Available at:

https://www.antislavery.org/wp-content/uploads/2019/03/Precarious-Journeysfull-report.pdf

Birks, M. \& Mills, J. (2015) Grounded Theory: A Practical Guide, London: Sage

Black, J. (2011) A Brief History of Slavery. First Edition. London: Constable \& Robinson

Blaikie, N. (2007) Approaches to Social Enquiry, Cambridge: Polity Press

Blaxter, L., Hughes, C. \& Tight, M. (2006) How To Research. $3^{\text {rd }}$ Edition. Milton Keynes: Open University Press

Bokhari, F. (2008) 'Falling Through the Gaps: Safeguarding Children Trafficked into the UK,' Children and Society, (22), pp. 201-211. doi: 10.1111/j.10990860.2008.00151.x

Boobyer, L. (2018) 'More than 60 incidents of slavery have been recorded in Gloucestershire in just three years- But there are very few charges being made', Gloucestershire Live, 25 May. Available at:

https://www.gloucestershirelive.co.uk/news/gloucester-news/more-60-incidentsslavery-been-1607651 (Accessed: 02 August 2018)

Bowersox, Z. (2016) 'International Sporting Events And Human Trafficking: Effects Of Mega-Events On A State's Capacity To Address Human Trafficking,' Journal of Human Trafficking, 2(3), pp. 201-213. doi:10.1080/23322705.2015.1131584

Brewster, B. (2019) 'Collaborating to identify, recover and support victims 
Of modern slavery.' Journal of modern slavery, 4(2), pp. 200-224.

Broad, R. \& Turnbull, N. (2018) 'From Human Trafficking to Modern Slavery: The Development of Anti-Trafficking Policy in the UK.' European Journal on Criminal Policy and Research 25 (2), pp. 119-133 doi.org/10.1007/s10610-0189375-4

Browne, K. (2005) 'Snowball Sampling: Using Social Networks To Research Non-Heterosexual Women,' International Journal of Social Research Methodology, 8(1), pp. 47-60. doi: 10.1080/1364557032000081663

Bulman, M. (2020) 'Surge in suspected modern slavery victims waiting years for Home Office decisions, figures show.' Independent, $17^{\text {th }}$ March. Available at: https://www.independent.co.uk/news/uk/home-news/modern-slaveryvictims-home-office-decisions-delays-nrm-a9261331.html

Burks, A. (2008) Roman Slavery: A Study of Roman Society and lts Dependence on slaves. Published Thesis. East Tennessee State University

Butler-Sloss, B., Field, F. and Randall, J. (2013) Establishing Britain as a World Leader in the Fight against Modern Slavery: Modern Slavery Bill Evidence Review. Modern Slavery Bill Evidence Review. Available at: http://www.frankfield.co.uk/upload/docs/Modern\%20Slavery\%20Bill\%20Ev idence\%20Review.pdf

Castillo-Montoya, M. (2016) 'Preparing for interview research: The interview protocol refinement framework,' The Qualitative Report, 21(5), pp. 811828.

Castleberry, A. and Nolen, A. (2018) 'Thematic analysis of qualitative research data: Is it as easy as it sounds?' Currents in Pharmacy Teaching and Learning, 10(6), pp. 807-815. doi: 10.1016/j.cptl.2018.03.019

Charmaz, K. (2014) Constructing Grounded Theory. $2^{\text {nd }}$ Edition. Los Angeles: SAGE

Charmaz, K. (2006). Constructing grounded theory: A practical guide through qualitative analysis. $1^{\text {st }}$ Edition. London: Sage. 
Chase, E. and Statham, J (2005) 'Commercial and sexual exploitation of children and young people in the UK-a review', Child Abuse Review, 14, pp. 14-21. doi: 10.1002/car.881

Cheltenham Borough Council (2019) Keeping Cheltenham safe and moving during race week. Available at: https://www.cheltenham.gov.uk/news/article/2241/keeping_cheltenham_sa fe_and_moving_during_race_week (Accessed 18 September 2019)

Christ, K. \& Burritt, R. (2018) 'Current Perceptions on the Problem of Modern Slavery in Business,' Business Strategy \& Development, 1(2), pp. 103114. doi:10.1002/bsd2.15

Chuang, J. A. (2015). Giving as governance? Philanthrocapitalism and modernday slavery abolitionism. University of California. Available at: https://www.uclalawreview.org/wp-content/uploads/2015/08/Chuangfinal_8.15.pdf (Accessed 28 July 2019)

Cockbain, E. \& Brayley-Morris, H. (2017) 'Human Trafficking and Labour Exploitation in the Casual Construction Industry: An Analysis of Three Major Investigations in the UK Involving Irish Traveller Offending Groups, Policing': A Journal of Policy and Practice 14 (2): doi:10.1093/police/pax032/3884650

Cooper, C., Hesketh, O., Ellis, N. \& Fair, A. (2017) A Typology Of Modern Slavery Offences In The UK. London: Home Office

Coy (2016) 'Joining the dots on sexual exploitation of children and women: A way forward for UK policy responses', Sage Journals, 36(4), pp. 572-591. doi: $10.1177 / 0261018316638460$

Craig, G. (2017) 'The UK's Modern Slavery Legislation: An Early Assessment of Progress,' Social Inclusion, 5 (2), pp. 16-27. doi: 10.17645/si.v5i2.833

Craig, G., Gaus, A., Wilkinson, M., Skrivankova, K., McQuade, A. (2007) Contemporary Slavery in the UK. York: Joseph Rowntree Foundation 
Crane, A. (2013) Modern slavery as a management practice: Exploring the conditions and capabilities for human exploitation.' Academy of Management Review, 38(1), pp. 49-69. doi:10.5465/amr.2011.0145

Creswell, J. (2013) Qualitative Inquiry \& Research Design: Choosing Among Five Approaches. $3^{\text {rd }}$ edn. United States of America: Sage

Crown Prosecution Service, (2018) Modern Slavery Report 2017-2018. Available at:

https://www.cps.gov.uk/sites/default/files/documents/publications/Modern _slavery_report_201718.pdf

Crotty, M. (2003) The Foundations of Social Research: Meaning and Perspectives in the Research Process. 3rd edition. London: Sage Publications

Danailova-Trainor, G., \& Laczko, F. (2010) 'Trafficking in persons and development: Towards greater policy coherence.' International Migration, 48(4), pp. 38-83. doi: 10.1007/s10610-018-9375-4

Davidson, J. (2015) Modern Slavery: The Margins of Freedom. $1^{\text {st }}$ edn. London: Palgrave Macmillan UK

Davies, J. (2018) 'From severe to routine labour exploitation: The case of migrant workers in the UK food industry.' Criminology \& Criminal Justice, 19(3), pp. 294-310. doi:10.1177/1748895818762264

DiCicco-Bloom, B. \& Crabtree, B. (2006) 'The Qualitative Research Interview,' Wiley Online Library, 40(4), pp. 314-321. doi:10.1111/j.13652929.2006.02418.x

Doody, O. \& Noonan, M. (2013) 'Preparing and Conducting Interviews to Collect Data,' Nurse Researcher, 20(5), pp. 28-32. doi:10.7748/nr2013.05.20.5.28.e327

Elwood, S.A and Martin, D.G (2000) "'Placing" Interviews: Location and Scales of Power in Qualitative Research.' The Professional Geographer, 52(4), pp. 649-657. doi:10.1111/0033-0124.00253

Faulkner, S. L. and Trotter, S. P. (2017). 'Data Saturation.' The International Encyclopedia of Communication Research Methods (eds J. Matthes, C. S. Davis and R. F. Potter). doi:10.1002/9781118901731.iecrm0060 
Findlay, A, McCollum, D (2013) 'Recruitment and employment regimes: Migrant labour channels and the UK's rural agri-business sector, from accession to recession,' Journal of Rural Studies, 30, pp. 10-19. doi:

10.1016/j.jrurstud.2012.11.006

Finkel, R. \& Finkel, M. (2015) 'The 'Dirty Downside' Of Global Sporting Events: Focus On Human Trafficking For Sexual Exploitation,' Public Health, 129(1), pp. 17-22. doi:/10.1016/j.puhe.2014.11.006

Gardner, A. (2018) 'An Idea Whose Time Has Come? Modern Slavery, Multiple Streams Approach And Multilayer Policy Implementation,' Journal of Human Rights Practice, 10(3), pp. 461-481.

doi.org/10.1093/jhuman/huy022

Gibbon, T. (2017) 'The children and adults being kept in slavery and exploited in Gloucestershire- It could just be the tip of the ice burg', Gloucestershire Live, 21 September. Available at:

https://www.gloucestershirelive.co.uk/news/gloucester-news/childrenadults-being-kept-slavery-511587 (Accessed 16 September 2019)

Gloucestershire Constabulary, (2018) What is Modern Slavery? Available at: https://www.gloucestershire.police.uk/campaigns/modern-slavery/ (Accessed 24 July 2019)

Gloucestershire County Council, (2019) Gloucestershire Anti-Slavery

Partnership. Available at: https://www.gloucestershire.gov.uk/health-andsocial-care/gloucestershire-anti-slavery-partnership/ (Accessed: 24 July 2019)

Gloucestershire County Council, (2019) Population Profile. Gloucestershire, UK. Available at: https://www.gloucestershire.gov.uk/media/12777/equalityprofile-2019-final.pdf (Accessed 01 September 2019)

Gloucestershire County Council, (2018) Gloucestershire Community Safety Strategic Needs Assessment. Available at:

https://www.gloucestershire.gov.uk/media/1520660/overview.pdf (Accessed 16 September 2019) 
Gold, S., Trautrims, A. \& Trodd, Z. (2015) 'Modern Slavery Challenges to Supply Chain Management, Supply Chain Management', An International Journal, 20 (5), pp. 485-494. doi: 10.1108/SCM-02-2015-0046

Gregoriou, C. \& Ras, I. (2018) 'Representations of Transnational Human Trafficking: A Critical Review', Representations of Transnational Human Trafficking: pp. 1-24. doi:10.1007/978-3-319-78214-0_1

Hammersley, M. \& Gomm, R. (2008). Assessing the radical critiques of interviews. In: M. Hammersley, (Ed.) Questioning Qualitative Inquiry: Critical Essays. London: Sage.

Ham, J. (2011). What's the cost of a rumour? A guide to sorting out the myths and the facts about sporting events and tracking. Bangkok, Thailand: Global Alliance Against Trafficking in Women.

Harvey, J. Hornsby, R. \& Sattar, Z. (2015) 'Disjointed Service: An English Case Study of Multi-Agency Provision in Tackling Child Trafficking,' British Journal of Criminology, 55(3), pp. 494-513. doi:10.1093/bjc/azu115

Haughey, C. (2016). Modern Slavery Act 2015 Review: One Year On. London: Home Office

Hayes, V. (2010). 'Human tracking for sexual exploitation at world sporting events'. Chicago - Kent Law Review, 85(3), pp. 1105-1146.

Heuman, G, \& Burnard, T. (2010) The Routledge History of Slavery, Routledge, Florence. Available from: ProQuest Ebook Central

Hinchliffe, S., Crang, M., Reimer, S. \& Hudson, A. (1997) 'Software for Qualitative Research: 2. Some Thoughts On 'Aiding' Analysis,' Environment and Planning, 29(6), pp. 1-10. doi:10.1068/a291109

HM Government, (2014) Modern Slavery Strategy. London: Her Majesty's Stationery Office. Available at: https://assets.publishing.service.gov.uk/government/uploads/system/uploa ds/attachment_data/file/383764/Modern_Slavery_Strategy_FINAL_DEC20 15.pdf 
HMICFRS, (2017a) Stolen Freedom: The Policing Response to Modern Slavery and Human Trafficking. Her Majesty's Inspectorate of Constabulary and Fire \& Rescue Services

HMICFRS (2017b) Crime and Policing Comparator. Available at: https://www.justiceinspectorates.gov.uk/hmicfrs/crime-and-policingcomparator/about-the-data/\#peerforces (Accessed: 15 September 2019)

Home Office, (2018) Home Office in the Media. Available at:

https://homeofficemedia.blog.gov.uk/2018/05/02/factsheet-on-modernslavery/. (Accessed 31 July 2019)

Home Office, (2018) Criminal Exploitation of children and vulnerable adults: County Lines guidance. Available at: https://assets.publishing.service.gov.uk/government/uploads/system/uploa ds/attachment_data/file/741194/HOCountyLinesGuidanceSept2018.pdf

Hope for Justice, (2017) Modern slavery in UK even more widespread than previously thought. Available at:

https://hopeforjustice.org/news/2017/08/modern-slavery-in-uk-even-morewidespread-than-previously-thought/ (Accessed 27 July 2019)

International Labour Organisation (2019) 40 million in modern slavery and 152 million in child labour around the world. Available at: http://www.ilo.org/global/about-theilo/newsroom/news/WCMS_574717/lang--en/index.htm (Accessed: 15 August 2019).

Independent Anti-Slavery Commissioner (2017). Collaborating for freedom: antislavery partnerships in the UK. University of Nottingham Rights Lab and the Office of the Independent Anti-Slavery Commissioner.

International Labour Organisation and Walk Free Foundation, (2017) Global Estimates of Modern Slavery: Forced Labour and Forced Marriage. Available at: https://www.ilo.org/wcmsp5/groups/public/---dgreports/--dcomm/documents/publication/wcms_575479.pdf 
Jamshed, S. (2014) 'Qualitative Research Method-Interviewing And Observation,' Journal of Basic and Clinical Pharmacy, 5(4), pp. 87-88. doi: 10.4103/0976-0105.141942

Jones, S. R., Torres, V., \& Arminio, J. (2014) 'Issues in analysis and interpretation. In Negotiating the complexities of qualitative research in higher education Fundamental Elements and Issues. $2^{\text {nd }}$ edition. New York. Routledge

Kidd, J. and Manthorpe, J. (2017), 'Modern slavery - the adult safeguarding interface', The Journal of Adult Protection, 19(3), pp. 158-166. doi:10.1108/JAP-09-2016-0021

Kiss, L. and Zimmerman, C. (2019) 'Human Trafficking And Labor Exploitation: Toward Identifying, Implementing, And Evaluating Effective Responses', PLOS Medicine 16 (1): doi:10.1371/journal.pmed.1002740

Landman, T. (2018) 'Out of the Shadows: Trans-disciplinary Research on Modern Slavery', Peace Human Rights Governance, 2(2), pp.143-162. doi:10.14658/pupj-phrg-2018-2-1

LeBaron, G. (2014). 'Subcontracting is not illegal, but is it unethical? Business ethics, forced labor, and economic success,' The Brown Journal of World Affairs, 20(2), pp. 237-249.

Lovejoy, P. E. (2000) Transformations in Slavery: A History of Slavery in Africa. 2nd Edition. Cambridge University Press.

Machura, S., Short, F., Hill, V., Suddaby, C., Goddard, F. \& Jones, S., LloydAstbury, E., Richardson, L., Rouse, C. (2018) 'Recognizing Modern Slavery', Journal of Human Trafficking: 5(3), pp. 1-19. doi:10.1080/23322705.2018.1471863

Maher, C., Hadfield, M., Hutchings, M. \& de Eyto, A. (2018) 'Ensuring Rigor In Qualitative Data Analysis,' International Journal of Qualitative Methods, 17 (1), pp. 1-5. doi: 10.1177/1609406918786362 
Majid, M., Othman, M., Mohamad, S., Lim, S. \& Yusof, A. (2017) 'Piloting For Interviews In Qualitative Research: Operationalization And Lessons Learnt,' International Journal of Academic Research in Business and Social Sciences, 7(4), pp. 1073-1080. doi: 10.6007/JJARBSS/v7-i4/2916

Mantouvalou, V. (2018) 'The UK Modern Slavery Act 2015 Three Years On', The Modern Law Review, 81 (6), pp. 1017-1045. doi: 10.1111/14682230.12377

Matheson, C.M. and Finkel, R. (2013), 'Sex Trafficking and the Vancouver Winter Olympic Games: Perceptions and Preventative Measures,' Tourism Management, 36(3), pp. 613-628.

Mantouvalou, V. (2005) 'Servitude and Forced Labour in the $21^{\text {st }}$ Century: The Human Rights of Domestic Workers', International Law Journal, 35(4), pp. 395-414 doi:10.1093/indlaw/dwl029

Mason-Jones, A J. and Loggie, J. (2019) 'Child sexual exploitation. An analysis of serious case reviews in England: poor communication, incorrect assumptions and adolescent neglect', Journal of Public Health. doi:10.1093/pubmed/fdy227

Maynard, M. (1994) 'Methods, practice and epistemology: The debate about feminism and research' Researching Women's Lives from a Feminist Perspective, eds M Maynard and J. Purvis, Taylor \& Francis, London, pp.10-26

McCollum, D, Findlay, A (2015) 'Flexible workers for flexible jobs? The labour market function of A8 migrant labour in the UK,' Work, Sage JournalsEmployment and Society, 29(3), pp. 427-443. doi:10.1177/0950017014568137

Meltzer, M. (1993) Slavery: a world history. $1^{\text {st }}$ Edition. New York: Da Capo 
Modern Slavery Act 2015, c. 30. Available at:

https://www.legislation.gov.uk/ukpga/2015/30/contents/enacted.

(Accessed: 9 July 2019)

Musmade, P., Nijhawan, L., Udupa, N., Bairy, K., Bhat, K. \& Janodia, M. et al. (2013) 'Informed Consent: Issues and Challenges,' Journal of Advanced Pharmaceutical Technology \& Research, 4(3), pp. 134-140. doi: 10.4103/2231-4040.116779

Murphy, C. (2018) A Game of Chance? Long-term support for survivors of Modern Slavery. St Mary's University Twickenham London: The Centre for the Study of Modern Slavery

Nardinelli, C. (1980). 'Child Labor and the Factory Acts', The Journal of Economic History, 40(4), pp. 739-755. doi:

$10.1017 /$ S0022050700100166

National Crime Agency, (2019a) National Referral Mechanism Statistics- End of Year Summary 2018. Available at:

https://nationalcrimeagency.gov.uk/who-we-are/publications/282national-referral-mechanism-statistics-end-of-year-summary-2018/file (Accessed 02 August 2019)

National Crime Agency, (2019b) County Lines Drugs Supply, Vulnerability and Harm 2018. Available at: https://www.nationalcrimeagency.gov.uk/whowe-are/publications/257-county-lines-drug-supply-vulnerability-and-harm2018/file. (Accessed: 03 September 2019)

National Crime Agency, (2019c) NCA publishes annual assessment of county lines as over 600 arrested as part of national coordinated activity targeting drug dealing model. Available at:

https://nationalcrimeagency.gov.uk/news/nca-publishes-annualassessment-of-county-lines-as-over-600-arrested-as-part-of-nationalcoordinated-activity-targeting-drug-dealing-model (Accessed: 25 July 2019) 
National Crime Agency, (2018) Law enforcement steps up response to modern slavery. Available at: https://nationalcrimeagency.gov.uk/news/lawenforcement-steps-up-response-to-modernslavery?highlight $=$ WyJrZXJyII0 $=($ Accessed 18 July 2019 $)$

National Crime Agency, (2016) County Lines Gang Violence, Exploitation \& Drug Supply 2016. Drug Threat Team, Organised Crime Command

New, S. (2015) 'Modern slavery and the supply chain: The limits of corporate social responsibility? Supply Chain Management,' An International Journal, 20(6), pp. 697-707. doi:10.1108/SCM-06-2015-0201

Nicholson, A., Dang, M. \& Trodd, Z. (2018) 'A Full Freedom: Contemporary Survivors Definitions Of Slavery,' Human Rights Law Review, 18 (4), pp. 689-704. doi:10.1093/hrlr/ngy032

Noor, K. (2008) 'Case Study: A Strategic Research Methodology,' American Journal of Applied Sciences, 5 (11), pp. 1602-1604. doi: 10.3844/ajassp.2008.1602.1604

Palinkas, L., Horwitz, S., Green, C., Wisdom, J., Duan, N. and Hoagwood, K. (2015). 'Purposeful Sampling for Qualitative Data Collection and Analysis in Mixed Method Implementation Research'. Administration and Policy in Mental Health and Mental Health Services Research, 42(5), pp. 533-544. doi: 10.1007/s10488-013-0528-y

Patton, M. Q. (2002). Qualitative research and evaluation methods (3rd ed.). Thousand Oaks, CA: Sage.

Paulus, T., Woods, M., Atkins, D. \& Macklin, R. (2015) 'The Discourse of QDAS: Reporting Practices of ATLAS.Ti and Nvivo Users with Implications for Best Practices,' International Journal of Social Research Methodology, 20 (1), pp. 35-47. doi:10.1080/13645579.2015.1102454

Pinheiro, S., Emberson, C. \& Trautrims, A. (2019) 'For The English To See' Or Effective Change? How Supply Chains Are Shaped By Laws And 
Regulations, And What That Means For The Exposure Of Modern

Slavery,' Journal of the British Academy 7 (1): pp. 167-190.

doi:10.5871/jba/007s1.167

Piotrowicz, R. (2018) Routledge Handbook Of Human Trafficking, London:

Routledge

Reed, S. Roe, S. Grimshaw, J. and Oliver, R. (2018). The economic and social costs of modern slavery. London: Home Office.

Richards, T. (2002) 'An Intellectual History Of NUD*IST And NVivo,'

International Journal of Social Research Methodology, 5 (3), pp. 199-214. doi: 10.1080/13645570210146267>

Ritchie, J. \& Lewis, J. (2014) Qualitative Research Practice, London: SAGE

Roberts, K. (2018) 'Life After Trafficking: A Gap In The UK'S Modern Slavery Efforts,' Anti-Trafficking Review, (10): pp. 164-168. doi:

10.14197/atr.2012181012

Robinson, G. McLean, R. Densley, J. (2018) 'Working County Lines: Child Criminal Exploitation and Illicit Drug Dealing in Glasgow and Merseyside', International Journal of Offender Therapy and Comparative Criminology, 63(5), pp. 694-711. doi: 10.1177/0306624X18806742

Robinson, R. N. S. (2013). 'Darker still: Present-day slavery in hospitality and tourism services,' Hospitality \& Society, 3(2), pp. 93-110. doi:

10.1386/hosp.3.2.93_1

Roundy, K. (2019) 'Did anyone get it "right?" A Comparison of the Netherlands' and the United States' prostitution-schemes on human trafficking', Creighton International and Comparative Law Journal, 10 (1), pp. 103-117

Saunders, B., Sim, J., Kingstone, T., Baker, S., Waterfield, J., Bartlam, B., Burroughs, H. and Jinks, C. (2017) 'Saturation In Qualitative Research: Exploring Its Conceptualization And Operationalization,' Quality \& Quantity, 52(4), pp. 1893-1907. doi: 10.1007/s11135-017-0574-8

Saunders, M., Lewis, P. and Thornhill, A. (2016). Research methods for business students. Harlow Essex: Pearson. 
Scott, R. J., de Andrade Barbosa, L. A. \& Borlido Haddad, C. H. (2017), 'How Does the Law Put a Historical Analogy to Work: Defining the Imposition of a Condition Analogous to That of a Slave in Modern Brazil', Duke Journal of Constitutional Law and Public Policy, 13(1), pp. 1-46. doi:10.2139/ssrn.3058191

Scott, S. (2017) Labour Exploitation and Work-Based Harm, Policy Press, Bristol. Available from: ProQuest Ebook Central.

Scotland, J. (2012). 'Exploring the Philosophical Underpinnings of Research: Relating Ontology and Epistemology to the Methodology and Methods of the

Scientific, Interpretive, and Critical Research Paradigms,' English Language Teaching, 5 (9), pp. 9-16. Published by Canadian Center of Science and Education. doi:10.5539/elt.v5n9p9

Stone, N. (2018) 'Child Criminal Exploitation: 'County Lines', Trafficking and Cuckooing', Sage Journals, 18(3), pp. 285-293

Reeves, (2013) Scrutiny Task Group Report, Sex Trade in Cheltenham. Available at: https://democracy.cheltenham.gov.uk/documents/s7115/2012_12_11_ST G_Sex_Trade_Draft_Final_report.pdf (Accessed 18 August 2018)

Silverman, B. (2014) Modern Slavery: an application of Multiple Systems Estimation. Available at:

https://assets.publishing.service.gov.uk/government/uploads/system/uploa ds/attachment_data/file/386841/Modern_Slavery_an_application_of_MSE _revised.pdf. (Accessed 10 September 2019)

Slavery Working Group (2013) It Happens Here Equipping the United Kingdom to fight modern slavery. Available at: https://www.antislaverycommissioner.co.uk/media/1070/csj_slavery_full_re port_web-5.pdf (Accessed 20 September 2019)

Slave Trade Act 1824, c. 113. Available at: http://www.legislation.gov.uk/ukpga/Geo4/5/113/section/2. (Accessed: 28 July 2019) 
Smith, M. and Davies, J. (2010) 'Qualitative Data Analysis', in Dahlberg, L. and McCaig, C. (eds) Practical Research and Evaluation A Start-to-Finish Guide for Practitioners. London: Sage, p. 151.

Smith, L. \& Healy Vardaman, S. (2010) 'The Problem of Demand In Combating Sex Trafficking,' Revue internationale de droit pénal, 81(3), pp. 607-624.

Stevenson, M. and Cole, R. (2018) 'Modern slavery in supply chains: a secondary data analysis of detection, remediation and disclosure, Supply Chain Management' An International Journal, 23(2), pp.81-99. doi 10.1108/SCM-11-2017-0382

Strauss, K. (2012) 'Unfree Again: Social Reproduction, Flexible Labour Markets and the Resurgence of Gang Labour in the UK', Antipode Foundation, 45(1), pp. 180-197. doi:10.1111/j.1467-8330.2012.00997.x

Tessier, S. (2012) 'From Field Notes, to Transcripts, to Tape Recordings: Evolution or Combination?' International Journal of Qualitative Methods, 11(4), pp. 446-460. doi: 10.1177/160940691201100410

Thanh, N. Thanh, T (2015) 'The interconnection between interpretivist paradigm and qualitative methods in education', American Journal of Education Science, 1(2), pp. 24-27.

Turner-Moss, E., Zimmerman, C., Howard, L. \& Oram, S. (2014) 'Labour Exploitation And Health: A Case Series Of Men And Women Seeking Post-Trafficking Services,' Journal of Immigrant and Minority Health, 16(3), pp. 473-480. doi:10.1007/s10903-013-9832-6

United Nations on Drugs and Crime (2016) Global Report on Trafficking in Persons. New York: United Nations Publication

United States Congress House. Committee on Foreign Affairs. Subcommittee on Africa, Global Health, Global Human Rights, and International Organisations (2014). Lessons learned from super bowl preparations: preventing international human trafficking at major sporting events. Washington U.S: Government Printing Office.

Urquhart C. (2013). Grounded Theory for Qualitative Research: A Practical Guide. $1^{\text {st }}$ Edition. London: Sage 
Van Dyke, R. (2017) 'Monitoring and Evaluation of Human Trafficking Partnerships in England and Wales', Anti-Trafficking Review (8), pp. 131146. doi: $10.14197 /$ atr.20121788

Wahyuni, Dina, (2012). 'The research design maze: understanding paradigms, cases, methods and methodologies,' Journal of applied management accounting research, 10 (1), pp. 69-70

Warren, Carol A.B. (2002). Qualitative interviewing. In Jaber F. Gubrium and James A. Holstein (Eds.), Handbook of interview research: Context and method (pp.83-101). Thousand Oaks: Sage.

Welsh, E. (2002). 'Dealing with Data: Using NVivo in the Qualitative Data Analysis Process,' Forum: Qualitative Social Research, 3(2). doi: http://dx.doi.org/10.17169/fqs-3.2.865

West Midlands Police (2018) County Lines drug boss jailed for trafficking children in the UK policy first. Available at: https://www.westmidlands.police.uk/news/county-lines-drug-boss-jailed-trafficking-childrenuk-policing-first (Accessed: 19 November 2019)

Wiedemann. T, (1981) Greek and Roman Slavery. ${ }^{\text {st }}$ edn. London: Routledge

Zamawe, F. (2015). 'The Implication of Using NVivo Software in Qualitative Data Analysis: Evidence-Based Reflections,' Malawi Medical Journal, 27(1), pp.13-15. 


\section{Appendices}

\section{Appendix A: Participant Consent Form}

\section{Consent to take part in Research}

- I voluntarily agree to participate in this research study.

- I understand that even if I agree to participate now, I can withdraw at any time or refuse to answer any question without any consequences of any kind.

- I understand that I can withdraw from the study without reason up until January 2019, in which case the material I provide will be deleted.

- I have had the purpose and nature of the study explained to me in writing and verbally. I have also had the opportunity to ask questions about the study.

- I understand that participation involves either undertaking an audio-recorded interview or giving permission for detailed notes to be taken during the interview.

- I understand that the information I provide for this study will be treated confidentially, unless the information reveals anything that puts myself or others at risk.

- I understand that extracts from my interview may be used or quoted in the dissertation, conference presentations and published papers.

- I understand that after the research project has been completed, the raw data will be destroyed unless I give permission for it to be archived.

- I understand that I can contact either the researcher; Jordan Brealy or Dr Rachel Bennett, Director of Studies to seek further clarification and information.

- I understanding and except the level of anonymity being provided for this research project.

Please tick ANY of the following boxes that apply:

$\checkmark$ I give permission for the interview to be audio-recorded

I give permission for detailed notes to be taken during the interview

$\square \quad$ I give permission for my profession to be mentioned in the research project

I give permission for the information I provide to be archived

\section{Signature of research participant}

Signature of participant

Date

\section{Signature of researcher}

I believe the participant is giving informed consent to participate in this study 


\section{$\underline{\text { Interview Guide }}$}

1. Could you tell me about how long you have been working in this area and what change have you observed with regards to modern slavery?

2. Official definitions can vary so for you (or for your organisation) what is modern slavery?

- Does prostitution link to modern slavery?

3. Could you tell me about the issue of modern slavery in Gloucestershire or the UK?

- -Do you think it is a significant problem?

- -Do you see it as a growing or declining problem?

- -Why?

4. To your knowledge, what types of modern slavery offences take or have taken place in Gloucestershire?

5. Based on your experiences, what would you say regarding the extent of modern slavery in Gloucestershire or the UK?

6. According to statistics from the National Crime Agency, victim referrals have increased in recent years. How would you interpret this?

- Do the statistics represent an increase in the occurrence of modern slavery or increased success of anti-slavery practices?

- Are there any factors that contribute to modern slavery in Gloucestershire?' e.g. geographical significance, events, policy etc...

- Are the any times of the year when the issue is exacerbated? -What impact does Race Week have?

7. What is available in terms of victim support in Gloucestershire?

- What procedures are involved here?

8. What are the signs to look out for?

9. In your field, what is being done to prevent/tackle modern slavery?

- To what extent are these strategies successfully tackling the issue?

- In your opinion, what more can be done to tackle modern slavery in Gloucestershire?

10. In terms of policy intervention, what can/should be done?

11. Are you aware of an anti-slavery partnership established in the area? If so, how does it work? Who leads it?

12. What further research would benefit your practice/organisation?

- Which factors should take priority when looking into this issue? 


\title{
Appendix C: Participant Information Sheet
}

\section{$\underline{\text { Participant information sheet }}$}

\author{
Research Project Title: \\ An evaluation of modern slavery, through the lens of practitioners operating in Gloucestershire.
}

\section{Invitation:}

I would like to invite you to take part in this research study. Please take time to read the following document carefully and ask any questions. You have been invited due to your unique experience/knowledge/insight regarding modern slavery in Gloucestershire. The study focusses on the views of practitioners that have dealt with modern slavery related issues in Gloucestershire.

\section{What is the purpose of the study?}

The main purpose of the research is to gain information regarding modern slavery in Gloucestershire through perspectives of practitioners working in the field. This research offers an opportunity to develop a broader understanding of this issue and with it, highlight the complexities related to the topic. The research will also contribute to the understanding of the perspectives of practitioners related to the topic. It must be stressed that in order to achieve the aim of this study, personal views and perspectives related to the topic are being asked for rather than comments from a company or organisational stance.

\section{Do I have to take part?}

Taking part in the following research project is entirely voluntary. The study will be described to you both verbally and in writing. After reading the details of the study on the information sheet, it is your decision whether or not to take part in this study. By signing the consent form you are indicating your willingness to take part. You are however, able to withdraw from the study without providing a reason, up until January 2019.

\section{What happens to me if I take part?}

If you agree to take part, a time and date will be arranged to conduct the interview. This will be arranged at your convenience to fit with your schedule. The interview will last approximately 1 hour and will be audio recorded for later analysis. Alternatively, if you do not wish to be audio-recorded, detailed notes will be taken instead.

You will remain anonymous for the duration of the study and be provided with an alias for the interview e.g. participant 1. You will be asked a series of questions during the interview, which will form the foundation of discussion. All that's asked of you, is that you answer the questions you feel comfortable answering to the best of your understanding, using your own opinion and perspective. Once the data has been collected, it will be transcribed and sections of the data will be used in the dissertation.

You do not have to answer all the questions asked in the interview and are free to pass any of the questions. Before analysis takes place, you will have the opportunity to read through the transcripts to ensure you are satisfied with the material provided. At this point you may request to have sections of the text deleted, which you are entitled to do so without reason.

\section{What are the benefits of taking part?}

The study does not aim to help you directly but the information that is collected throughout the research project will aid in expanding the research regarding modern slavery in Gloucestershire.

Once the research project is completed, all participants will have access to a summary report of the study, which will outline the main findings of the research.

\section{What happens to the data after the study?}

The data will be handled with the utmost care and confidentially will be key throughout the research project. This will be obtained through storing the data on a password protected computer. Only the researcher and the research supervisors will have access to the raw data. Once the data has been transcribed, the raw data will be destroyed unless permission to archive is granted.

\section{What if there is a problem?}

If you have concerns about any aspect of this study you should speak to Jordan Brealy who will be happy to answer any questions at:[phone number redacted] or by emailing: [email redacted].

If you remain unhappy and wish to complain formally you can do this through contacting the University of Gloucestershire or Dr Rachel Bennett, Director of Studies at:[email redacted]. 